Florida International University FIU Digital Commons

\title{
Research on the influence of behavioral forces that motivate trader behavior and sentiment- a prospect theory exegesis
}

Deanne Butchey

Florida International University

DOI: $10.25148 /$ etd.FI14052505

Follow this and additional works at: https://digitalcommons.fiu.edu/etd

Part of the Business Administration, Management, and Operations Commons

\section{Recommended Citation}

Butchey, Deanne, "Research on the influence of behavioral forces that motivate trader behavior and sentiment- a prospect theory exegesis" (2005). FIU Electronic Theses and Dissertations. 2000.

https://digitalcommons.fiu.edu/etd/2000 
Miami, Florida

\section{RESEARCH ON THE INFLUENCE OF BEHAVIORAL FORCES}

THAT MOTIVATE TRADER BEHAVIOR AND SENTIMENT-

A PROSPECT THEORY EXEGESIS

A dissertation submitted in partial fulfillment of the

requirements for the degree of

DOCTOR OF PHLLOSOPHY

in

BUSINESS ADMINISTRATION

by

Deanne Butchey

2005 
To: Dean Joyce Elam

College of Business Administration

This dissertation, written by Deanne Butchey and entitled Research on the Influence of Behavioral Forces that Motivate Trader Behavior and Sentiment - A Prospect Theory Exegesis, having been approved in respect to style and intellectual content, is referred to you for judgment.

We have read this dissertation and recommend that it be approved.

Arun J. Prakash

Juan I. Sanchez

William W. Welch

Ali M. Parhizgari, Major Professor

Date of Defense: July 26,2005

The dissertation of Deanne Butchey is approved.

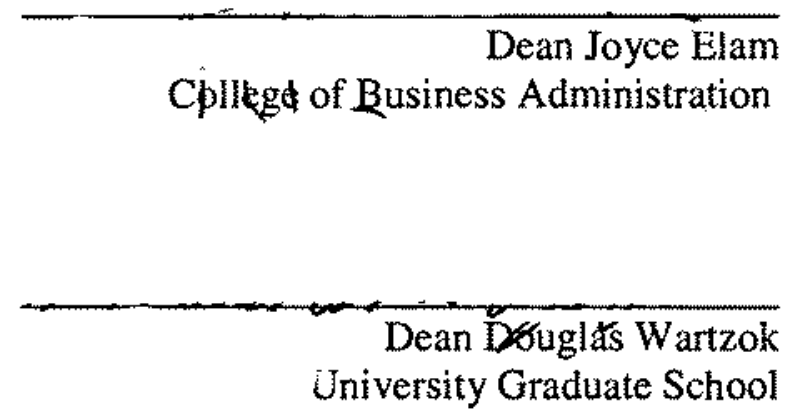

Florida Intemational University, 2005 
(C) Copyright 2005 by Deanne Butchey

All rights reserved. 


\section{DEDICATION}

I dedicate this dissertation to my family. Without their patience, understanding, support, and most of all love, the completion of this work would not have been possible. 


\section{ACKNOWLEDGMENTS}

I wish to thank the members of my committee for their support, patience, and good humor. Their gentle but firm direction has been most appreciated. Dr. Arun J. Prakash was particularly helpful in guiding me toward a quantitative methodology. Dr. Juan I. Sanchez's interest in psychological issues and area of competence was the impetus for my request for his participation on my committee. Dr. William W. Welch provided me with moral support and good advice throughout the way. Finally, I would like to express my utmost thanks to my major professor, Dr. Ali M. Parhizgari. From the beginning, he had confidence in my abilities not only to complete a degree, but also to do so with excellence. Without his benevolent coercion and econometric expertise, this study would not have becn accomplished.

I have found my coursework throughout the Curriculum and Instruction program to be stimulating and thoughtful, providing me with the tools with which to explore past, present and future undertakings. 


\section{ABSTRACT OF THE DISSERTATION \\ RESEARCH ON THE INFLUENCE OF BEHAVIORAL FORCES \\ THAT MOTIVATE TRADER BEHAVIOR AND SENTIMENT -}

A PROSPECT THEORY EXEGESIS

by

Deanne Butchey

Florida International University, 2005

Miami, Florida

Professor Ali M. Parhizgari, Major Professor

This study focuses on empirical investigations and seeks implications by utilizing three different methodologies to test various aspects of trader behavior. The first methodology utilizes Prospect Theory to determine trader behavior during periods of extreme wealth contracting periods. Secondly, a threshold model to examine the sentiment variable is formulated and thirdly a study is made of the contagion effect and trader behavior.

The connection between consumers' sense of financial well-being or sentiment and stock market performance has been studied at length. However, without data on actual versus experimental performance, implications based on this relationship are meaningless. The empirical agenda included examining a proprietary file of daily trader activities over a five-year period. Overall, during periods of extreme wealth altering conditions, traders "satisfice" rather than choose the "best" alternative. A trader's degree of loss aversion depends on his/her prior investment performance. A model that explains 
the behavior of traders during periods of turmoil is developed. Prospect Theory and the data file influenced the design of the model.

Additional research included testing a model that permitted the data to signal the crisis through a threshold model. The third empirical study sought to investigate the existence of contagion caused by declining global wealth effects using evidence from the mining industry in Canada. Contagion, where a financial crisis begins locally and subsequently spreads elsewhere, has been studied in terms of correlations among similar regions. The results provide support for Prospect Theory in two out of the three empirical studies.

The dissertation emphasizes the need for specifying precise, testable models of investors' expectations by providing tools to identify paradoxical behavior patterns. True enhancements in this field must include empirical research utilizing reliable data sources to mitigate data mining problems and allow researchers to distinguish between expectations-based and risk-based explanations of behavior. Through this type of research, it may be possible to systematically exploit "irrational" market behavior. 
I. INTRODUCTION

General Statement of Problem

Significance of the Study

II. REVIEW OF THE LITERATURE

Introduction

Prospect Theory.

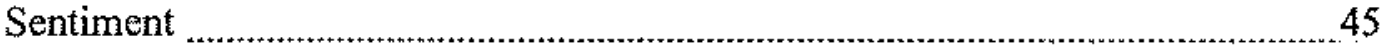

Contagion

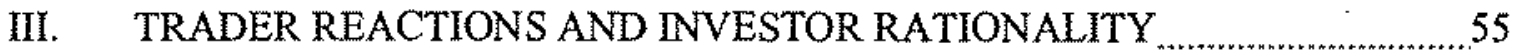

Introduction . . . . .

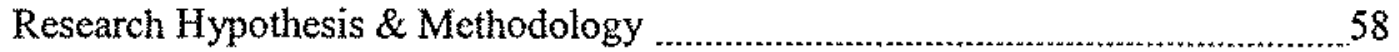

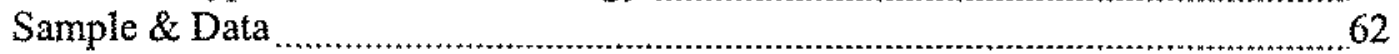

Empirical Applications

Conclusions

IV. EFFECT OF SENTIMENT IN THE CONTEXT OF PROSPECT THEORY $\ldots 123$

Introduction

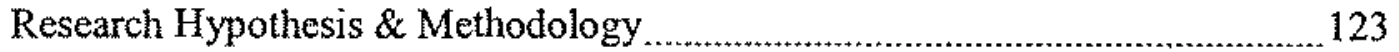

Sample \& Data $\ldots$

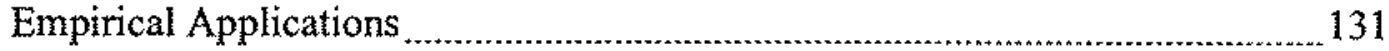

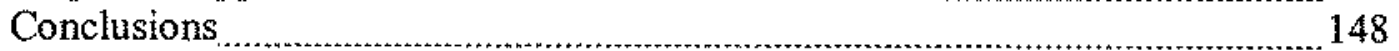

V. IS THERE EVIDENCE OF CONTAGION?

Introduction

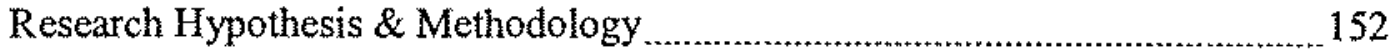

Sample \& Data

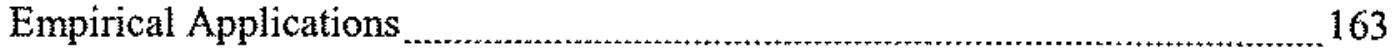

Conclusions

VI. CONCLUSION

Summary and Conclusions of the Research

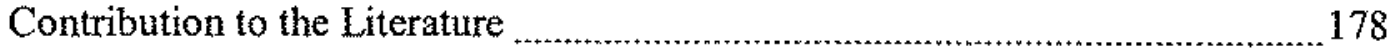

Limitations of this Study

Implications for Future Research

BIBLIOGRAPHY

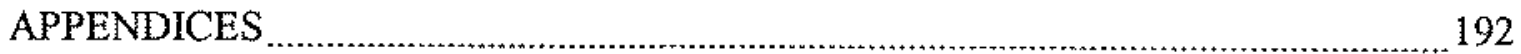

VITA 


\section{LIST OF TABLES}

TABLE

PAGE

\section{CHAPTER III}

1 Summary Statistics for the Index Return Data 79

2-1 Statistical Estimation and Inference of DJIA Returns on Broker Buys/Sells or No Change: Probability modeled is buy versus sell/no change $=1$

2-2 Tests of Equality between Turmoil and Stable Observations of DJIA Retums on Broker Buys/Sells or No Change: Probability modeled is buy versus sell/no change $=1$

3-1 Statistical Estimation and Inference of S\&P500 Returns on Broker Buys/Sells or No Change: Probability modeled is buy versus sell/no change $=1$

3-2 Tests of Equality between Turmoil and Stable Observations of S\&P500 Returns on Broker Buys/Sells or No Change: Probability modeled is buy versus sell/no change $=1$

4-1 Statistical Estimation and Inference of S\&P/TSX Retums on Broker Buys/Sells or No Change: Probability modeled is buy versus sell/no change $=1$

4-2 Tests of Equality between Turmoil and Stable Observations of S\&P/TSX Returns on Broker Buys/Sells or No Change: Probability modeled is buy versus sell/no change $=1$

5-1 Statistical Estimation and Inference of DJIA Returns and Group Effect on Broker Buys/Sells or No Change: Probability modeled is buy versus sell/no change $=1$

5-2 Tests of Equality between Turmoil and Stable Observations of DJIA Returns and Group on Broker Buys/Sells or No Change: Probability modeled is buy versus sell/no change $=1$.

6-1 Statistical Estimation and Inference of S\&P500 Returns and Group Effect on Broker Buys/Sells or No Change: Probability modeled is buy versus sell/no change $=1$ 
6-2 Tests of Equality between Turmoil and Stable Observations of S\&P500 Retums and Group on Broker Buys/Sells or No Change: Probability modeled is buy versus sell/no change $=1$

7-1 Statistical Estimation and Inference of S\&P/TSX Retums and Group Effect on Broker Buys/Sells or No Change: Probability modeled is buy versus sell/no change $=1$

7-2 Tests of Equality between Turmoil and Stable Observations of S\&P/TSX Retums and Group on Broker Buys/Sells or No Change: Probability modeled is buy versus sell/no change $=1$

8 Regression Results of DJIA on lagged DJIA, Sentiment, Lagged Sentiment and Buy/Sell Statistics.

9 Regression Results of S\&P500 on lagged S\&P500, Sentiment, Lagged Sentiment and Buy/Sell Statistics.

10 Regression Results of S\&P500 on Sentiment, Lagged Sentiment and Buy/Sell Statistics.

11 Regression Results of S\&P500 on Buy/Sell Statistics

12 Regression Results of DJIA on Buy/Sell Statistics 118

\section{CHAPTER IV}

1 Estimation Results of the Threshold Effect on Monthly US Data

2 Full Estimation Results of the Threshold Effect in Both Regimes on Monthly US Data.

3 Full Estimation Results of the Threshold Effect in Both Regimes with a second lag of the Stock Index.

4 Estimation Results of the Threshold Effect on Monthly Canadian Data.

5 Full Estimation Results of the Threshold Effect in Both Regimes on Canadian Monthly Data

6 Estimation Results of the Threshold Effect on Quarterly Canadian Data 144 


\section{CHAPTER V}

1 Total Country Indices from Datastream

2 Correlation Test for Contagion originating in Canada on G9 Countries and Indonesia Adjusted for Heteroskedasticity.

3 Correlation Test for Contagion originating in Canada on G9 Countries and Indonesia Not Adjusted for Heteroskedasticity.

4 Total Canada Index from Datastream versus Gold/ Basic Resources of the Regional Indices

5 Correlation Test for Contagion originating in Canada on the Major Regional Mining Indices Adjusted for Heteroskedasticity

6 Correlation Test for Contagion originating in Canada on the Major Regional Mining Indices Not Adjusted for Heteroskedasticity.

7 Total Canada Gold Market from Datastream versus Gold/ Basic Resources around the World

8 Correlation Test for Canadian Gold Contagion effects on the World's Mining Indices Adjusted for Heteroskedasticity

9 Correlation Test for Canadian Gold Contagion effects on the World's Mining Indices Not Adjusted for Heteroskedasticity. 


\section{LIST OF FIGURES}

FIGURE

PAGE

Chapter II

1 Value Function Hypothesized from Prospect Theory 34

Chapter IV

1 Confidence Interval Construction for Threshold - US Data 135

2 Confidence Interval Construction for Threshold - Monthly Canadian Data 142

Chapter V

1 Volatility of the S\&P/TSE: Event date March 21, 1997 159

2 Volatility of the S\&P/TSE with 3-Month Moving Average: Event date March 21, 1997 160

3 Price Chart of the S\&P/TSX from June 1996 to June 1998 160

4 Volatility of the S\&P500 with 3-Month Moving Average: Event date March 21, 1997. 161

5 Price Chart of the S\&P500 from July 1996 to December 1997 161 


\section{CHAPTER 1 - INTRODUCTION}

A great deal of evidence suggests that share returns can be predicted by factors that are inconsistent with Sharpe-Lintner's (1964) Capital Asset Pricing Model (CAPM) and Fama's (1970) Efficient Market Hypothesis (EMH). Variables which have been shown empirically to have explanatory power in predicting the cross-section of share market returns include size measured by market equity (Banz, 1981), earnings-price ratio (Ball, 1978; Reinganum, 1981; Basu, 1983; Jaffe, Keim and Westerfield, 1989), the ratio of book-market equity (Rosenberg, Reid and Lanstein, 1985), leverage (Bhandari, 1988), dividend yield (Litzenberger and Ramaswamy, 1979), and cash-flow-to-price (Lakonishok, Schleifer and Vishny, 1994).

Fama and French (1992) studied the joint effects of market beta, size, E/P ratio, leverage, and the book to market ratio on the cross-section of average returns on the NYSE, AMEX, and NASDAQ shares over the period 1963-1990. Their tests did not find that average share returns are positively related to market beta, the most basic tenet of the CAPM. They did find however, that the univariate relationships between average return and size, leverage, earnings/price ratio and book/market (BE/ME) value are strong. Furthermore, when doing multivariate tests, they find that $\mathrm{BE} / \mathrm{ME}$ are both robust to the inclusion of other variables, but that $\mathrm{BE} / \mathrm{ME}$ plays the stronger role in the prediction of the cross-section of average returns. Paradoxically therefore, Fama and French (1992), conclude that in the period 1963-1990 the two variables, size and BE/ME, "provide a simple and powerful characterization of the cross-section of returns" (Fama and French, 1992:429). 
In 1998, Fama produced a survey of empirical work on the challenges to market efficiency explained by behavioral finance theorists. He concluded, "Behavioral finance is nothing more than anomalies dredging since the apparent over-reaction to information is about as common as under-reaction."

These studies affirm the fact that there is a burgeoning field concerned about financial market anomalies, which suggests that returns and behavior are still predictable in specific yet unexplained ways. Social scientists aim to find parsimonious models that predict human behavior. It is a common belief that Miller's $1977^{1}$ work on the possibility of superior returns based on the uncertainty about an IPO, is the forerunner to the discipline of Behavioral Finance, but Kahneman and Tversky's $(1974)^{2}$ Prospect Theory (PT hereafter) provides the core theory in this field. These Nobel Prize winners proved that humans are innately loss-averse, particularly when it comes to money. Losses hurt twice as much as gains give pleasure. A central tenet in behavioral choice theory is that decisions are influenced by how the choices are framed. Consequently the perception of these choices will be affected by an investor's frame of mind which can be measured by surveys on his sentiment.

\section{General Statement of Problem}

Using the work on Prospect Theory advanced by Kahneman and Tversky (1992) this study seeks to understand the cognitive/behavioral biases that face traders and

\footnotetext{
Miller, Edward M., (1977), Risk, Uncertainty, and Divergence of Opinion. The Journal of Finance, Volume 32, Issue 4, 1151-1168.

${ }^{2}$ Tversky, Amos and Daniel Kahneman, (1974), Judgement under Uncertainty: Heuristics and Biases, Science, New Series, Volume 185, Issue 4157, 1124 1131.
} 
influence their trading. A model that ascertains the probability that an institutional trader will buy or sell components of his portfolio during periods of extreme wealth altering periods evolves. Additionally a model is designed to measure a regime shift in economic conditions based on behavioral factors. Finally a test of contagion based on crisis conditions originating in Canada is performed.

\section{Objectives for the Dissertation}

I. Determine whether Prospect Theory can predict the behavior of traders during periods of extreme wealth altering circumstances or "crises".

2. Identify components of institutional trader risk aversion and risk preferences, and determine associations regarding sentiment, herd behavior, overconfidence and other predictions of behavioral finance.

3. Determine whether there is evidence of herd behavior as exemplified by contagion in the context of an incident of fraud in the Canadian mining industry.

The first investigation looked for a direct relationship between buying and selling activity and stock market returns. Good times bring about a positive mood for investors and, consistent with the experimental evidence (Isen (I999) and others), a heightened pain from any potential loss. In an attempt to maintain their mood, investors become less willing to bear any portfolio risk, i.e. they become more risk averse. Conversely, during bear market conditions they possibly seek additional risk and become less risk averse. The study also investigated whether understanding buying/selling activities during market turmoil or catastrophic periods together with other economic measures can help to predict trader behavior. Finally, existence of contagion or interdependence among 
international markets was investigated and a conclusion made as to whether it is a phenomenon that can be explained by behavioral factors.

\section{Background and Motivation for the Dissertation}

The dissertation has a theoretical basis in Prospect Theory. This is the study of the integration of economics and cognitive science in assessing how people manage risk and uncertainty. It focused on loss aversion rather than the typically described risk aversion. Loss aversion is the bias that people prefer avoiding losses than seeking gains and evaluate their decisions based on the prospect of losses rather than the presumption of gains. Some studies imply that experimentally, losses are as much as twice as psychologically powerful than gains. Consequently, the Prospect Theory utility graph has a curvilinear shape in the positive domain. Conversely in the loss region of the utility function, people tend to prefer risks that could possibly mitigate a loss (called risk seeking behavior). Accordingly it might be argued that a positive change in sentiment leads to either risk aversion, or depending on the original wealth levels of the investor, loss aversion. The general motivation of this dissertation is to determine "How do consumer sentiment and investor propensity interact with market conditions to give rise to behavior that can be observed?"

Herbert Simon pointed out that individuals do not fully optimize, they optimize until it is close enough to their ideal state, or in Simon's words, they "satisfice". He calls this "bounded rationality". Andrew Lo believes "adaptation and evolution" dictate the balance of "bounded rationality". Kahneman and Tversky's "S' shaped utility theory that maximizes the probability of creating wealth, implies that if one has lost a lot of money 
he/she will be extremely risk seeking. However, once a level of loss neutrality is achieved, exemplified by a 'kink' at the origin showing greater sensitivity to losses than gains, defined as loss aversion, one will again be conservative and consequently riskaverse.

One can argue that since every financial model depends on uncertainty and its effect on the behavior of investors, and in due course, market prices, the entire study of finance is behavioral in nature. An important consideration therefore, is how can the effect of psychological or cognitive biases in the market be evaluated? The main question of the dissertation is, "Can Prospect Theory (PT) explain investor or trader behavior during unusual periods or "market crises"?" While Prospect Theory provides sufficient methodological structure for tightly controlled laboratory experiments, it is difficult to derive meaningful econometric exercises that test this theory because of the myriad of competing forces at play in financial markets. Therefore, it has become standard in the literature to seek proxies and implications. Even though the behavioral proxies should have no explanatory power from the perspective of expected utility theory, decision makers reveal their preferences through their subsequent decisions, thus allowing the direct examination of the behavioral thesis. This dissertation focused on determining a proxy for risk aversion and testing for differences in the behavior of institutional traders with respect to this proxy especially during these unusual periods.

Numerous authors have noted a significant comovement of risk-aversion in equity markets around the world suggesting a significant cross-country component of investor sentiment. The observation of "irrational exuberance" by Shiller and Greenspan suggests that sentiment plays a role in market pricing. Based on the Kahneman-Tversky 
objective function, the question that can be asked is how is the main argument defined? The literature in behavioral finance contends that wealth is the argument of the objective function. In fact, investors have separate "mental accounts" for each asset, evaluating the investment outcomes on an asset-by-asset basis. In other words, the "kink' at the reference point is relevant and can determine whether an investor is risk-averse or lossaverse. Since wealth is a major argument, it is important to measure how "wealthy" an individual feels. Therefore, Consumer Sentiment is utilized as a proxy, not to measure his/her absolute wealth, but how the investor/consumer feels about his/her level of wealth.

In as much as this behavior has a causal effect on the market as a whole and is itself caused by the market's behavior, a "bi-directional causality effect," a scenario very common in finance, is encountered. A threshold model was utilized to investigate the instance when retums, sentiment, as well as several other measures of financial development and economic growth, show a structural break-point. Finally, the effects of "contagion" and "spillover" effects on the countries of the G7, Russia, Australia and Indonesia are investigated. Issues that motivate this study are:

1. Public announcement is known to be of low value. Since institutional traders typically have more resources available for the collection of exceptional fundamental information, their trading activity is sometimes viewed as being more astute. Therefore, while small traders are typically viewed as being "noise traders" which makes them more prone to succumb to behavioral biases such as past trading experiences, herding and overconfidence no evidence has been presented that institutional traders also succumb to these predispositions. Institutional investors 
especially of mutual funds usually sell because they expect massive redemptions after catastrophic events, if they buy it may encompass a behavioral signal.

2. Errors, caused by biases, made by institutional investors can affect security prices especially as the size of the trade is usually much larger than that of small traders. Barber and Odean show that institutional traders trade less often than traders do with discount brokers suggesting that they avoid the trading bias that can lead to lower returns. However, they do not recognize that institutional traders also face cognitive forces that can influence their trading patterns. Therefore, it is important to examine the predictability of security returns as well its calibration to expected returns, interest rates, consumption and risk.

3. Barclay and Warner (1993) suggest there is a direct and proportional correlation between informed (institutional) traders and stock price changes. This suggests that the type of brokerage house, the size of the trade and the percentage of transaction volume may predict the rate of return.

4. Varian (1985) suggests investigating tbe lack of homogeneity in investors' opinions as a risk factor that may result in excess returns. Chordia, Subramanyam and Anshuman (2001) show this lack of divergence could be proxied by unexpected volume and is not simply a well-known risk factor in different guise. This lends credence to the argument that opinion divergence should be viewed as a factor that could proxy for additional tisk.

"Rational markets" typically mean that investors follow the Savage (1954) axioms (a set of precepts such as the transitivity principle where "if $A$ is preferred to $B$ and $B$ to C, then A will be preferred to C"). The implication here is that investors attempt to 
maximize expected utility using unbiased subjective probabilities. Even though human judgment research suggests that individuals are poor statisticians, for a market to exhibit rational characteristics, the prices of assets should convey much of what an investor needs to know to act intelligently. Before Prospect Theory, investment decisions noted in academia have been solely guided by efficient market theory. The theory is based on the notion that investors behave in a rational, predictable and unbiased manner. The model assumes that investors taken together, correctly price stocks to reflect all publicly available information. Excess returns are not attainable even with asymmetrical information, (Strong Form of Efficient Market Hypothesis) ${ }^{3}$. The field of behavioral finance challenges these traditional views through the study of how investors' interpret and act on all available information as well as their personal heuristic biases. The findings suggest the following:

1. There are individual investor heuristic (nule of thumb) driven biases: this observation is based on the fact people find out things for themselves and behave based on mental short cuts used in place of purely (unboundedly) rational thinking. Therefore, he/she may exhibit overconfidence because of education or past accomplishments, or may be anchored to the downward trend that had previously provided a successful investment strategy. Examples in the literature point to the bankruptcy of Orange County, CA in 1994. Examples that are more recent can be seen in the numerous explosive recovery attempts by the Nasdaq since its peak in March 2000 and the subsequent debilitating dives - termed "Bear Market Rallies." Investors have been

\footnotetext{
${ }^{3}$ Jensen, Michael, (1978), Some Anomalous Evidence Regarding Market Efficiency, Journal of Financial Economics, Vol. 6, Nos. 2/3, 95-101.
} 
viewed as creatures that overemphasize the relevant risk both on the downside and on the upside and consequently overreact.

2. There are anomalies found in the market: these are economic puzzles, which cannot be explained by the efficient market theory. This is consistent with the conclusion that as a component of the market as a whole, investors do not behave rationally. If stock prices were determined rationally, they should reflect the value of the firm and the only reason for a change in stock prices should be a change in the intrinsic values of the firm (Marsh and Merton 1986). Therefore the field of behavioral finance has the potential of identifying investor mistakes in the market, with an expectation that if one were to fully become knowledgeable about the psychological (including quasirational) aspects of decision-making, investors would be more successful than market traders, and could possibly beat market benchmarks.

3. The investor is influenced by regret-pain and attempts to shift the blame, which are experienced from recognizing that a different path could have been taken. These issues tend to cloud his/her judgment. When faced with cognitive dissonance, rationalizing their prior investment decision no matter what the consequences, most people resolve the dissonance by choosing the comfortable route (Shefrin, Beyond Greed and Fear p 204).

\section{Significance of the Study}

The assurance of the efficiency of financial markets especially stock prices is extremely important and the activity of professional traders, because the volume of their trading has the potential to significantly affect stock market returns, needs to be 
considered. It is necessary to investigate whether arbitrage forces impede or amplify the demand shocks caused by the interplay between "noise" traders and rational arbitrageurs. This type of investigation is useful in our ongoing attempts to determine the factors that affect the proclivity of investors/traders to buy or sell stocks en masse. In as much as behavioral factors are interrelated it is common to find experimental investigations rather than empirical ones. Therefore, when a data file is obtained of actual trading behavior a valid contribution can be achieved.

\section{Contributions of the Dissertation}

While Prospect Theory provides sufficient methodological structure for tightly controlled laboratory experiments, it is difficult to derive meaningful econometric exercises that test this theory because of the myriad of competing forces at play in financial markets. Therefore, it has become standard in the literature to seek proxies and implications. While behavioral proxies have no explanatory power from the perspective of expected utility theory, decision makers reveal their preferences through their subsequent decisions, thus allowing the direct examination of the behavioral thesis. This dissertation focused on determining a proxy for risk aversion and testing for differences in the behavior of institutional traders with respect to this proxy especially during these unusual periods. Since wealth is a major argument of PT, it is important to measure how "wealthy" an individual feels. Therefore, Consumer Sentiment is utilized as a proxy, not to measure his/her absolute wealth, but how the investor/consumer feels about his/her level of wealth. Next, a threshold model was utilized to investigate the instance when returns, sentiment, as well as other measures of economic activity, show a structural 
break-point. Finally, the effects of "contagion" and "spillover" effects on the countries of the $\mathrm{G} 9$ and Indonesia are investigated.

This study contributed to the literature by examining whether a relationship can be found in Canadian data between stock market returns, consumer confidence and trader behavior. The use of a threshold model was an innovative method to check for the association between returns and sentiment. In addition, the relationship between stock market returns and consumer confidence changes during market turmoil periods or "crises" was investigated. Specifically, the coefficients in the relationship between consumer sentiment and stock returns were allowed to change overtime depending on whether the economy is in a high or low volatility state. Finding evidence of a stable significant relationship between consumer sentiment and the stock market is consistent with the assumptions of Prospect Theory. Conversely, a finding that the relationship changes overtime implies that consumer sentiment/moods become more or less important to investor decisions depending on whether the economy is perceived to be in a highly variable state. Finally, the interdependence of stock market returns was analyzed in an attempt to determine whether behavioral factors can influence contagion among countries of the industrialized world. While the study of behavioral finance attempts to investigate instances of abnormal asset pricing by seeking deviations to the Efficient Market Hypothesis, it also endeavors to explain the action of certain investors and does not necessarily claim that these actions affect prices. This dissertation will seek to identify and explain these actions rather than attempt to investigate the "limits to arbitrage". The basic argument inherent in the relevant aforementioned studies is the view that psychological factors influence trading activity. Some of these factors have long been 
identified specifically as heuristics that are incorporated into Prospect Theory, for example sentiment, herding, and overconfidence. Others views like that of contagion being classified as a wealth effect that can be explained by Prospect Theory are only just being advocated ${ }^{4}$. This study contributed to the literature by utilizing a proprietary database to identify trader behavior during crises; additionally it identified structural shifts during times of crises and finally investigated the components of a crisis and whether contagion in the market retums of the countries with similar economic backdrops could be predicted.

${ }^{4} \mathrm{Kyle}$ A. S., Xiong. W, (2001), Contagion as a Wealth Effect, Journal of Finance, Volume LVI, No. 4, pp. $1401-1440$. 


\section{CHAPTER II: REVIEW OF THE LITERATURE}

\section{Introduction}

While research into the idiosyncrasies of man and his influence in the financial markets has developed at a rapid pace over the last twenty years, there have been many unanswered questions. Part of the reason for this debacle is the dearth of publicly available aggregate trading data and knowledge of the thought processes that contribute to a trade. The field of behavioral finance can be subdivided into investigations on anomalies in asset pricing and the Efficient Market Hypothesis, and the field that relies on psychological biases to explain trader behavior.

\section{Behavioral Finance}

Behavioral finance has become a buzzword in the investment community and numerous articles have appeared in the financial press reporting on anomalies that may be explained by behavioral finance. However, the study of behavioral finance is not a recent phenomenon. As far back as the 1800 's, in The Crowd by Gustave Le Bon, Extraordinary Popular Delusions and the Madness of Crowds by Charles Mackay, there have been observations of herd irrationality.

The first area of the study of behavioral finance subdivides investors into two categories: "noise" traders and "arbitrageurs". Research in this area focuses on deviations from traditional asset pricing theories. The Efficient Market Hypothesis is predicated on heterogeneous investor beliefs. This heterogeneity of the market has been explained in traditional finance as 'noise'. Behavioral finance investigates this 'noise' and considers that it reflects market sentiment that can be priced in traditional asset 
pricing models. Alpha measures this noise and represents the extra risk priced into a stock over and above the market risk. While the review of this aspect of the literature is by no means exhaustive, it is arranged chronologically to provide a historical perspective on research along these deviations.

- Reinganum (1982) showed empirically that size as measured by market equity has explanatory power in predicting the cross-section of share market retums.

- Shiller (1984) and Summers (1986) showed that even if noise trader demand is so strong as to cause a large and persistent mispricing, it may go undetected since most models of returns will lack predictive capacity.

- De Bondt and Thaler (1985) reported that stock prices overreact to current changes in eamings and in 1987, they report positive (negative) estimated abnormal stock retums for portfolios that previously generated inferior (superior) stock price and earning performance.

- DeLong, Shleifer, Summers and Waldmann, (1993) found that the mispricing (divergence from the fundamental value) being exploited by the arbitrageur worsens in the short run.

- Benertzi and Thaler (1995) argued that the equity premium could be explained by "myopic loss aversion". Loss aversion, referring to the observed tendency for losses to hurt investors twice as much as gains feel good, and myopic referring to the tendency of investors even those with long-term horizons, to care about shortterm losses and gains. 
- Campbell, Lo and Mackinlay (1996) documented the tendency for stock prices to continue in the same direction over intervals of six months to a year, but to reverse themselves over longer intervals.

- Shleifer and Vishny, (1997) showed that "noise traders" can force arbitragers to liquidate their positions early bringing them potentially steep losses, partly because professional money managers are not managing their own money but rather managing money for other people. Therefore, when markets are already lower, selling activity may be magnified since money managers are preparing for anticipated redemptions.

- Biais and Shadur (2000) offered a counter-argument to Friedman (1953)'s claim that irrational agents are certain to be eliminated by market forces. They investigated a financial market where some traders over- and under-estimate the dividend flow. This "noise" trading permits the trader to enhance his/her bargaining power, so that he/she benefits from larger gains from trade than a rational agent does. They analyzed the stochastic evolutionary dynamics of the fraction of agents who are irrational, and show that they may well survive in the long term.

- Barberis, Huang and T. Santos (2001) analyzed asset prices based on a model where investors may derive direct utility not only from consumption but also from fluctuations in the value of their financial wealth. While investors show loss aversion tendencies, the degree of loss aversion depends on their prior investment performance. This framework is tested to explain the high mean, excess volatility, and predictability of stock returns, as well as their low correlation with 
consumption growth. The design of their model is influenced by Prospect Theory. However, it is based on experimental evidence on how prior outcomes can affect risky choice.

- Bleichrodt et al (2001) proposed a model of standard utility elicitation procedures, such as the probability and certainty equivalence methods, to correct for commonly observed violations of expected utility. Historically, decision analysis assumed expected utility not only for the prescriptive purpose of calculating optimal decisions but also for the descriptive purpose of calculating utilities. However, descriptive violations of expected utility, adversely affect the calculation of utility. That such biases are effective became clear when systematic discrepancies were found between different utility maximization methods that, under expected utility, should have yielded identical utilities. As it is not clear how to correct for these biases without further knowledge of their size or nature, most examples of utility maximization still use the expected utility formula. This paper speculates on the biases and their sizes by using the quantitative assessments of probability transformation and loss aversion suggested by Prospect Theory. It presents quantitative corrections for the probability and certainty equivalence methods. If interactive sessions to correct for biases are not possible, then they propose to use the corrected utilities rather than the uncorrected ones in prescriptions of optimal decisions. In an experiment, the discrepancies between the probability and certainty equivalence methods are removed.

- Shefrin (2005) has attempted to collate all the theories in the field of behavioral approaches to asset pricing models. 
The alternative consideration of behavioral finance is to explain trader behavior. In December 1996, the Chairman of the Federal Reserve System, Alan Greenspan commented that there was "irrational exuberance" in the markets, but in recent times the flip side of the question has been asked, "is the market exhibiting signs of irrational pessimism," or "has 'inational exuberance' shifted from the stock market to the real estate market". Behavioral economists have taken on the challenge inherent in this question by attempting to study how investors and traders behave.

- Myopic loss aversion is the combination of a greater sensitivity to losses than to gains and a tendency to evaluate outcomes frequently. Thaler, Tversky, Kahneman \& Schwart (1997) observed that investors who display myopic loss aversion will be more willing to accept risks if they assess the return of their investments more infrequently. The investors who benefited from the most frequent feedback (and thus the most information) took the least risk and earned the least money. The implication here is that institutional investors who have the resources to become better informed trade less often and earn excess returns.

- Andreassen and Kraus (1988) found that when people are shown real historical stock prices in sequence and invited to trade in a simulated market that displays these prices, their behavior showed that they extrapolated past price changes into their predictions of the trend in prices. This notion of feedback, where human judgments of the probability of future events sbow systematic biases, is also predicted in Prospect Theory. This is probably why today one sees stocks on an uptrend continue for a long period while others continue to go down. 
- Daniel, Hirshleifer, and Subrahmanyam (1998) stressed biases in the interpretation of private versus public information.

- Barberis, Shleifer, and Vishny, (1998) argued that rational models typically measure risk as the covariance of retums with marginal utility of consumption. Therefore, stocks are risky if they fail to pay out at times of high marginal utility (bad times) and instead pay out when marginal utility is low (good times). Evidence against these models is the result of systematic errors that investors make when using public information to estimate future cash flows.

- Odean (1998a) argued that the results for stock purchases are in part due to an attention effect. When buying a stock, people do not tend to do research through the thousands of listed shares until they find a good "buy." Instead, they typically buy a stock that has caught their attention based on past performance. This behavioral characteristic is not exhibited for stock sales because of fundamental short-sale constraints that make the selling decision different from the buying decision.

- Odean (1998b) found that individuals trade too much because of overconfidence in thinking they can pick winners, whereas the stocks they buy do worse than the stocks they sell, and are reluctant to sell losers even though they could potentially benefit from selling a loser than a winner because of tax laws.

- Hong and Stein (1999) assumed that private information is disseminated slowly. Since investors are unable to extract private information from each other, price momentum is created. 
- In one of the few empirical studies on trader behavior, Nofsinger and Sias (1999) found evidence that the use of momentum strategies by institutional traders is an important source of herding behavior.

- Mullainathan and Thaler (2000) began with a preliminary question about relevance. Does some combination of market forces, learning and evolution render these human qualities irrelevant? Perfect agents survive and influence market outcomes because there are limits to arbitrage. The decisions made by man deviate from the standard economic model because of bounded rationality, which reflects his limited cognitive abilities and hinders his problem solving. The heuristic of bounded willpower suggests that occasionally people choose things that will not benefit them in the long run. Another heuristic, "bounded selfinterest" incorporates the comforting fact that humans are often altruistic. They illustrate how these concepts can be applied in two settings: finance and savings. Financial markets have greater arbitrage opportunities than other markets, so behavioral factors might be thought to be less important here, but they showed that even here, the limits of arbitrage create anomalies that the psychology of irrational decision-making can help explain. They concluded that behavioral factors are essential elements of any complete descriptive theory. They believe poor problem solving occurs because of overconfidence, too much optimism, anchoring and extrapolation all of which lead to wealth diminishing consequences.

- Daniel, Hirshleifer and Subramanyam $(1998,2001)$ identified "overconfidence" whereby individuals attribute events that confirm the validity of their own actions 
to their own high ability, and events that disconfirm their actions to bad luck or sabotage.

- Benartzi and Thaler (2001) investigated portfolio diversification. They show that some investors follow the " $1 / n$ " strategy and divide their contributions evenly across the investment opportunities. This naive notion of diversification leads to better performance when there are more opportunities offered to an investor.

- Rubinstein, (2001) on the other hand, believes that markets are rational. Some of his evidence point to research, which reflect the inability of professional money managers to beat the market. He reasoned, "Although academic models often assume that all investors are rational, this assumption is clearly an expository device, not to be taken seriously. What is in contention is whether markets are "rational" in the sense that prices are set as if all investors are rational. Even if markets are not rational in this sense, abnormal profit opportunities still may not exist. In that case, markets may be said to be "minimally rational." Financial markets have developed to be minimally rational but tbere are two qualifications. Realistically, market rationality needs to be defined to allow investors to be uncertain about the characteristics of other investors in the market. Additionally, investor irrationality, to the extent that it affects prices, is particularly likely to be manifest through overconfidence, which in turn, is likely to make the market hyper-rational". It is important to note that irrational decisions are not synonymous to unpredictable events since it is possihle for unlikely events and

\footnotetext{
${ }^{\text {t}}$ Rubenstein, Mark, Rational Markets: Yes or No? The Affirmative Case, Financial Analysts Journal, May/June 2001 . Volume 57 Number 3.
} 
consequent actions to be still rational. Even though the demise of the stock market in March 2000 was not likely or predicted, the reaction of investors in selling off their stock holdings en masse was not irrational. It was simply a reaction to the probability that the economy was headed into a downturn.

- Barberis and Huang (2001) attempted to explain aggregate stock market behavior by combining loss aversion and narrow framing with assumptions of how the degree of loss aversion changes over time. They found that the investor is loss averse when there are individual stock fluctuations and the pain of a loss on a specific stock depends on that stock's past performance. They study equilibrium firm-level stock returns in two economies, one in which investors are loss averse over the fluctuations of their portfolio, and another in which they are loss averse over the fluctuations of individual stocks they own. Both approaches can shed light on empirical phenomena. However they find the second approach to be more successful in that the typical individual's stock return has a high mean and excess volatility, and there is a large value premium in the cross section, which can, to some extent, be captured by a commonly used multi factor model.

\section{Critics to the Theory of Behavioral Finance}

Robert Merton (1987) believed that the evidence against market efficiency was "premature" based on technical difficulties ascribed to Shiller's (1985) framework on

stock market volatility, and weak statistical effects in the De-Bondt -Thaler (1985) study on the overreaction effect. 
Eugene Fama (1970) in "Efficient Capital Markets: A Review of Empirical Work" extolled the virtues of market efficiency and in 1998 he produced a survey of empirical work on the challenges to market efficiency explained by behavioral finance theorists. He concluded, "behavioral finance is nothing more than anomalies dredging." Merton Miller (1986) used a study on dividends to affirm the existence of stock market rationality. He argued that while there are many interesting stories in finance, they should be ignored since they tend to be distracting and divert the attention of scholars away from identifying the fundamental forces, which drive markets.

\section{Reasons for Expansion of the Behavioral Finance Theory}

Answers to and explanations of the anomalies are needed so that past mistakes could be avoided. The key to evasion is recognition. Why else would past anomalies like the Tulip Bubble and the NASDAQ bubble of the late 1990's occur? The after effects of major crises like wars resulting in stock market crashes have been widely documented, yet it happened again in the week after the stock market reopened following the September 11,2001 terrorist activity. The anticipated rapid recovery from these lows occurred as early as the following month. Therefore, it is obvious that irrational exaggerations in financial markets are not a new issue since many of the extreme losses are recovered shortly thereafter. It is important to investigate these exaggerations to seek a rule of thumb since much pain and suffering could be avoided by anticipation of these anomalies and to model behavior to combat these wealth destructive forces. It seems that during "catastrophes" or "crises," investors ignore rational expectations resulting in observations of herd behavior and other destructive tendencies. 
The fact that so many proponents and critics of this facet of finance have emerged lends credibility and critics of this facet of finance lends credibility to the study. However, there remain many challenges regarding the testing of the theories. Since the field draws significantly from psychology, much of the empirical work is based on experiments with just a few based on actual data from market participants. The study of finance postulates that the markets in which "rational man" participates are efficient since all the information about a stock (even that known by only a select few) is already incorporated into the stock price. Over the last quarter of a century, research in markets with asymmetric information has expanded. The forerunners of this type of work are the 2001 Nobel Prize Winners in Economics: George Akerlof, Michael Spence and Joseph Stiglitz. While much of the work on asymmetric information was produced in the 1970's, the basic premise is still being used in applications today. Several of these publications attempted to explain anomalies in the Efficient Market Theory and so are the precursors of the study of Behavioral Finance. This attempts to explain anomalies in Standard Utility Theory using a broader social science perspective drawn from psychology and sociology.

Trends in Behavioral Finance -Market Microstructure

The study of the idiosyncratic behavior of man has evolved into the analysis of a process that details the informational content of prices broadly defined as market microstructure. This area attempts to link the two areas of behavioral finance, seeking deviations from traditional asset pricing methods to reflect trader activity. While this is a 
burgeoning empirical field of finance, it requires data accumulated at the micro level and is beyond the scope of this study.

\section{Experimental Design in the study of Behavioral Finance}

Thaler, Tversky, Kahneman \& Schwartz (1997) designed an experiment to simulate investment over time in two hypothetical funds to test the theory of Myopic Loss Aversion. This theory is reflected in the observed greater sensitivity to losses than gains as well as the tendency to evaluate outcomes frequently using mental accounting. It predicts that an investor who frames decisions narrowly will tend to make short-term choices rather than adopt long-term policies. An investor who frames past outcomes narrowly will evaluate gains and losses frequently. The combination of these tendencies defines a myopic investor. In general, this type of individual behavior consistently predicts poor decision-making and too frequent trading. An experiment with 80 undergraduate Berkeley students substantiates their claim.

Willman, O'Creevy, Nicholson \& Sloane (2001) test theory based on professional London trader data. In this experiment, traders were asked to describe their behavior under differing instances in order to determine their risk tolerance. They argued that managers focus on avoiding losses rather than making gains.

\section{Empirical Studies in Behavioral Finances}

A theory and its resulting models are only as good as the evidence. Empirical testing is the logical way to compare alternative theories. Lee, Shleifer and Thaler (1991) tested their model's prediction that small firm returns will be correlated with closed-end 
fund discounts. Hong, Lim and Stein (2000) tested the implications from the Hong and Stein (1999) model that momentum will be stronger among stocks with thinner analyst coverage. Other test sought evidence in support of a model for example the Odean (1998) and Genesove and Mayer (2001) investigations of the disposition effect using actual market behavior.

Locke \& Mann (1999) empirically tested currency and commodity data from the Chicago Mercantile Exchange to examine the trading activity of professional futures traders for evidence of the behavioral characteristics generally referred to as overconfidence and/or "gambling with the house money". The results lent support to the Gervais and Odean (2001) model of overconfidence and leaming, which predicted that successful and inexperienced traders are the most likely to be overconfident. They found little evidence of overconfidence in the group of predominantly experienced traders. However, they noted that the most successful traders are more likely to take risk when winning than the less successful traders are. This provided support for the notion that successful traders are more likely to be overconfident. They also found that trader experience is related to a measure of overconfidence - traders with more experience are less likely to take more risk after a period of abnormally good profits.

Fielding and Stracca (2003) proposed a model of expected returns under loss aversion. They found that agents are irrationally shortsighted and forgo superior returns by being too anxious about short-term outcomes, but they are "rational" in the sense that they treat safe and risky retums in the same way since they have the same reference point for both types of investment. 
A unique daily trade level data set from the main stock market in Pakistan compared the trades done by brokers on their own behalf and those done as intermediaries for outside investors. A study on this data set performed by Khwaja and Mian (2003) found the brokers earn at least $8 \%$ higher retums for their own trades as well as evidence of "pump and dump" price manipulation schemes. While this type of investigation is not the primary focus of our study, the techniques used may uncover some interesting characteristics.

Coval and Shumway $(2002,2005)$ study on behavioral biases suggested that traders behave differently in the aftemoons after experiencing moming losses or gains. They studied the behavior of proprietary traders at the CBOT and found that traders who experience losses in the morning are more likely to assume above average aftemoon risk than traders with morning gains. Their study was based on their assumption that each trader closes out his position at the end of each day, thus beginning each day with no position. The work by Kolb (1991), Kuserk and Locke (1993) and Manaster and Mann (1996) supported this view.

Coval, Hirshleifer and Shumway (2002) showed that contrary to evidence on previous studies on professional money managers of mutual funds, individual investors can beat the market. They reported, "That although individuals under perform the market over short horizons by trading excessively, over the longer term most performance persistence is concentrated among individuals with positive ability". They based this observation on trades placed through a large discount brokerage over 1990 through 1996. They described a procedure, which they claim adjusts for good performance during a period when the overall market appreciated. 
Paul Willman et al (1999) observed that traders' behavior within well-established markets appeared to deviate substantially from that predicted by theory. Using data from a study of traders within financial markets in London, the paper seeks to document this apparent paradox and assess its implications. General theories about how the financial world works are distinct from but compatible with more instrumental behavioral rules about how to work in the financial world. The latter is seen as an internally consistent recipe for action, which requires concurrent belief in both the validity of the general theories - for example about the relationship between risk and return - as well as the ability of individual agency to secure outcomes. In terms of the general theory, this has a low probability.

Using logit regressions on a unique data set of two years of investor behavior for almost the entire set of investors from Finland, Grinblatt and Keloharju (2001) found that distance, language, and culture influence stock trades. Investors exhibit reluctance to realize losses and engage in tax-loss selling activity. Past returns and historical price patterns, such as being at a monthly high or low, affect trading behavior.

Barber and Odean (2001) predicted overconfident investors will trade too much, and test this prediction by partitioning investors based on a variable that provides a natural proxy for overconfidence gender. Psychological research has established that men are more prone to overconfidence than women are. Thus, models of investor overconfidence predict that men will trade more, and perform worse, than women do. Using data from a large discount brokerage firm, they analyze the common stock investments of men and women. Congruent with the expectation of the overconfidence models, they give evidence that men trade more than women do, and earn annual risk- 
adjusted net returns that are less than those earned by women. In fact, the differences in the sexes are magnified among unmarried individuals. Using the same discount brokerage data Barber and Odean (2002b) tested the idea that for individual investors, buying decisions are more driven by attention than are selling decisions. They found that the individual investors in their sample are more likely, on the following day, to be purcbasers of these high-attention stocks than sellers.

\section{Prospect Theory}

The most current theories in behavioral finance that incorporate the tenets from Prospect Theory have been collated, and put forward as explanations for the deviation from standard utility theory. This theory has been promoted as an exegesis of behavioral finance anomalies.

Kahneman and Tversky have long been viewed as the pioneers in tbe field of behavioral finance. In awarding the Bank of Sweden Prize in Economic Sciences in Memory of Alfred Nobel 2002 - the following observation was disseminated. "Traditionally, economic theory has relied on the assumption of a "homo economicus," whose behavior is governed by self-interest and who is capable of rational decisionmaking." Economics has also been regarded as a non-experimental science, where researchers - as in astronomy or meteorology - have had to rely exclusively on field data, that is, direct observations of the real world. During the last two decades, however, these views have undergone a transformation. "Controlled laboratory experiments have emerged as a vital component of economic research and, in certain instances, experimental results have shown that basic postulates in economic theory should be 
modified. Researchers in two areas have generated this process: cognitive psychologists who have studied human judgment and decision-making and experimental economists who have tested economic models in the laboratory. This Nobel Prize was awarded to the innovators in these two fields: Daniel Kahneman and Vernon Smith"2 . Honorable mention was also given to Tversky for his work with Kahneman on Prospect Theory.

An essential component in any model that attempts to understand trading behavior is an assumption of investor preferences - how he/she evaluates risky gambles. Von Neumann and Morgenstern (1944) showed that if investors followed the axioms of completeness, transitivity, continuity and independence then their preferences in reviewing choices made under risky conditions, could be represented by some utility function. Historically, models of decision making under uncertainty or risky situations, assume that investors are risk- averse. When the utility of wealth is defined by $\mathrm{U}(w)$, risk aversion implies that $U^{\prime}(w)>0$ and $U^{\prime \prime}(w)<0$ (Markowitz (1952a); Samuelson (1958); Pratt (1964); Sharpe (1964); Arrow (1965); and Lintner (1965)). These models imply the market is homogeneous. However, the market's participants are very much heterogeneous in their beliefs and actions. In fact, the Efficient Market Hypothesis is predicated on heterogeneous investor beliefs. This heterogeneity of the market has been explained in traditional finance as 'noise'. Behavioral finance investigates this 'noise' and considers that it reflects market sentiment that can be priced in traditional asset pricing models.

Since Friedman and Savage (1948) and Markowitz (1952b) theorists have suggested that the utility function should also have a risk-seeking segment with $U^{\prime \prime}(w)>$

\footnotetext{
${ }^{2}$ Source: www. J-bradford-delong.net/movable_type/archive/001010.html.
} 
$0^{3}$. While these theorists only speculated on the existence of risk-seeking segments, psychologists led by Kahneman and Tversky (1979) began conducting experimental studies to investigate this property. Tversky, the late Stanford University cognitive psychologist, and Kahneman, of Princeton University, declared that the ever-rational economic person or "homo economicus" did not correspond to observed human behavior. They found in their experiments, for example, that investors focus more on the risk of a prospect (losses) than the benefits (gains), and espoused the now famous "Prospect Theory".

\section{Philosophical Base}

The "Chicago School" approach to human behavior led by Milton Friedman (1953) has many followers. The most important characteristic of 'homo economicus' is his rationality. However, what has been termed anomalies in the stock market probably has a large part to do with the fact that vcry often investors do not act rationally.

The scope of the price anomalies is diverse, for example, Vriend (1996) asserts while rational agents do not generally buy at the lowest price available in the market, they will nomally search objectively for the best strategy available in their environment, affirming that irrational behavior does not occur. However, an anomaly is the commonly observed one where investors, especially institutional traders and market makers react to a falling stock or bond price by buying more in an attempt to prop up the price.

\footnotetext{
${ }^{3}$ Levy H., and Wiener Z., (1998) Stochastic Dominance and Prospect Dominance with Subjective Weighting Functions, Journal of Risk and Uncertainty, Volume 16, Issue 2, Pages $147+163$.
} 
Under uncertainty, and assuming Friedman's position, an individual's ranking of a prospect (the object of choice) is usually denoted by the matbematical expectation of utility or benefit resulting from the action. Utility is derived from outcomes (consequences). It occurs because of beliefs (probability assessments over states of the world) in the occurrence of certain outcomes. These preferences are incorporated by some mathematical function (for example lognormal, exponential, power function) to give some level of utility. The usual criteria for these utility functions are monotonicity and convexity to imply risk-aversion. Non-convex preferences are avoided since they tend to have indifference surfaces, which are tangent to budget, and set boundaries at several places. As well, risk preferences change over time. In addition, it has been shown that measurement errors in variables could bias utility function coefficients (Knowles 1984) and that changes in wealth cannot to explain the preference shifts over time. Fishburn (1988) presents a survey of decisions under uncertainty, which violate Von Neuman-Morgenstern's Expected Utility (VMUT) theory.

Apparent violations of expected utility theory are sometimes explained by information processing costs, which lead researchers to use a simplified rather than complete model (Demski, 1972). Kahneman \& Tversky (1979, later modified in 1992) (hereafter referred to as KT) proposed an exegesis, which they called Prospect Theory, as an alternative theory of behavior in response to these violations of expected utility theory. This theory postulates that individuals behave differently after periods of losses compared to periods of gains. While a loss minimizing investor may be more risk averse after gains have been secured, behaving like a portfolio insurer, when confronted with losses, the investor attempts to maximize the probability that terminal wealth exceeds his 
aspiration level. Therefore, he may tend to employ activities such as averaging down, window dressing, or some other type of misguided action. This behavior is reflected in his trading activity.

\section{Definition of Prospect Theory}

Kahneman and Tversky (1979) (KT) developed Prospect Theory as an alternative method of explaining individuals' choices made under conditions of risk or in terms of the common buzzword of today "volatility." KT's basic theory proposes that the choices that individuals make in risky situations exhibit several characteristics that are inconsistent with the basic principles of risk aversion hypothesized by Von Neuman and Morgenstern (VM). VM predicts that decisions in risky situations are based on an individuals' expected final wealth and probabilities of different states in the economy. Prospect Theory theorizes that when individuals are faced with making a choice among different prospects, they disregard components that are common to all prospects under consideration and make a decision based on values assigned to gains and losses from a certain reference point and decision weights. These decision weights are lower than the corresponding probabilities of VMUT. This may explain why individuals buy insurance, but at the same time are willing to gamble.

This theory postulates that individuals behave differently after periods of losses compared to periods of gains. While a loss minimizing investor may be more risk averse after gains behaving similar to a portfolio insurer, when confronted with losses, the investor attempts to maximize the probability that terminal wealth exceeds his aspiration level. Therefore, he may tend to employ activities such as averaging down, window 
dressing, or some other type of misguided action. This behavior is reflected in his trading activity and has been used to explain investor behavior in avoiding selling losers.

They assert that individuals face choices or prospects, which are defined in terms of gains and losses relative to some neutral reference point. The relevance of the reference point results from the observation that people are usually risk averse when gains are experienced, but risk seeking when losses have been incurred. Therefore when choosing among risky and uncertain prospects with a finite number of outcomes, a person may prefer a large uncertain loss to a sure small loss, whereas a small sure gain may be preferred to a gamble involving a large uncertain gain. K-T refers to this as the reflection effect where reflection occurs at the origin, i.e. for zero losses and zero gains. The reflection effect implies there is risk aversion in the positive (gains) domain but risk seeking behavior in the negative (losses) domain. Thus, the value (or utility) function is concave for gains and convex for losses. Expected utility theory makes no restriction on the shape of the utility function, therefore this reflection effect does not represent a violation.

The origin or reference point characterizes K-T's Value Function, which is derived from Prospect Theory, which is the perceived status quo. They propose lossaverse utility functions that are convex over losses and concave over gains. Value is measured by the change from the perceived starting point. The function is theorized to be steeper for losses than for gains. In Prospect Theory, how the situation is "framed" i.e. the attainable gains or losses, determines the path the individual may take. The individual also distinguishes between losses on paper versus realized losses. When an individual has already experienced a given monetary loss, greater hurt is experienced and 
the curve is steeper from the origin (see Figure 1). The curve is less steep from the starting point (status quo) when gains have already becn enjoyed.

\section{Figure l}

Value Function Hypothesized from Prospect Theory

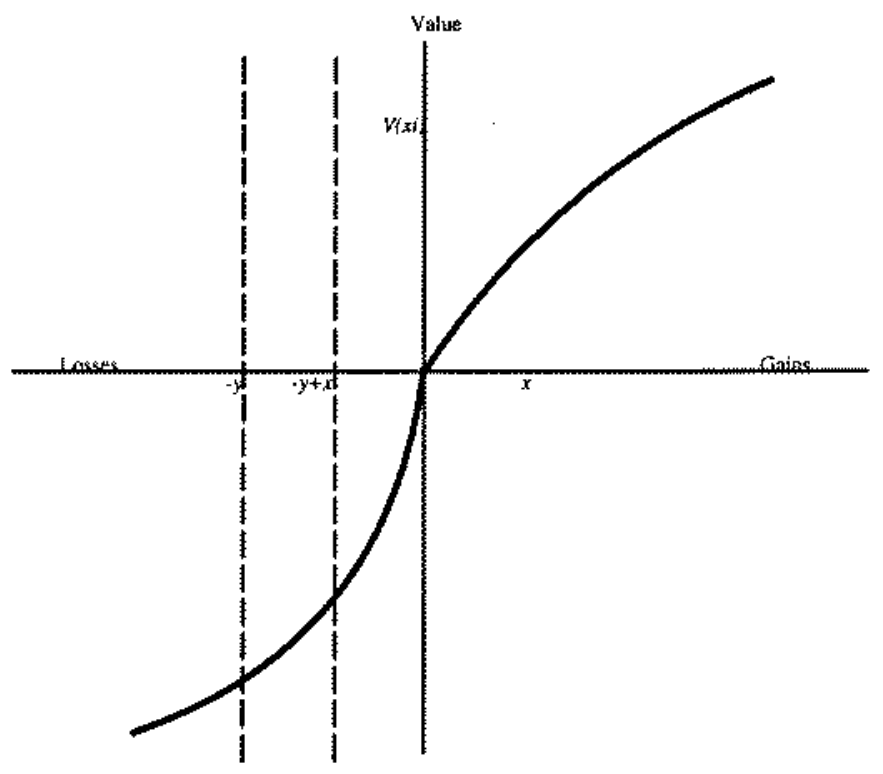

The utility or value function (denoted by $\mathrm{V}\left(x_{\mathrm{i}}\right)$ in Figure 1 ) is defined in terms of two scales. The first is the decision weighting function denoted as $\pi(p)$, which reflects the impact of $p$ (the probability of receiving $x$ ) on the total value of the prospect. The second scale $v$ reflects the value of changes from the reference point, its gains or losses. It is important to note that the $x_{i}$ 's in the value function are outcomes and are defined as changes in wealth or position rather than absolute wealth, unlike expected utility theory. However, K-T's utility function is similar to the Von Neumann-Morgenstem expected utility theory (VMUT) function, which is convex for losses and concave for gains above. Convexity implies most probabilities are underweighted while very small probabilities 
are over weighted. In addition, K-T"s value function is steeper for losses than for gains, compared with the typical expected utility function. KT finds that individual decisionmakers have limited ability to process information when making decisions and suggests the preference for a risk-taking attitude in the domain of losses. They believe that the prevalence of risk-taking attitude may be "rooted in people's limited sensitivity to low probability events."

Prospect Theory Methodology

$$
V(x, p ; y, q)=\pi(p) v(x)+(1-\pi)(q) v(y)
$$

Pratt's absolute risk aversion coefficient $(R)$ for individual investors is used to measure investors' responses under conditions of gains and losses in wealth.

$$
R=-U U^{\prime \prime}(W) / U \prime(W)
$$

While the ideal situation is to study investors' preferences under different wealth changing scenarios and to add them up in a coherent manner to test the total effect, this method is impractical. Therefore, special cases of wealth altering conditions can be highlighted by analyzing abnormal or major events in an aggregate sense or by reviewing Wall Street Joumal's announcements of unusual events that may lead to significant wealth losses. In the terminology of Prospect Theory, this would constitute the editing phase. Examples of wealth losing events are "Black" Monday, "Blue" Monday, "Turnaround" Tuesday, and days when the DJIA changed by a specific number of points in a single day.

Prospect Theory provides no prediction of the changes in $R$ if changes in wealth have already been incorporated into investors' choices. However, failure to incorporate 
prior wealth changes into choices, gives definite predictions for changes in $R$. Recent reductions in wealth should result in the value function being convex for both gains and losses. The patterns identified by KT are:

1. risk-seeking over low probability gains (lottery)

2. risk-aversion over low probability losses

3. risk-aversion over high probability gains

4. risk-seeking over high probability losses

Thus, measures of $R$ would tend to be negative after the wealth loss and positive after the wealth gain. These arguments lead to the following testable hypothesis:

Hypothesis: During periods of catastrophe, when investors experience massive wealth losses as defined by an appreciable absolute change in the index, the change in the absolute risk aversion coefficient, $R$, should be below zero i.e. investors should become less risk-averse or exhibit risk-seeking behavior, and above zero if investors become more risk-averse i.e.:

$H_{0}: \Delta R<0$

$H_{A}: \triangle R \geq 0$

While Equations (2) and (3) are theoretically accurate, they pose difficulties at the empirical level. Realistically a formularized expansion is needed that leads to the testing of equations (2) and (3).

A few other features of Prospect Tbeory are of special interest. These have been identified as isolation and certainty effects. The isolation effect occurs when people who are faced with a choice among different prospects, often disregard components that the 
alternatives share and focus on the distinguishing features. This approach to choice may lead to inconsistent preferences, since a pair of prospects can be decomposed into common and distinct components in more than one way leading to different preferences. The certainty effect is described as a systematic overweighting of outcomes considered certain, relative to outcomes, which are probabilistic. These observations which occur during the decision making process are not adequately explained by conventional expected utility theory. Thus when there are "departures from expected utility theory which lead to normatively unacceptable consequences such as inconsistencies, intransitivities, and violations of dominance," the value function, the underlying concept of Prospect Theory render a suitable alternative.

Prospect Theory describes decisions as having two stages - editing and evaluation. Editing is a reviewing process, which simplifies the decision problem for the evaluation stage. Aspects of editing involve coding (for example, when alternative outcomes of a decision are redefined as gains and losses from a reference point $\mathbf{P}_{\mathrm{r}}$ (in Figure 1$)$. This can be the current wealth or equity capital position of an individual (or, in the case of a mutual fund manager, the net asset value of his bond or equity fund). Another operation that occurs during the editing phase is combination where probabilities associated with identical outcomes are combined. In segregation, aspects of editing involve separating the risky component from the riskless component of a prospect. Finally, common components contained in all the prospects evaluated are discarded (cancelled).

The second major operation described in Prospect Theory is evaluation, which occurs subsequent to editing. The prospect is evaluated in a manner similar to an expected utility formulation; subjective values are assigned to the outcomes in the 
prospect. Then decision weights (analogous to subjective probabilities) are assigned to the outcomes. The values and weigbts across outcomes are combined (using a multiply and add rule-just like the Rational Expectations Principle in Utility Theory). Finally, the decision-maker chooses the prospect with the highest value based on the operations from the editing phase that has the highest preference rating.

Newman (1980) explains that while VMUT is based on an explicit set of axioms or is deductive, Prospect Theory is inductive or based on observations of behavior. Arkes and Blumer (1985) apply PT to examine the irrational behavior of individuals wbo continue with a losing prospect simply because they have already invested money in that project. They argue that the concept of individuals" "throwing good money after bad": is appropriately described by PT. They present 10 experiments involving a decision prospect to a group of college students. Each student is presented with one experiment where a sunk cost decision has already been made. The experiments range from deciding whether to proceed with a $\$ 10$ million investment project to choosing between two ski trips. Tbey find that the characteristics of PT explain the "sunk cost" reaction. First, the value function represents the relation between objectively defined gains and losses and the subjective value a person places on these gains and losses. Secondly, the certainty effect implies that a sure gain is overvalued and a sure loss is undervalued. However, PT does not explain why sure losses are so abhorrent and sunk costs are so difficult to ignore.

Fiegenbaum (1990) use COMPUSTAT data of U.S. industrial firms to explain Bowman's risk-teturn paradox. They found that firms tend to demonstrate risk-seeking behavior (a convex value function) when they are suffering losses or are below targeted 
ROE levels. In contrast, when targets have been achieved, they tend to exhibit riskaverse behavior (i.e. a concave value function. These findings are consistent with Prospect Theory.

The utility function alone does not incorporate losses into prospective gambles of uncertain outcomes. In this instance, prospects will have to be re-evaluated and can even be evaluated with a convex value function. This is very different from expected utility theory, which postulates concave utility function for risk-averse individuals. Thus, individuals in a loss situation would exhibit risk-seeking behaviors. Kahneman and Tversky (1979) cite a well-known example of this, the tendency toward betting on "long shots" near the end of a trading day. Coval and Shumway (2005) presented evidence of loss aversion in a study where proprietary traders displayed significantly more risk in aftemoon trading following moming gains placing price-setting trades more frequently, paying higher prices for purchases and accepting lower prices for sales. By contrast, afternoon prices set by traders with morning losses show the reverse noticeably more than the prices set by others. This study directly linked the value function from Prospect Theory to gains and losses in the futures pit. They predicted a curvature of the value function, which implies that traders with profits (losses) by the middle of the trading day will take less (more) risk in their afternoon trading.

The decision weighting function distinguishes Prospect Theory from expected utility theory. This function is applied to the probability of each occurrence and reflects the impact of probability on the overall value of the prospect. Thus, small probabilities are overweighted and large probabilities are underweighted. Allais (1953) famous 
paradox has been used to highlight the benefits of Prospect Theory. It focuses on the choice of rational man:

Decision 1: Choose between $A$ and B:
A $\$ 1,000,000$
$E(A)=\$ 1,000,000$
with probability 1.00
B $\$ 5,000,000$
$\$ 1,000,000$
$\$ 0$
$E(B)=\$ 1,390,000$
with probability 0.10
with probability 0.89
with probability 0.01

Decision 2: Choose between $C$ and D:
C $\$ 1,000,000$
$\$ 0$
$\mathrm{E}(\mathrm{C})=\$ 110,000$
D $\$ 5,000,000$
$\$ 0$
$E(D)=\$ 500,000$
with probability 0.11
with probability 0.89
with probability 0.10
with probability 0.90

Many subjects chose $A$ when faced with Decision 1 even though there was a $10 \%$ probability of a larger payoff, with only a $1 \%$ chance of losing it all, and $D$ when faced with Decision 2 , breaking the expected utility rule of linearity of preferences in choices. Based on the 'strong independence' axiom of expected utility theory, the mixtures involved in Decisions 1 and 2 should not affect the ranking of these gambles, just the expectations. However investors' preferences were more affected by the probabilities of $0.99(0.89+0.10)$ to 1.00 , than the smaller probabilities of large payoffs.

Assuming a utility function which satisfies concavity for $r>0$ and convexity for $r$ $<0$ i.e. $v(r)=r^{1 / 3}$ and a $\pi$ function which satisfies $\mathrm{K}$-T's requirements, i.e. $\pi(p)=0.1+0.9$ $\left(p^{2}\right)$ for $p \in(0,1)$ and $\pi(p)=0$ for $p=0$, Allais' (1953) famous paradox can instead be evaluated using Prospect Theory: 
Decision 1: Choose between $A$ and $B$ :
A
$\$ 1,000,000$
with probability 1.00
B
$\$ 5,000,000 \quad$ with probability 0.10
$\$ 1,000,000 \quad$ with probability 0.89
0
with probability 0.01

$$
\begin{aligned}
V(A) & =v(1,000,000) \pi(1)=(1,000,000) 1 / 3=100 \\
V(B) & =v(5,000,000) \pi(0.1)+v(1,000,000) \pi(0.89)+v(0) \pi(0.01) \\
& =99.928
\end{aligned}
$$

\section{Decision 2: Choose between $C$ and D:}

$\mathrm{C}$

$\mathrm{D}$

$\$ 1,000,000$

0

$\$ 5,000,000$ with probability 0.11

with probability 0.89

with probability 0.10

with probability 0.90

$V(C)=11.089$

$V(D)=18.639$

Thus, Alais' paradox can be solved accurately by using Prospect Theory. However, a descriptive theory should be reconcilable with empirical results involving violations of independence axioms. K-T shows that the preference axioms are usually satisfied (risk aversion) when gains have already been made. When losses are incurred, risk taking occurs. This problem, known as framing/context, may lead to the failure of the axioms of invariance, dominance, independence and transitivity. Therefore $\mathrm{K}-\mathrm{T}$ suggests that Prospect Theory can be used as a viable altemative to expected utility theory.

They noted that occasionally investors perform activities that violate the axioms of dominance or invariance. They show experimentally that typical preferences are given by an S-shaped value function, $\mathrm{V}(x)$, (to distinguish from utility function) with the following properties: $\mathrm{V}^{\prime}(x)>0$ for all $x, \mathrm{~V}^{\prime \prime}(x)<0$ for $x>0$ and $\mathrm{V}^{\prime \prime}(x)>0$ for $x<0$, where $x$ stands for the change of wealth. Thus risk seeking prevails in the range $x<0$. The 
result is concave utility functions in the domain of gains (denoting risk aversion) and convex in the domain of losses (indicating risk seeking behavior).

K-T showed that the preference axioms are usually satisfied (risk aversion) when gains have already been made. However when losses are incurred, risk taking occurs. This problem, known as framing/context, may lead to the failure of the axioms of invariance, dominance, independence and transitivity. However, K-T's utility function is similar to the Von Neumann-Morgenstern expected utility theory (VMUT) function, which is convex for losses and concave for gains above. Convexity implies most probabilities are underweighted while very small probabilities are over weighted. In addition, K-T's value function is steeper for losses than for gains, compared with the typical expected utility function. Therefore K-T suggests that Prospect Theory can be used as a viable alternative to expected utility theory.

These findings contradict expected utility theory, and, cast doubt on the validity of most fundamental economic, and finance models. PT has gained many believers over the years, and increasingly academicians employ PT to explain phenomena in the capital markets. PT plays a central role in the area called "behavioral finance" or "behavioral economics", which has recently attracted much attention both from practitioners and surveyed in academia (chronologically for example, Thaler (1994); Benartzi \& Thaler (1995); Barberis, Shleifer, \& Vishny (1998); Daniel, Hirshleifer, \& Subrahmanyan (1999); Barberis, Huang, \& Santos, (1999) and Shefrin (2005)).

Plous (1993) summarized tbe psychological research into investor heuristics in his book, "The psychology of judgment and decision making". Slovic (2000), additionally, translated psychological research methods, and research results on decision-making into 
the language of economics. By their studies, these researchers and other psychologists have introduced psychological research methods and findings to economists/finance researchers who were looking for a more accurate model for human judgment, than "Homo economicus". These studies conclude that investors act under cognitive constraints failing to achieve rationality, in a manner that can potentially be accounted for, predicted, and exploited.

Herbert Simon (1955) challenged the economic orthodox of the definition of rationality by proposing the concepts of 'satisficing', bounded and procedural rationality. He believed that the alternative to the traditional notion of rationality is by no means irrationality but the notion of bounded rationality. This is described as limited cognitive abilities that constrain problem solving. "Despite - and sometimes even because of - their bounded resources in knowledge, time, and computational resources, humans are able to make good decisions." This theory showed man has a "choice" in decision-making.

\section{Theoretical Aspects}

Investors' investment decisions may change because of adverse economic or social conditions. In the context of Prospect Theory, when losses have already been made, risk- seeking behavior is exhibited, as the investor prefers the slim chance of returning to a reference point, the origin in Figure 1, to the option of a sure loss with a higher expected value. Therefore, the investor is expected to show a tendency to commit new resources to the same negative prospect.

If one were to adhere to expected utility theory, the set of desirable options was only as good as the assumed stable utility function. Prospect Theory on the other hand, 
while it is inherently based on expected utility, is strongly influenced by cognitive theories of bounded rationality. The term bounded rationality is used to designate rational choice that takes into account the cognitive limitations of both knowledge and cognitive capacity. This theory emphasizes the fact that investors' capabilities are constrained by perception, logical power and economic capacity (Vriend 1996). Therefore, it does not eliminate times when investors are irrational.

Several researchers have contended that the right choice of mean-variance efficient portfolios will give precisely optimum expected utility if and only if all distributions are normal or if the utility function is quadratic (Levy and Markowitz (1979), and more recently, Robison and Barry (1987)). A corollary to this argument is implied: that a well-selected point from the mean-variance efficient set can be trusted to yield almost maximum expected utility if and only if the investor's utility function is approximately quadratic or the investor's a priori beliefs are approximately normal. Since many people reject the hypothesis that retum distributions are normal, and Pratt and Arrow (1964) have each shown that quadratic utility functions produce absurd implications, it makes sense, that another specification of the utility function is desirable.

Numerous researchers have investigated other utility functions using various mathematical aberrations for example lognormal, exponential etc. Though each of these has been shown to have relatively good approximations, they do not stand up in times of irrationality. Traders have shown that tbey sometimes react irrationally when faced with extremely volatile conditions. Many observations have been presented to explain their behavior. The herd atmosphcre sometimes prevails whereby traders do not want to be caught holding unwanted positions and so start selling in large chunks once the market 
moves downward. Again, on the downside, some traders have tried to prop up the stocks in which they have a large position simply by buying more. Traders may also view these times as opportunities to "average-down". Individuals tend to be less risk-averse or bolder during catastrophic times. On the other hand, when the market shows volatility on the upside, traders who do not want to "miss the boat" jump in without any regard for changes in the fundamentals of the stock.

\section{Sentiment}

Shefrin (2005, p 219) defines market sentiment, a concept typically described in finance as 'noise', as the measurement of the degree of excessive optimism or pessimism among investors. Kahneman and Tversky's (1979) Prospect Theory has been incorporated into traditional asset pricing models in order to explain asset price anomalies such as the equity premium and excess volatility in stock returns. A central feature of Prospect Theory is the idea that agents/investors derive utility from their financial wealth, not just from the level of consumption as is assumed in traditional utility theory. In addition, it is assumed that agents' risk aversion changes depending on whether they experience gains or losses, a feature termed loss aversion. Overreaction and underreaction of stock prices is linked to a model of investor sentiment or how investors form eamings expectations by Barbaris, Shleifer and Vishy (1998). Two of the most recent theoretical contributions to the asset pricing literature are found in Barberis, Huang, and Santos (2001) (BHS hereafter) and Falato $(2003)^{4}$.

"Falato, 2003. "Happiness Maintenance and Asset Prices," Finance 0310003, Economics Working Paper Archive at WUSTL. 
BHS showed that incorporating Prospect Theory ideas into the traditional model helps to explain many of the empirical findings on stock returns. Their model allowed agents to derive utility directly from changes in financial wealth in addition to consumption growth. Specifically, agents become more risk averse if they experience prior stock market losses and less risk averse after prior gains. Falato (2003) used the term "happiness maintenance" to describe the feature that: "investor's risk aversion depends partly on their current affective state, which, in turn, is a function of the current state of the economy. In particular, good times bring about a positive mood for investors and, consistent with the experimental evidence (1sen (1999) and others), a heightened pain from any potential loss." (Falato, p 5). Using this modification to the preference structure of the model, Falato was able to reproduce many features observed in U.S data such as the equity premium and the volatility and predictability of stock returns.

The two aforementioned studies show that assuming that investor preferences depend on economy wide state variables such as the stock market is crucial to developing a successful theoretical model of asset prices. Since estimating risk aversion is an extremely difficult exercise it is necessary to consider a proxy for this emotion. Baker and Wurgler (2003) find that "when sentiment appears to be high, stocks that are relatively attractive to optimists and speculators (young stocks, small stocks, unprofitable stocks, non-dividend paying stocks, high-volatility stocks, extreme-growth stocks, and distressed stocks) experience low future returns relative to other stocks" and vice versa. They noted that the rise and fall of dividend payouts between 1963 and 2000 closely tracked investor sentiment. They grew when investors were most risk averse. This suggests that sentiment can be used as a proxy for risk aversion. 
There are several papers directly linking sentiment to stock market returns. Otoo (1999) documented a strong contemporaneous relationship between the Michigan consumer confidence index and stock market returns in the U.S using monthly data for the period from June 1980 to June 1999. A more recent paper by Brown and Cliff (2004) found a strong relationship between investor sentiment and the stock market using data on survey measures of investor sentiment as well as a variety of investor sentiment indicators, such as advance-decline ratios and closed-end fund discounts.

Ding et al (2004) found the asymmetry in the impact of positive and negative earnings growth on analysts' forecast errors (which they use as a proxy for analysts' sentiment since analyst's forecasts are influenced by market sentiment) is similar to the value function of Prospect Theory, where gains and losses have an asymmetric impact on the value of a prospect. They noted, "Since investors have a loss aversion according to the predictions of Prospect Theory, analysts would avoid making pessimistic forecasts if their incentives are tied to investor trading activity".

The aforementioned studies show that the assumption that investor preferences depend on economy wide state variables such as the stock market, is crucial to developing a successful theoretical model of asset prices. It is important to check for stability of regression coefficients when the model is estimated on sub-samples that are specifically selected based on categorical or continuous variables. A decision has to be made at which point or threshold is it reasonable to split the sample. A method devised to make this selection is a special case of the threshold regression model. A threshold variable is endogenously determined and is used to split the sample into two groups called classes or regimes. The Threshold Autoregressive Model (TAR) was first devised 
by Tong (1983, 1990). Bruce Hansen (1996) approached the problem with a simple threshold model involving an analog of the two regimes. In deriving the distribution, he allowed for conducting inference using the model where previously standard errors could not be computed giving no theoretical basis for inference. He noted, "We find that if we let the threshold effect (the difference in slopes between the two regimes) become small as the sample size increases, then the asymptotic distribution of the threshold estimator is free of nuisance parameters (up to scale)". The threshold estimator is assumed to have an asymptotic distribution and a Brownian motion. When the homoskedasticity condition does not hold a scaled likelihood ratio statistic and an amended confidence region deals with the problem of biased correlation coefficients.

\section{Contagion}

Recent research into financial crises, suggest that they appear in tandem. In September 1992, the lira and sterling were expelled from the Exchange Rate Mechanism of the European Monetary System (EMS). In 1993, Spain and Portugal, Ireland and France were also forced to devalue again due to another surge of speculative pressure. This caused the demise of EMS and Europe's attempt at unified monetary policy. In 1994, a number of countries were affected by the sudden and dramatic devaluation of the Mexican peso, nicknamed the "Tequila" crisis. A series of crises in 1997 affected several Asian economies. These episodes have led economists to suggest that financial crises are contagious, that they spread from the originating country to other countries, and that an understanding of the reasons for contagion is essential for forming appropriate economic policies. 
Explanations for the transmission of a crisis across countries include fundamental factors, trade linkages that transmit a crisis, where currency depreciation in one country weakens the fundamentals in other countries by reducing the competitiveness of their exports. Additionally, financial inter-dependence can contribute to the spread of a crisis, as initial turmoil in one country can lead to loan redemptions, thereby creating a credit crunch in other debtor countries. Finally, a currency crisis in one country can worsen market participants' perception of the economic outlook in countries with similar characteristics and elicit a fall in investor confidence throughout the region.

Lee and Kim (1993) found evidence of contagion in stock markets around the world after the 1987 U.S. stock market crash using correlation statistics. The verification of inter-relationships in stock market returns is muddied since the World Bank's definition of contagion is similar: contagion exists when cross-country correlations increase during crisis times relative to correlations during tranquil times. It is therefore necessary to find a definition of contagion that can be identified and not confused with other less catastrophic conditions.

Some of the conclusions that have been predicated include the theories of "monsoonal effects", "spillovers", and "pure contagion". The theory of "monsoonal effects" suggests that financial crises appear to be contagious because the underlying macroeconomic causes are correlated. "Spillovers," describes a crisis which affects another country through external links such as trade. The theory of "pure contagion" theorizes that the market jumps from a "good" to a "bad" equilibrium. The jump could be caused by a reversal in a long-standing information cascade. A financial crisis in one country could be considered a signal that, for example, a certain type of economic 
development strategy is unsustainable. Investors would withdraw their money from countries with apparently similar development strategies and cause a cluster of financial crises. The first two cases, monsoonal effects and spillovers, are examples of interdependence. Crises resulting from inter-dependence should be largely predictable using macroeconomic fundamentals. If the inter-dependence during non-crises periods is known, the effect of a financial crisis in one country on the likelihood of a crisis in another country can be evaluated. The third case, jumps between states of equilibrium, is what is referred to as contagion in this study: a largely unpredictable, higher correlation during crises times. This definition of contagion means that a crisis in one country increases the likelihood of a crisis in another country over and above what would be implied by the inter-dependence that prevails between these countries in non-crises times. This definition corresponds to that given by Forbes and Rigobon (2002).

Implications of understanding the distinction between contagion and interdependence are crucial for gaining the benefits of international portfolio diversification. If markets exhibit higher correlation after crises than before, diversification of portfolios across countries might be less useful than previously established.

Part of the empirical literature on contagion has focused on currency crises. Eichengreen, Rose, and Wyplosz (1996) used a set of macroeconomic variables and a dummy variable for contagion in a probit model to explain a binary indicator of currency crises. Their results show that a crisis elsewhere raises the likelihood of currency crises by about $8 \%$. They interpret this as evidence of contagion. Other research focuses on investigating contagion of financial markets by testing for higher correlation between markets during times of crises that could be identified ex post (King and Wadhwani 
(1990), Boyer, Gibson, and Loretan (1999), Loretan and English (2000), Forbes and Rigobon (2002) and Corsetti, Pericoli and Sbracia (2002)). Bae, Karolyi and Stulz (2003) tested whether the number of contemporaneous extreme stock market returns across a number of markets in a given region can be explained. They found that the average exchange rate in the region, the average interest rate in the region, and the conditional volatility of a regional stock market index are all significant predictors. Dungey and Zhumabekova (2001) suggested consideration of sample sizes has to be taken into account when investigating contagion since most crisis periods are much smaller in size than non-crisis period data, greatly reducing the power of the test.

Kyle et al (2004) found "that when an agent with a Prospect Theory utility function (compared to a risk-averse agent) realizes gains and losses, he delays liquidation when the project is in losses". This assumption is different from Barberis, Huang, and Santos (2001) that allowed unrealized paper gains and losses to affect an agent's utility. They make two assumptions. First, the investor is more sensitive to paper losses than to paper gains due to loss aversion. Second, after a prior loss, the investor becomes more risk averse: after being injured by the initial loss, he is more sensitive to additional setbacks. Note that the second assumption, which is motivated by an earlier study by Thaler and Johnson (1990), could generate an incentive for the agent to liquidate early in the presence of earlier losses, because the agent is more risk averse in these situations.

Forbes and Rigobon (2002) and Corsetti, Pericoli and Sbracia (2002) have attempted to identify contagion effects from pairwise contalion of stock market returns by testing whether correlation is significantly higher during crises times compared to normal periods. "The three criteria are: a major shift in market volatility; clear 
identification of which country generates this shift in volatility; and inclusion of the relevant country as one market in the estimated correlation," Forbes and Rigobon (2002 p14).

The studies required a priori specification of the crises periods. The tests by Boyer Gibson and Loretan, and Rigobon and Forbes, for instance, are developed under the strong assumption that country noise is small and invariant. Corsetti Pericoli and Sbracia (2002) show the striking result of this literature ("no contagion, only interdependence") is no longer valid because of these biases. When contagion is defined as a significant increase in market co-movement after a shock to one country, previous work suggests contagion occurred during recent crises and is conditional on market volatility. Corsetti et al (2002) however found that after adjusting for the bias caused by market volatility there is no evidence of contagion since there is no increase in the unconditional correlation coefficients during the 1997 Asian crisis, 1994 Mexican devaluation, and 1987 U.S. market crash. However, there is a high level of market co-movement in all periods, which they call interdependence.

Rigobon (2003) recognized that the endogeneity problem could be circumvented by separating crises periods from non-crises periods. However, since crisis periods are identified ex post, after passing through the observations, the endogeneity bias is reintroduced in the form of a sample selection bias. The main difference among the studies is the method of adjustment for the correlation coefficient in crises periods. Forbes and Rigobon's (2002) methodology ignored the importance of country specific shocks which biases the results towards no contagion. 
In the context of behavioral finance, there has been evidence of herding and contagion. After the catastrophic attack on the United States on $9 / 11$, stock markets around the world reacted in tandem. Hon, Strauss and Yong (2004) showed that since international markets especially in Europe followed the US stock market so closely in the three to six months after the event, benefits from international portfolio diversification are significantly reduced. ${ }^{5}$ Additionally, since Prospect Theory asserts behavior changes after severe wealth altering circumstances, Kyle and Xiong (2001) found evidence that financial contagion is a wealth effect. They noted that when noise or "convergence" traders lose money in one market they liquidate positions in both markets, a process defined as contagion. Therefore, returns become more volatile and correlated. Since these "convergence" traders take large risky positions in a small number of assets, unfavorable shocks cause liquidation of entire portfolios. This liquidation in itself can magnify the original shocks and cause the transmittal to other asset classes. They believe that there is cause for concern since "contagion reduces benefits from portfolio diversification and raises issues for risk management". They note that even if "long series of data are available, the potential changes in the structure of the market can make it hopeless to determine these extreme risks from historical data". This argument has been suggested as the reason why Federal Reserve Board Chairman Alan Greenspan interjected to avoid the liquidation and meltdown of the assets of Long Term Capital Management. Since asset prices and traders' wealth are simultaneously determined, risk is endogenously introduced in the form of contagion.

\footnotetext{
${ }^{5}$ Hon M.T.; Strauss J., (2004), Yong, Soo-Keong, Conlagion in financial markets afler Seplember 11: myth or realily, Journal of Financial Research, Vol. 27, No. 1, pp. 95-114.
} 


\section{Conclusion}

Chairman Greenspan (2001) has recognized the value in understanding the idiosyncrasies of economic man. He noted, amid the weakening of the U.S. economy in early 2001 , "The unpredictable rending of confidence is one reason that recessions are so difficult to forecast. They may not just be changes in degree from a period of economic expansion, but a different process engendered by fear. Our economic models never have been particularly successful in capturing a process driven in large part by nonrational behavior." Inherent in his statement are the views that fear and sentiment are factors that affect the behavior of market participants and consequently the retums of the market. The literature review reflects the fact that while important work has been accomplished in a short space of time, improvements to the theory will only be accomplished by testing the hypotheses under actual trading conditions instead of experimental ones. This type of research is essential to the improved decision making of practitioners.

${ }^{6}$ Greenspan Alan. 2001. Monetary Policy Report to the Congress. Before the Committee on Banking, Housing, and Urban Affairs. U.S. Senate. February 13. 


\section{CHAPTER III - TRADER REACTIONS AND INVESTOR RATIONALITY}

\section{Introduction}

There is an extensive body of research documenting significant market reaction to changes in market conditions. Barberis, Huang, and Santos (2001) ${ }^{11}$ (BHS) posited that an investor becomes less risk averse after stock prices increase because his previous gains underpin subsequent losses making him less loss averse, and more risk-seeking. Consequently he has a tendency to pay even higher prices for the stocks, whereas after declines in stock prices, he becomes more concemed about further losses, exhibits a higher degree of risk aversion and becomes more loss averse. They note, "After being burned by the initial loss, he is much more sensitive to additional setbacks", implying fewer purchases of stocks.

Shefrin (2001) presented the case of potential bankruptcy at Sony Corporation in which a co-founder led a project that had suffered heavy losses ${ }^{12}$. He showed that even though traditional corporate finance and accounting theory stipulate ignoring sunk costs there was a tendency for the co-founder to continue to invest in it, refusing to accept a sure loss.

Based on survey data, Thaler and Johnson (1990) (TJ) found that in the presence of prior losses, individuals who suffer initial losses were more willing to take gambles

\footnotetext{
${ }^{3} \mathrm{~N}$. Barberis, M. Huang, and T. Santos, Prospect Theory and asset prices, Quarterly Journal of Economics 116, (2001), 1-53.

${ }^{52}$ Shefrin, H., 2001, Behavioral corporate finance, Journal of Applied Corporate Finance, Fall issue.
} 
that would allow them to break even. ${ }^{13}$ They noted that subjects indicated that new losses hurt more when they occur after a loss than wben they occur in isolation. This is interpreted as an indication that prior losses "sensitize people to subsequent losses of a similar magnitude" (p. 656), while prior gains are perceived as "bouse money" and that "losing some of tbe house money doesn't hurt as much as losing one's own cash."

There is an obvious dichotomy in the views parlayed by BHS and TJ. BHS' view implies more loss aversion (or more risk aversion in an expected utility framework) after prior losses, whereas TJ's view (like Shefrin's anecdotal evidence) implies more risk seeking or less loss aversion after similar prior losses. These opposing points of view are puzzling since both these studies rely on Prospect Theory as the underlying framework. Prospect Theory postulates that individuals make decisions under uncertainty by maximizing a value function that evaluates wealth changes, rather than an expected utility function that ranks choices according to the level of expected utility.

While, it should be noted that Prospect Theory was designed to understand single period decision-making and these studies imply multi-period horizons, it seems that the main reason for the contradiction is that the reference point turns out to be crucial for risk taking. The perceived change in wealth, a notion that is ignored in a rational framework is crucial in the behavioral framework. Different assumptions about what reference point subjects use to evaluate outcomes can lead to very different predictions about risk taking and about the effect of prior outcomes on risky choice. BHS's study suggests that investors feel wealthy after their investments increase in value wbile TJ's view is based

\footnotetext{
13Thaler, R., and E. Johnson, 1990, Gambling with the house money and trying to break even: The effects of prior outcomes on risky choice, Management Science 36, 643-660.
} 
on the investors' original wealth endowment. Prospect 'Theory suggests that after periods of losses, 'economic man' no longer follows the idealized behavior attributed to expected utility maximizers. This occurs because his decisions in uncertain conditions are weighted more heavily with prospective losses than prospective gains.

This chapter empirically investigates these decisions. It is unusual in that it uses actual trading data to check behavioral patterns rather than indirect measures like price changes and survey data. The question to be examined is whether or not traders exhibit behavior consistent with more purchases in periods of turmoil (decreases in wealth) and, correspondingly, fewer purchases after increases in wealth. It is postulated here that during periods of market turmoil, a higher level of risk aversion displayed by additional purchases reflects an attempt to return to the reference point. In terms of Prospect Theory, this tendency of more risk aversion in an expected utility framework is noted as exhibiting more 'loss aversion' or more 'risk seeking'. In contrast, fewer purchases reflect less loss aversion. Loss aversion is a greater sensitivity to losses than to gains of the same size, and is represented by a kink in the utility function. Prospect Theory generally predicts that investors prefer long-shots, avoid sure-things, buy insurance against unlikely losses, and take risky chances to win back large losses. The theory notes that those suffering from loss aversion do not measure risk consistently.

In order to test for differences in trader reactions to varying economic conditions two primary data elements are required: a measure of information and a measure of reaction. In this chapter, reaction is measured by a trader's inactivity, purchases or sales of securities. The measure of information is a significant change in the value of a major 
index. A significant change in market returns will ensure a clearly identifiable and important event since it will directly affect the wealth of the trader.

Porfolio managers, institutional traders and investors are known to act differently when markets are "up" versus when they are "down". Wermers (1999) finds that these market participants "herd". 14 Behavioral influences like overconfidence and optimism make portfolio managers sell their winners too early to chase better opportunities. ${ }^{15}$ Shame, avoiding regret and embarrassment, and unwillingness to admit errors make managers hold their losers. ${ }^{16}$ Investors are prone to a mean reverting mindset; a permanent positive change will not be recognized at first. They may first under-react. Investors will rethink their position after several positive changes in information emerge, then they may over-react, a procedure Thaler (I985) terms "mental accounting"."

\section{Research Hypothesis and Methodology}

Prospect Theory analysis involves defining an editing phase. Here a reference point is designated to differentiate between potential gains and losses. The theory stipulates that after a period of considerable losses, sentiment changes. The process of

\footnotetext{
${ }^{14}$ Wermers, R. (1999), Mutual Fund Herding and the Impact on Stock Prices, The Journal of Finance, Volume 54 Issue 2 Page 581-622.

is Barber, B.M., T Odean, (2000) Trading is Hazardous to Your Wealth: The Common Stock Investment Performance of Individual Investors, Journal of Finance 55:2 p. 773-806.

${ }^{16}$ Shefrin, H., and M Statman, (1985) The Disposition to Sell Winners too Early and Ride Losers too Long: Theory and Evidence, Journal of Finance, 60:3 p 777-792.

${ }^{17}$ De Bondt, W., and R. Thaler (1987), Further evidence on investor overreaction and stock market seasonality, Journal of Finance 42:557-581.
} 
establishing a reference point that defines a significant change in sentiment is ascertained by a significant change in a major market index like the DIIA. The DIIA is a useful index for representing short-term market movement since it concentrates on large, actively traded firms; this minimizes problems associated with non-synchronous trading (Rudd 1979).

After an event that results in market turmoil, traders may feel less wealthy. Their reactions, predicated by their behavioral characteristics, may compound losses. The null hypothesis formulated is one of no direct relation between the institutional trader's probability of purchasing more securities when the market is in a downtrend and probability of selling when the market is in an uptrend. A model structure, which incorporates behavioral factors, is not consistent with expected utility maximization, for it assumes decision-makers put weight on something that is meaningless in a rational framework, but in the Prospect Theory framework, weight is placed on the perceived change in wealth relative to the reference point. The validity of Prospect Theory is investigated on a data file of volatile swings in the Dow Jones Industrial Average by employing relationships (1) and (2) from Chapter II.

$$
\begin{aligned}
& V(x, p \cdot y, q)=\pi(p) v(x)+(1-\pi)(q) v(y) \\
& R=-U^{\prime \prime}(W) / U^{\prime}(W)
\end{aligned}
$$

The following hypothesis is set forth: During periods of market turmoil, when investors experience massive wealth losses as defined by an appreciable absolute change in the index, the change in the absolute risk (loss) aversion coefficient, $R$, is below zero if 
investors become less risk-averse (i.e. exhibit risk-seeking behavior), and above zero if investors become more risk-averse i.e..:

$$
\begin{aligned}
& H_{0}: \Delta R<0 \\
& H_{A}: \Delta R \geq 0
\end{aligned}
$$

These equations suggest that people use a weighted value function to think about risky decisions, and standard economic theory predicts that people are roughly risk neutral when faced with small gambles.

While the ideal methodology is to devise a study that measures investors' preference under different wealth changing scenarios and add them up in a coherent manner to test the total effect, this method is impractical. To cast relationships (1) and (2) into testable form, an assumption is made, that investors' risk-aversion, or the lack thereof, is exemplified by the purchase or sale of securities. To that end, since the goal of this study is to analyze the behavior of individual investors, an alternative way to address the problem is to review their actions under normal conditions in comparison to market turmoll ones - 'editing' in PT terminology. Risk-averse investors should avoid risk when markets are under pressure and only seek risk when markets are orderly, and the typical risk-reward trade-off is observed. Given this assumption, the hypothesis in (3) can be restated as:

$\left(H_{0}\right):$ There is no difference in investors/traders' behavior during market turmoil and the alternative, $\left(H_{A}\right):$ Investors/traders behave differently during market turmoil. 
If one considers small changes around the current reference point as important in determining a trader's loss aversion and a loss is twice as important (in terms of utility consequences) as a gain of equal size, the above hypothesis can be tested by an analysis of the market turmoil and non-turmoil days under two alternatives. Here instead of inequality in the risk aversion coefficient, $R$ we have equality between two alternatives, which is more empirically manageable.

The empirical model is thus given by:

$$
\begin{aligned}
& y=\alpha+\beta x+\varepsilon \quad \text { on market turmoil days } \\
& y^{\prime}=\alpha^{\prime}+\beta^{\prime} x+\varepsilon^{\prime} \text { on non-turmoil days }
\end{aligned}
$$

Where the $y$ 's are increases, decreases or no change in security position, and the $x^{\prime}$ 's are the change in the value of a select market index. Equation (4) shows that the reaction of traders to the market index may be different on turmoil days. More specifically, the variables are defined as:

$y \& y^{\prime}$ : increases (buys), dummy variable is 1 ; decreases (sells) or no change in security position, dummy variable is zero;

$x$ : the percentage change in the value of a representative market index;

$\alpha$ and $\beta$ : coefficients for market turmoil observations;

$\alpha^{\prime}$ and $\beta^{\prime}$ : coefficients for non-turmoil market observations.

The null hypothesis can now be stated specifically as a test of equality of coefficients in equation 4 , as follows:

$$
\begin{aligned}
\mathrm{H}_{0}: \quad \alpha^{\prime} & =\alpha \\
\beta^{\prime} & =\beta \text { and }
\end{aligned}
$$




$$
\left(\alpha^{*}, \beta^{\prime}\right)=(\alpha, \beta)
$$

The null hypothesis states that the coefficients are invariant between the two sets of observations. If the null hypothesis is not true, and investors become risk seekers during market turmoil times, then as a first and necessary condition, the above coefficients will not be equal.

\section{Sample \& Data}

It is necessary to formulate the association between information and reaction to test the above hypothesis. The measure of information needs to be a noteworthy event that forces the trader to evaluate his position of wealth. Coval and Shumway (2004) showed that proprietary traders at the CBOT evaluated their wealth position at the end of each morning and traded differently in the afternoons following morning losses. ${ }^{18}$ It is postulated here that a trader may behave similarly during days of market corrections. A market correction is typically defined as a decrease in the value of stocks, usually $10 \%$ or more over several days. The market corrections of the 1990's and early in the current millennium occurred over a more extended period. Chicago researchers Ibbotson and Associates argued in 2004, "Since 1926, the market has advanced more than two out of every three years-with an average annual gain of $22.87 \%$ in up years. Although the average annual stock market return since 1926 has been 10 percent, many individual years have seen losses. The most recent example is the four-year period 2000 through 2003 when the stock market lost an average of 5 percent per year". Daily swings

\footnotetext{
${ }^{18}$ Coval, J., and T. Shumway (2004), "Do behavioral biases affect prices?" Journal of Finance, Volume 60 Issue 1, pp 1.34.
} 
however achieve more notoriety. An example of the swings under consideration is Black Monday, October 19, 1987 - a 508 point (or $22.61 \%$ ) loss. The largest one day point drop in history, Monday October 27, 1997 of 554.26 points (or 7.19\%) was followed by the largest one day point gain of 337.17 (or $4.71 \%$ ) on "Turn-around" Tuesday October 28,1997 , an event with little corresponding fundamental rationale. More recently, after the events of September 11, 2001, the stock market closed for a week. On September 17, the day the NYSE and the NASDAQ reopened after the market turmoil, the DIIA fell by 684.81 points, a $7.13 \%$ fall.

The period under consideration in this study does not cover these more recent events. The database investigated consisted of the daily closing prices of the Dow Jones Industrial Average from the period October 6, 1987 through October 30, 1992. There were only 9 days in 1987 when the index fell by more than 100 points, 3 in 1988,4 in 1989,3 in 1990,8 in 1991 and 5 in 1992. There were only 36 days when the Dow fell more than 50 points, and 7 days when it fell more than 100 points. Beginning in 1996 when there were 19 such days, a 100-point fall has become more frequent. Effectively, investors bave become blasé about large index swings and may tend to avoid letting behavioral biases affect their activity as frequently. Absolute capitulation is now a rarity.

Rather than considering absolute index changes like 50 or 100 point deviations, outcomes can be identified on the basis of percentage changes in the "Dow," for example $1 \%, 11 / 2 \%$, and $2 \%$. More recently, the high absolute level of the Dow Jones Industrial Average has led to up and down swings of $1-2 \%$ points to be relatively insignificant events. However during the period under consideration, larger sample sizes of 146 days were found for days when the Dow fell more than $1 \%, 104$ days when it fell more than 
$1.25 \%, 73$ days at $1.5 \%$ and only 36 days when the Dow fell more than $2 \%$. These benchmarks are arbitrarily set but are to some extent dictated by the feasibility of the data to allow statistical significance. A fairly significant sample size of 159 days was achieved during this period for a drop in the DJIA of $0.95 \%$ and greater. Since the major averages were at significantly lower nominal values and lower levels of volatility, a $0.95 \%$ fall was viewed as being an unusual event. This interval (October 6, 1987October 30,1992$)$ is chosen for several reasons. Too long an interval will involve several shifts that may confound the outcome. Additionally, this period includes the effects of several days of near capitulation in the markets, days when investors really believed "the sky was falling".

Measurement of the reaction of traders is obtained through their daily purchases and sales of securities. The database under investigation is a selective one. It is made up of the changes in daily position in securities for which the brokerage has a sizeable position. Two brokerage houses are considered, the Toronto offices of First Boston (Canada) Ltd., and Merrill Lynch (Canada) Ltd. The activities of proprietary traders at these firms trading on the firm's own account, including trading as a market maker are identified. Since the period over which data were collected, significant changes have occurred with these facilities. First Boston (FB) closed its Canadian enterprise shortly after Credit Suisse purchased the American parent and remained closed for several years. Merrill (MER) has since merged with a large independent retail Canadian broker.

While the study acknowledges that there are significant weaknesses in the data, the benefits of obtaining actual versus experimental data to investigate the behavior of traders, compensate for these shortfalls. Typically, revealed preferences have more 
relevance over stated preferences for an analysis of the determination of economic value. When data are self-reported it is difficult to verify and can be heavily influenced by the interviewer. As a result, it is necessary to construct the modeling effort to be applicable considering the limitations of the data. We will consider the two companies separately to avoid confounding effects. The raw data is available on request; a sample is displayed in the appendix. Part of the data collected is highly proprietary. The researcher was forced to compile this data set under extreme secrecy conditions since many of the trades were made under restrictive circumstances. While the paucity of this data is regretful, the benefits outweigh the deficiencies. Although it is necessary to preserve the anonymity of the traders involved, the raw data points are available on request. The risk preferences of the large traders in the data file were examined after each of these events to determine their market reactions. The bid prices of these investors showed whether they still sought risk (by purchasing more securities at the market price) or averted risk otherwise.

After days when the index closed down by a predetermined percentage level, a review is made of the daily trades of the Toronto branches of the two large multinational brokerage houses. The focus is on sizeable positions of individual stocks, that is, stocks which comprise more than $10 \%$ of the portfolio holdings. Risk seeking behavior is displayed when traders purchased more shares of stock where positions had already been taken. Notations are made when position sizes are increased, signifying purchases. Alternatively, notations are made when position sizes decrease or remain the same, signifying sales or otherwise. Note in some cases, there are two or more securities that encompass more than $10 \%$ of the portfolio's holdings. Under these circumstances, there was more than one observation on a particular market turmoil or conversely, non-turmoil 
day. On several of the days, more than three stocks fitted the criteria but on most days, only one stock ended up meeting the $10 \%$ benchmark. Many of these stocks were shares of principally Canadian Corporations. However, several stocks were inter-listed on major world exchanges. The data was then subdivided into periods of market turmoil defined as days when a major market index fell by at least $0.95 \%$ and coded as one during these periods and zero during the much larger data set of non-turmoil periods. There were some limitations on the data, for example, specific daily portfolio sizes were not given and the value of the other securities held in the portfolio was unknown. The portfolio size dilemma is difficult to solve since these companies were privately held and absolute monetary values were usually lumped under dubious categories. However, it is fair to assume that in the 1980 's these companies were willing to put up sizeable capital chunks to build their presence in Canada. The causal relationship of a massive change in the price of a stock being effected may be a problem since large institutional purchases or sales may lead to others following suit. However, the fact that these traders are very small components of the market and are often price takers should alleviate that concern.

The data can be summarized in two groups, the market turmoil data and the nonturmoil events. The DJIA had 159 days when the index fell by $0.95 \%$ or more with a range of $-22.61 \%$ to $10.15 \%$, during the five year period under review. FB had 180 market turmoil observations and 1259 non-turmoil observations in this period. MER had 182 market turmoil observations and 1255 non-turmoil.

The S\&P500 had 154 days when the index fell by $0.95 \%$ or more with a range of $20.46 \%$ to $9.10 \%$, similar statistics to the DOW. FB had 173 market turmoil observations 
and 1271 non-turmoil observations in this period. MER had 182 market turmoil observations and 1262 non-turmoil.

In the case of the S\&P/TSX, there were only 74 days during the period under question where the index experienced market turmoil conditions (defined as a fall of $0.95 \%$ or more). In fact the daily range of changes during this period was $-11.31 \%$ to $9.04 \%$ as compared to a much larger range for the DIIA. However, there were 196 cases of market turmoil conditions for $\mathrm{FB}$ versus 1247 cases of non-turmoil conditions. MER however did not have substantially more observations, 108-market turmoil and 1339 nonturmoil.

\section{Empirical Applications}

Considering the scope of the data as discussed above, empirical application of the testable model in equation (4) poses some restrictions since the $y$ 's are binary. Therefore, application of OLS is not appropriate. The logistic regression model (Cox 1970) is conventionally used to predict the likelihood of the outcome (the odds ratio) based on the explanatory variables (called covariates in logistic regression).

To investigate the research question, a logit model is specified and applied on the dataset of trader buys and sells for the initial task of determining investor's risk preferences during periods of "market turmoil" versus "non-turmoil. The logistic regression model attempts to predict the probability of the event such that:

Or:

$$
\hat{p}(y=1 \mid x)=\frac{e^{(\alpha+\beta x)}}{1+e^{(\alpha+\beta x)}}
$$

$$
\operatorname{logit}(\hat{p})=\ln [\hat{p} /(1-\hat{p})]=(\alpha+\beta x)+e
$$


Where:

- $\quad p$ follows an independent Bernoulli function and is the probability that the event $y$ occurs, $p(y=1)$ given $x$

- $\quad p /(1-p)$ is the "odds ratio" or the ratio of the probabilities or the probability of the outcome event occurring divided by the probability of the event not occurring

- In $[p /(1-p)]$ is the actual log odds ratio, or "logit" which corresponds to the unit change of $x$

- $x$ is the predicting independent variable or covariate

- $\alpha$ is the intercept parameter and $\beta$ is the slope parameter

\section{Pertinent factors of the Empirical Applications}

1. The logistic regression model fits the $\log$ odds through a linear function of the explanatory variables (similar to multiple regression models). ${ }^{19}$ Instead of choosing parameters that minimize the sum of squared errors, estimation in logistic regression chooses parameters that maximize the likelihood of observing the sample data. This occurs because the logit function is non-linear; therefore, the sum of squared errors is no longer a convex function and may not have a unique minimum solution. After transforming the dependent into a logit variable, the logistic regression uses Maximum Likelihood Estimation (MLE) techniques to calculate the logit coefficients. The likelihood function is the probability that a model could generate the actual data. The technique maximizes the log-likelihood function, which reflects how likely the observed values of the dependent variable may be predicted from the observed values

\footnotetext{
"Hosmer, D.W. and Lemeshow, S. (2002). Applied Logistic Regression. 2nd ed. Wiley: New York.
} 
of the independent variables. The MLE method lowers the mean square error and increases the probability of the event. ${ }^{20}$

2. For ordinary least squares (OLS) to yield best linear unbiased (BLUE) estimators, the classical regression assumptions must be met. OLS models require quantitative, continuous, unbounded dependent variables. One of the assumptions is that the variance of the dependent variable is constant across values of the independent variable (homoskedasticity). This cannot be the case with a binary variable, because of its discrete nature. The variance is given by $p *(1-p)$. When 50 percent of the observations are 1's ( $p=0.5$ ), then the variance is .25 , its maximum value. As more extreme values occur, the variance decreases. When $p=0.10$, the variance is $.1^{*} .9=$ 0.09 , so as $p$ approaches one, the variance approaches zero. Consequently while the OLS coefficients will still be unbiased they will not be efficient, invalidating hypothesis tests.

3. Logistic regression has many analogies to OLS regression: logit coefficients in the logistic regression equation correspond to slope coefficients, the standardized logit coefficients correspond to the weights of the slopes, and an adjusted $R^{2}$ statistic is available to summarize the strength of the relationship. Unlike OLS regression however, logistic regression does not assume linearity of the relationship between the independent variables (covariates) and the dependent, does not require normally distributed predictor variables or error terms, nor does it assume homoskedasticity or homogeneity of variance, and in general has less stringent requirements to ensure

\footnotetext{
${ }^{20}$ Note MLE and OLS give equivalent results when the errors in the OLS model are assumed to be normally distributed.
} 
unbiased and efficient coefficients. It does however still assume that all observations are independent and the model is correctly specified. If the variables display multicollinearity and are linear functions of each other, the resultant large standard errors will result in inaccurate estimates of the coefficients. Another major concern in logistic regression is the omission of outliers. Misspecification can lead to bias and erroneous results. $^{21}$

4. Unfortunately, time series data cannot be treated as randomly selected observations from a population. Lagged dependent variables can affect the estimation since the data is likely to exhibit some degree of dependence over time. That circumvents the violations of the assumption of independence. Return data (computed as percentage change in index prices) as compared to the actual level data are generally not serially correlated. Therefore it is customary to treat stock price data as non-stationary and stock return data as stationary. Accordingly, using the return data can ensure the assumption of independence is not violated.

5. The structure of the error term is important in binomial choice models. By making assumptions about the probability density of the residuals, one can choose from several different binomial choice model formulations. The logistic regression model assumes a logistic distribution of errors, and the probit model assumes normal distributed errors. Since the probability $p$ that the dependent variable takes the value of one (and by extension, the probability $(1-p)$ that it takes the value of zero) is being considered, the linear regression model poses serious inference problems. This is

\footnotetext{
${ }^{21}$ DeMaris, A. (1992), Logit modeling: Practical applications. Newbury Park, CA: Sage Publications. Series: Quantilalive Applications in the Social Sciences, No. 86.
} 
because for extreme values of the independent variable, the predicted value of the dependent variable will be either less than zero, or greater than one, values not appropriate for probabilities. OLS if used can give incongruent predictions. Probability must be modeled by a function that never exceeds the $\{0,1\}$ boundaries, consequently the natural $\log$ of the odds or logit specification lends itself to this modeling.

6. Another problem that can arise in using logistic regressions on rare events data (like wars, catastrophes or market turmoil) are inefficient coefficients. This can be rectified in the statistical package SAS however, through weighting the likelihood function and performing maximum-likelihood logit analysis by finding the value of the coefficients that gives the maximum value of this weigbted function. Weighting can therefore outperform prior correction when both a large sample is available and the functional form is mis"specified (Xie and Manski 1989).

7. Logit and probit models are based on the same underlying threshold model. The threshold (Long 1997) defines the dichotomous variable and is used to divide the two portions of the $y$ distribution, for example, the probability that the event occurs is one and zero otherwise. ${ }^{22}$ Since the threshold model is based on the probability of observing the error term in a certain range, a distribution must be specified for estimation. The generalized linear model (GLM) corresponding to the binomial $(1, \rho)$ distribution with canonical link is the binary logistic regression model. The logistic distribution is easier to calculate than the probit since no tables are required to

\footnotetext{
${ }^{22}$ Long, J. S. (1997). Regression models for categorical and limited dependent variables. Thousand Oaks, CA: Sage.
} 
compute the cumulative probability; therefore its use has been more proliferate. In general, the coefficients derived from logit estimation are equal to 1.6 times the coefficients obtained from using probit. The logistic distribution has a variance of $\pi^{2} / 3$ while the probit function is based on the standard normal distribution with variance one, so in many instances the difference is only in a matter of scale.

8. This raises the question of whether logit modeling is preferable to probit. If the responses are "unordered", a logistic transformation is preferred. Logit is typically used in the literature when the categorical dependent variable is more qualitative whereas probit assumes the dependent variable reflects an underlying quantitative variable. The fundamental theoretical difference between the two approaches concerns the distribution of the error term, logistic versus normal. While there is typically an important difference between odds-ratios and risk-ratios, with binary logit there is no difference between the two ratios. The odds ratio provides a way of assessing the relationship between the dependent and independent variables by comparing whether the probability of a certain event is the same for two groups. A ratio of one implies the event is equally likely in both groups. Aldrich and Nelson (1984) provide a detailed comparison of logit and probit models.

9. Logistic regression is a non-parametric technique for determining the estimates of independent variables on a dependent variable. Because it is a non-parametric technique, the tests available are not as powerful as for OLS regression and other parametric statistical tests. This means that logistic regression will not pick up relationships between variables as comprehensively as OLS regression analysis for a given number of observations, however, given departures from normality conditions, 
the results are more robust (Cox and Snell 1989, p. 132-134). To compensate, Mc Cullugh and Neder (1989) suggest using several diagnostic tests to check for goodness/lack of fit thus ensuring robustness. The Pearson chi-square value (used with the number of degrees of freedom) indicates the level of certainty with which one can reject an associated model. -2 log likelihood is similar to an $F$ statistic, it tells whether or not the entire model is any better at predicting the outcomes than no model at all. It has an approximate chi-square distribution for large samples. $F$ and chi-square statistics are essentially the same thing after normalization and as the denominator degrees of freedom goes to infinity. -2 log likelihood ratio test reflects the desirability of running separate models for different groups. Deviance residual is another type of residual. It measures the disagreement between the maxima of the observed and the fitted log likelihood functions. Since the logistic regression uses the maximal likelihood principle, the goal in logistic regression is to minimize the sum of deviance residuals. Recall that the least squares estimator for the ordinary linear regression model is also the maximum-likelihood estimator in the case of normally distributed error terms. Therefore, this residual is the GLM equivalent of the residual sum of squares (RSS) in linear regression as it compares the logmlikelihood for the "model" with the maximal achievable value and tests the significance of individual independent variables.

10. The success of the logistic regression can be assessed by looking at the correct and incorrect classifications of the dichotomous dependent variable. A statistic that measures the strength of the association is the pseudo $R^{2}$ approach of McFadden (1974). Another common measure of goodness of fit is the percentage of correctly 
classified cases. Although the logistic model can provide accurate estimates of the probability $p$, it has weaknesses. First, it is hard to determine when a satisfactory model is found, because there are few diagnostic procedures to guide the selection of variable transformations and no true test of good fit, and secondly it is difficult to interpret the coefficients of the fitted model, except in very simple situations. Hosmer and Lemeshow (1989) provide a relatively good approximation for a lack-offit test on logistic regressions. In fact, it is more aptly called a "badness of fit" test since the null hypothesis is rejected if this statistic is significant.

11. Interpretation of the coefficients is ambiguous since it gives the relationship between the independent variable and the unobservable predicted dependent one. Since $y$ is observable, the interpretation of the marginal effect is less ambiguous, giving a robust result. The marginal effect is the effect of the independent variable on the probability of observing a success for the dependent variable. For every unit increase in the independent variable, the odds that the event will occur $(\mathrm{Y}=1)$ is increased by $e^{(\beta)}$.

12. There is potentially a problem with dispersion. In logistic regression, the expected variance of the dependent can be compared to the observed variance. The overall correlation may be either positive, where the actual observed variance from the data is larger than the variance imposed by the model (over-dispersion relative to binomial variation), or negative (under-dispersion). ${ }^{23}$ Over-dispersion is a phenomenon that sometimes occurs in data that are modeled with the binomial or Poisson distributions. The source for this may be a lack of independence in the data or a misspecification of

\footnotetext{
${ }^{23}$ Engel, B, Joop te Brake, Analysis of Embryonic Development with a Model for Under-or Overdispersion Relative to Binomial Variation, Biometrics, Vol. 49, No. 1. (Mar., 1993), pp. 269-279.
} 
the model. Lack of independence arises when there is unobserved heterogeneity for "grouped data", that is, many observations for each value of the input variables, so that the probabilities of the event in one group differ from the probabilities in another group because of some factor(s) not considered in the model (Burnham and Anderson 1998, Allison 1999). The effects of over-dispersion are the same as heteroskedasticity in the OLS model. Cox and Snell (1998) suggest that overdispersion produces standard errors that are too small, resulting in misleading inferences. To solve this dilemma, McCullagh and Neder (1989) suggest a correction that can be applied that is analogous to weighted least squares - obtain an estimate of the dispersion parameter, either Pearson or deviance divided by the residual degrees of freedom, and using it to adjust the correlation. Williams (1988b) suggests that when the number of observations is small, the Pearson dispersion is preferable to the deviance for estimation of dispersion parameters. ${ }^{24}$

\section{Empirical Model}

While acknowledging the above caveats, the option of using binomial choice models is unavoidable. Specifically, the equation estimated is the probability that a trader will buy (1) or sell/no change $(0)$ as a function of the return of the market and the environment (market turmoil or not) ${ }^{25}$ :

$$
B U Y \_S E L L=\alpha+\beta^{*} R E T U R N
$$

\footnotetext{
${ }^{24}$ SAS provides this adjustment through either a SCALE_DEVIANCE or PEARSON option in its model statement.

${ }^{25}$ Estimation of the model was performed using PROC LOGISTIC from the SAS ${ }^{\circ}$ statistical package. The method utilizes the Fisher scoring technique, a model fit with iteratively weighted least squares.
} 
Where BUY_SELL is a 0-1 dichotomous variable equal to 1 for a "buy" transaction and 0 for a "sell" or "no change" transaction; RETURN represents the percentage change in a market index. To compute the restricted and unrestricted sum of squares, necessary to conduct a test of structural change in the separate group regressions, three logistic regression procedures are designed, for the non-turmoil events, for the market turmoil events, and a separate model for the complete (restricted or full) sample data set including both market turmoil and non-turmoil events. By estimating three different regressions it is possible to first look for relationships and associations between index returns and the probability that a trader will buy, sell or not change his position. The Chow $F$ test is typically used to check for structural changes. However since it assumes equal variances, it must be modified in the presence of heteroskedasticity. One method of correcting for non-equal variances is to use the dummy variable approach with White's Robust Standard Errors. Thursby 1992 (Journal of Econometrics 53, 363-386) shows if the data shift is known one can test for parameter constancy, stability of linear trends and single slopes, with a single heteroskedastically correct asymptotic likelihood ratio test, a variant of the Chow test. Since the Chow test and the "pool the data, interact, and test" procedure are the same, the results will be the same using both procedures.

In as much as there is a significant disparity between the number of turmoil observations and stable ones, another option is to concatenate the data and differentiate the observations using dummy variables. The model can therefore be specified as BUY_SELL $=\alpha+\beta_{1}^{*}$ RETURN $+\beta_{2}{ }^{*}$ GROUP $+\beta_{3}{ }^{*}$ RETURN $*$ GROUP 
Where $G R O U P=1$ for market turmoil events and $G R O U P=0$ for non-turmoil events.

The generalized formulation above is appropriate for the full model. Allison (1999) ${ }^{26}$, reports the following:

\begin{abstract}
"In logit and probit regression analysis, a common practice is to estimate separate models for two or more groups and then compare coefficients across groups. An equivalent method is to test for interactions between particular predictors and dummy (indicator) variables representing the groups."
\end{abstract}

GROUP is a binary vector, i.e. 0 or 1 . Since this equation is to be estimated for the overall sample as well as the two sub-samples, the ( $\left.\mathrm{X}^{\prime} \mathrm{X}\right)$ matrix on the right hand side becomes singular for the sub-samples and possibly for the overall sample. Thus, the interaction effect is dropped from the above specification. The final form for estimation is:

$$
B U Y_{-} S E L L=\alpha+\beta_{1}^{*} R E T U R N+\beta_{2}^{*} G R O U P
$$

The use and interpretation of this model must be explicitly adjusted for the presence of the other predictor in the model especially since over-dispersion is likely to be an issue. Following this estimation for FB, the steps were repeated for the MER data. The analysis on each brokerage house attempted to determine whether market turmoil as determined by a specified fall in a market index (representing a wealth effect), predicated buyer behavior.

The questions that need to be addressed regarding the estimation are, how well does the model fit the data and what is the significance of the estimated coefficients? Other relevant issues are a test of the structural change in the parameters of the

\footnotetext{
${ }^{26}$ Allison, "Comparing Logit and Probit Coefficients Across Groups," Sociological Methods \& Research, Vol. 28 No. 2, November 1999 186-208.
} 
regressions as well as a measure of the marginal effects of the independent variables or covariates. Since the estimated coefficients themselves do not indicate the change in the probability of the event occurring given a one-unit change in the relevant explanatory variable, (the sign of the estimated coefficient indicates the direction of the change in probability only), the actual level of the change in probability, given a one-unit change in an explanatory variable, will differ based upon the initial values of all the explanatory variables and their coefficients. Thus, it is conventional to evaluate the explanatory variables at their mean values as a basis for inferring a change in probability.

The first set of results was obtained for the market as defined by the Dow Jones Industrial Average (DJIA) since changes in this index are most heavily reported in the press and its movement can lead to a significant level of trading activity. It has been viewed as a sentiment factor because of the emotion aroused by investors and in the press (Bange 2000). ${ }^{27}$ Next, the S\&P500 index measured the return on the market since it is the most typically used representative of the market. Subsequent results were given using the S\&P Toronto Stock Exchange index (S\&P/TSX) data since all the stocks under investigation trade on that exchange. A short covering of using the S\&P/TSX to measure Canadian trader behavior is that the index is heavily weighted in the resources sector especially gold and other mining companies, whose stock returns can sometimes be negatively correlated with the market. However since the database is made up primarily of Canadian stocks it is useful to employ the S\&P/TSX index as well.

\footnotetext{
${ }^{27}$ Bange, M (2000), Do the Portfolios of Small Invesiors Reflec1 Positive Feedback Trading?, Journal of Financial and Quantitative Analysis, Vol 35, No. 2, p 239-255.
} 
Sensitivity analyses were performed including modeling the probability of the event 'buy' being zero versus one, interaction effects of the independent variables from Equation 6, and various levels of changes in the indices.

The most parsimonious and statistically significant results are presented. The tables are displayed for the logistic regressions using the daily returns and trader activities when the three different indices experience a $0.95 \%$ daily fall. Table 1 presents summary statistics for the data; it is noteworthy that the sample means from the two brokerage houses are relatively similar with the DIIA data but not the other indices.

Table 1

Summary Statistics for the Index Return Data

\begin{tabular}{|c|c|c|c|c|}
\hline $\begin{array}{l}\text { Pair of } \\
\text { Variables }\end{array}$ & $\begin{array}{l}\text { Mean of the } \\
\text { Index Returns }\end{array}$ & $\begin{array}{l}\text { Standard } \\
\text { Deviation }\end{array}$ & Minimum & Maximum \\
\hline DIIA-FB & 0.02346 & 1.3036 & -22.61 & 10.15 \\
\hline DIIA-MER & 0.0138 & 1.3084 & -22.61 & 10.15 \\
\hline S\&P-FB & 0.2179 & 1.2103 & -20.46 & 9.10 \\
\hline S\&P-MER & -0.0033 & 1.1916 & -20.46 & 9.10 \\
\hline S\&P/TSX $-F B$ & 0.05159 & 1.1045 & $-\mid 1.31$ & 10.15 \\
\hline S\&P/TSX - MER & 0.144 & 1.075 & -11.31 & 10.15 \\
\hline $\begin{array}{l}\text { Pair of } \\
\text { Variables }\end{array}$ & $\begin{array}{l}\text { Total Number } \\
\text { of Observations }\end{array}$ & $\begin{array}{l}\text { Market } \\
\text { Turmoil }\end{array}$ & $\begin{array}{l}\text { Market } \\
\text { Stable }\end{array}$ & \\
\hline DHA-FB & 1439 & 180 & 1259 & \\
\hline DJIA-MER & 1437 & 182 & 1255 & \\
\hline S\&P-FB & 1444 & 178 & 1266 & \\
\hline S\&P-MER & 1430 & 175 & 1259 & \\
\hline S\&P/TSX -FB & 1443 & 196 & 1247 & \\
\hline S\&PITSX - MER & 1447 & 108 & 1339 & \\
\hline
\end{tabular}

It is necessary to determine if separate models for different groups of observations lead to better explanatory power. While the Chow test is a popular test for parameter stability, this test requires a priori knowledge of the break-point date. If there is heteroskedasticy in the restricted model, then this $F$-statistic is biased upward and 
indicates greater instability in the coefficients estimate than actually exists (Toyoda I974). Additionally, in the event of multicollinearity, the estimates of the coefficients are less reliable. The SAS PROC LOGISTIC procedure utilizes penalized logistic regression which iteratively solves any problems of multicollinearity through the use of the AIC statistic. The key idea in penalization methods is that over fitting is avoided by imposing a penalty on large fluctuations on the estimated parameters and thus on the fitted curve. It can be identified when the standard errors are greater than two, because too many of the subjects have the same value of zero. However, this is not a major issue in this estimation.

The following issues are pertinent to the specification of Equation (5). Levene's test of the Homogeneity of Variances between the two sets of observations, Welch's test of Equality of $\mathrm{Means}^{28}$ when the variances are known a priori to be unequal as well as Chow's standard test of equality of coefficients are performed. These test the assumption that the regression line expressing the dependent variable as a function of covariate is constant across various conditions. The ordinary residual sum of squares (RSS) necessary for computation of the Chow statistic is calculated as follows:

$$
\mathrm{RSS}=\Sigma\left(\hat{Y}_{i}-Y_{i}\right)^{2}
$$

where $\hat{Y}_{i}$ is the $i^{\text {th }}$ fitted value on the logistic "curve":

$$
\hat{Y}_{i}=\mathrm{I} /\left(\mathrm{I}+e^{(-1(\alpha+\beta X))}\right)
$$

and $Y_{i}$ is the $i^{\text {th }}$ observed frequency of response. This residual variance is a measure of the deviation of the predicted probability of the event success from the actual probability.

\footnotetext{
${ }^{28}$ Logistic regressions belong to the class of Generalized Linear Models (GLM). Therefore these statistics were computed using the GLM procedure in SAS.
} 
Even when the variable is not normally distributed, the residual variance is still useful in determining how well the model fits the data. The Pearson Chi-square, which is the standardization of the ordinary residual, produces test statistics for the null hypothesis that the logistic function adequately describes tbe observed frequencies versus the alternate tbat it did not. $D F$ are the degrees of freedom associated with each Chisquare test.

The tests of comparing the two separate groups of data directly within Equation (6) is accomplished through an odds ratio between GROUP $=1$ and GROUP $=0$. The techniques of computing adjusted Chow Tests using the -2 Log Likelihood and the deviance (analogous to the residual sum of squares) statistics are presented here in the spirit of non-reliance on any single statistic to show significance. Hanushek and Jackson $(1977,1992)$ consider the $-2 \log$ Likelihood statistic a variant of the Chow test. ${ }^{29}$ The deviance statistic measures tbe group effect directly here by comparing the three different regressions. Here the assessment of dummy variables or the group effect can be made using the chi-square difference, a nested technique based on an adapted Chow test. Adjustment for over-dispersion is made since it is likely that the two groups exhibit this problem. The Pearson residual is used because of the smaller number of turmoil observations.

Table 2 reports the results for Equation (5) of both brokerage houses for the DJIA, Table 3 for tbe S\&P500 and Table 4 the Canadian S\&P/TSX for the First Boston (FB) and Merrill Lynch (MER) data. The first parts present the estimation results and the

\footnotetext{
${ }^{29}$ Hanushek, Eric A.; Jackson, John E. 1977. Statistical Methods for Social Scientists, New York Academic Press.
} 
second parts present various tests of equality and structural change. The Tables 5,6 , and 7 report the results from Equation (6). The first parts in these tables present the estimation results and the second parts present several tests for structural change. Pertinent points regarding the statistical estimation follow the tables. 


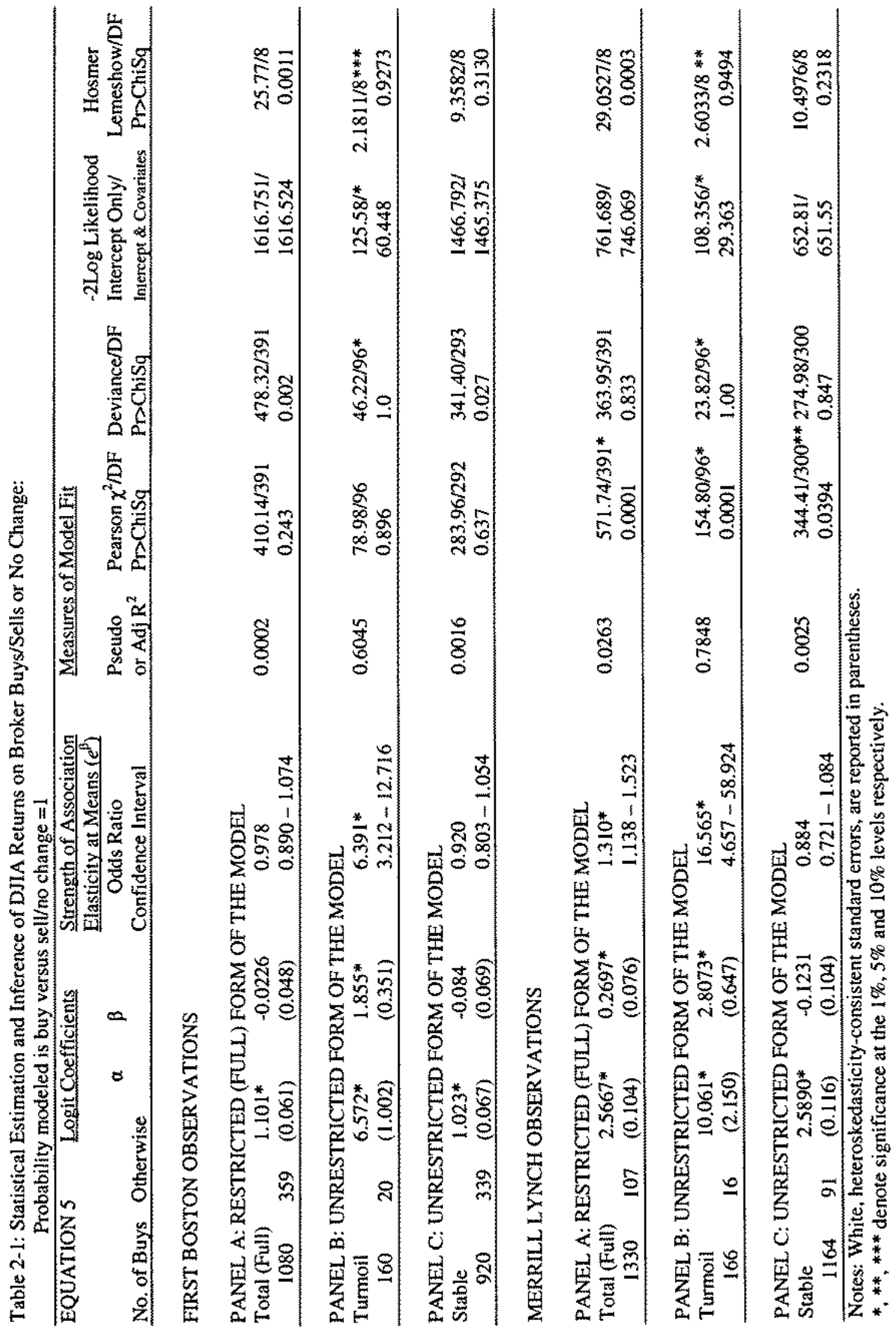


Table 2-2: Tests of Equality between Turmoil and Stable Observations of DJIA Returns on Broker Bays/Sells or No Change: Probability modeled is buy versus sell/no change =1

\begin{tabular}{|c|c|c|c|c|}
\hline \multirow[t]{2}{*}{$\begin{array}{l}\text { EQUATION } 5 \\
\text { FIRST BOSTON }\end{array}$} & \multicolumn{2}{|c|}{$\begin{array}{l}\text { Levene Test of } \\
\text { Equality of Means }\end{array}$} & \multicolumn{2}{|c|}{$\begin{array}{l}\text { Welch Test of } \\
\text { Equality of Variances }\end{array}$} \\
\hline & F Value & $\operatorname{Pr}>F$ & F Value & $\mathrm{Pr}>\mathrm{F}$ \\
\hline Total (Full) observations & 1.25 & $0.0143 *$ & 0.41 & 1.000 \\
\hline Turnoil observations & 4.51 & $0.0001 *$ & 0.02 & 0.994 \\
\hline Stable observations & 1.25 & $0.0143 *$ & 0.41 & 1.000 \\
\hline \multirow[t]{3}{*}{ RSS (Full) $=269.366$} & \multicolumn{4}{|c|}{ RSS (Stable) $=247.479$} \\
\hline & \multirow{2}{*}{\multicolumn{2}{|c|}{$\begin{array}{l}\text { Chow Test of } \\
\text { Equality of Coefficients } \\
\text { F Value }\end{array}$}} & \multicolumn{2}{|c|}{$\begin{array}{l}\text { Amended Chow Test of } \\
\text { Equality of Coefficients }\end{array}$} \\
\hline & & & & $\mathrm{Pr}$ ChiSq \\
\hline
\end{tabular}

PANEL A:

Equality of Intercepts, $\alpha$ (turmoil) $=\alpha$ (stable)

$24.22 *$

$25.280^{*}$

0.0001

PANEL B:

Equality of Slopes,

$\beta$ (turmoil $)=\beta$ (stable $)$

$24.24 *$

$29.349^{*}$

0.0001

PANEL C:

Equality of Regressions,

$\alpha, \beta($ turmoil $)=\alpha, \beta$ (stable)

$18.17 *$

$30.628^{*}$

0.0001

EQUATION 5

MERRILL LYNCH

Levene Test of

Welch Test of

Equality of Means

Equality of Variances

F Value $\quad \operatorname{Pr}>F$

F Value $\quad \operatorname{Pr}>F$

Total (Full) observations

Turmoil observations

$1.65 * \quad 0.0001$

0.25

1.000

$11.77 * \quad 0.0001$

0.00

1.000

Stable observations

$1.65^{*} \quad 0.0001$

0.25

1.000

RSS (Full) $=95.876 \quad$ RSS (Turmoil) $=3.893 \quad$ RSS (Stable) $=84.343$

Chow Test of

Equality of Coefficients

F Valtse
Amended Chow Test of

Equality of Coefficients

$\chi^{2}$

Pr>ChiSq

PANEL A:

Equality of Intercepts,

$\alpha($ turmoil $)=\alpha($ stable $)$

21.68*

4.393*

0.0361

PANEL B:

Equality of Slopes,

$\beta($ turmoil $)=\beta$ (stable $)$

$21.70^{*}$

$19.969^{*}$

0.0001

PANEL C:

Equality of Regressions,

$\alpha, \beta$ (turmoil) $=\alpha, \beta$ (stable)

16.24*

$17.434 *$

0.0001 


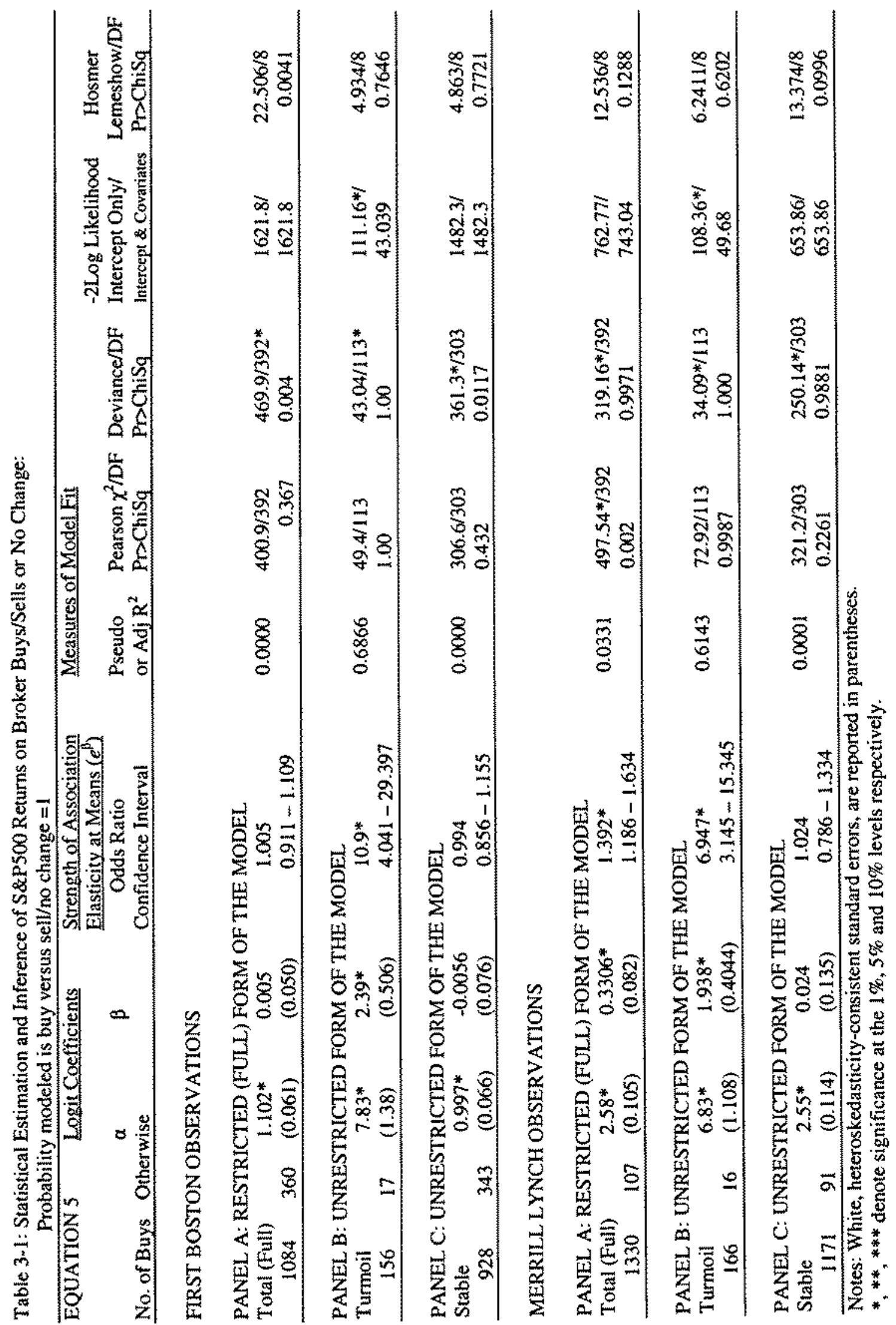


Table 3-2: Tests of Equality between Turmoil and Stable Observations of S\&P500 Returns on Broker Buys/Sells or No Change: Probability modeled is buy versus sell/no change $=1$

\begin{tabular}{|c|c|c|c|c|}
\hline \multirow[t]{2}{*}{$\begin{array}{l}\text { EQUATION } 5 \\
\text { FIRST BOSTON }\end{array}$} & \multicolumn{2}{|c|}{$\begin{array}{l}\text { Levene Test of } \\
\text { Equality of Means }\end{array}$} & \multicolumn{2}{|c|}{$\begin{array}{l}\text { Welch Test of } \\
\text { Equality of Variances }\end{array}$} \\
\hline & F Value & $\operatorname{Pr}>\mathrm{F}$ & F Value & $\operatorname{Pr}>\mathrm{F}$ \\
\hline $\begin{array}{l}\text { Total (Full) observations } \\
\text { Turmoil observations } \\
\text { Stable observations } \\
\end{array}$ & $\begin{array}{l}1.21 * * \\
12.38 * \\
1.21 * *\end{array}$ & $\begin{array}{l}0.0424 \\
0.0001 \\
0.0424\end{array}$ & $\begin{array}{l}0.37 \\
0 \\
0.37\end{array}$ & $\begin{array}{l}1.00 \\
1.00 \\
1.00\end{array}$ \\
\hline Stable observations & \multicolumn{2}{|c|}{$\begin{array}{l}\text { Chow Test of } \\
\text { Equality of Coefficients } \\
\text { FValue }\end{array}$} & \multicolumn{2}{|c|}{$\begin{array}{l}\text { Amended Chow Test of } \\
\text { Equality of Coefficients }\end{array}$} \\
\hline RSS (F:11) $=270.246$ & \multicolumn{4}{|c|}{ RSS (Turnoil) $=7.0502 \quad$ RSS $($ Stable $)=250.435$} \\
\hline $\begin{array}{l}\text { PANEL A: } \\
\text { Equality of Intercepts, } \\
\alpha \text { (turmoil) }=\alpha \text { (stable) }\end{array}$ & \multicolumn{2}{|l|}{$35.72 *$} & $31.1744^{*}$ & $<0.0001$ \\
\hline $\begin{array}{l}\text { PANEL B: } \\
\text { Equality of Slopes, } \\
\beta \text { (turmoil) }=\beta \text { (stable) }\end{array}$ & \multicolumn{2}{|l|}{$29.17^{*}$} & $21.8690^{*}$ & $<0.0001$ \\
\hline $\begin{array}{l}\text { PANEL C: } \\
\text { Equality of Regressions, } \\
\alpha, \beta \text { (turmoil) }=\alpha, \beta \text { (stable) }\end{array}$ & \multicolumn{2}{|l|}{$23.76^{*}$} & $24.4130^{*}$ & $<0.0001$ \\
\hline $\begin{array}{l}\text { EQUATION } 5 \\
\text { MERRILL LYNCH }\end{array}$ & \multicolumn{2}{|c|}{$\begin{array}{l}\text { Levene Test of } \\
\text { Equality of Means }\end{array}$} & \multicolumn{2}{|c|}{$\begin{array}{l}\text { Welch Test of } \\
\text { Equality of Variances }\end{array}$} \\
\hline $\begin{array}{l}\text { Total (Full) observations } \\
\text { Turmoil observations } \\
\text { Stable observations }\end{array}$ & $\begin{array}{l}1.38^{*} \\
1.61 \\
1.38^{*} \\
\end{array}$ & $\begin{array}{l}0.0013 \\
0.1160 \\
0.0013 \\
\end{array}$ & $\begin{array}{l}0.23 \\
0.07 \\
0.23 \\
\end{array}$ & $\begin{array}{l}1.00 \\
0.9861 \\
1.00 \\
\end{array}$ \\
\hline Stable observations & \multicolumn{2}{|c|}{$\begin{array}{l}\text { Chow Test of } \\
\text { Equality of Coefficients } \\
\text { F Value }\end{array}$} & \multicolumn{2}{|c|}{$\begin{array}{l}\text { Amended Chow Test of } \\
\text { Equality of Coefficients }\end{array}$} \\
\hline RSS (Full) $=95.41$ & il) $=6.62$ & RSS (Stab) & 84.436 & \\
\hline $\begin{array}{l}\text { PANEL A: } \\
\text { Equality of Intercepts, } \\
\alpha \text { (turmoli) }=\alpha \text { (stable) }\end{array}$ & $26.90^{*}$ & & $6.0249 * *$ & 0.0141 \\
\hline $\begin{array}{l}\text { PANEL B: } \\
\text { Equality of Slopes, } \\
\beta \text { (turmoil) }=\beta \text { (stable) }\end{array}$ & $20.92 *$ & & $20.17 *$ & 0.0001 \\
\hline $\begin{array}{l}\text { PANEL } C: \\
\text { Equality of Regressions, } \\
\alpha, \beta \text { (turmoil) }=\alpha, \beta \text { (stable) }\end{array}$ & $20.88^{*}$ & & $17.284 *$ & 0.0001 \\
\hline
\end{tabular}




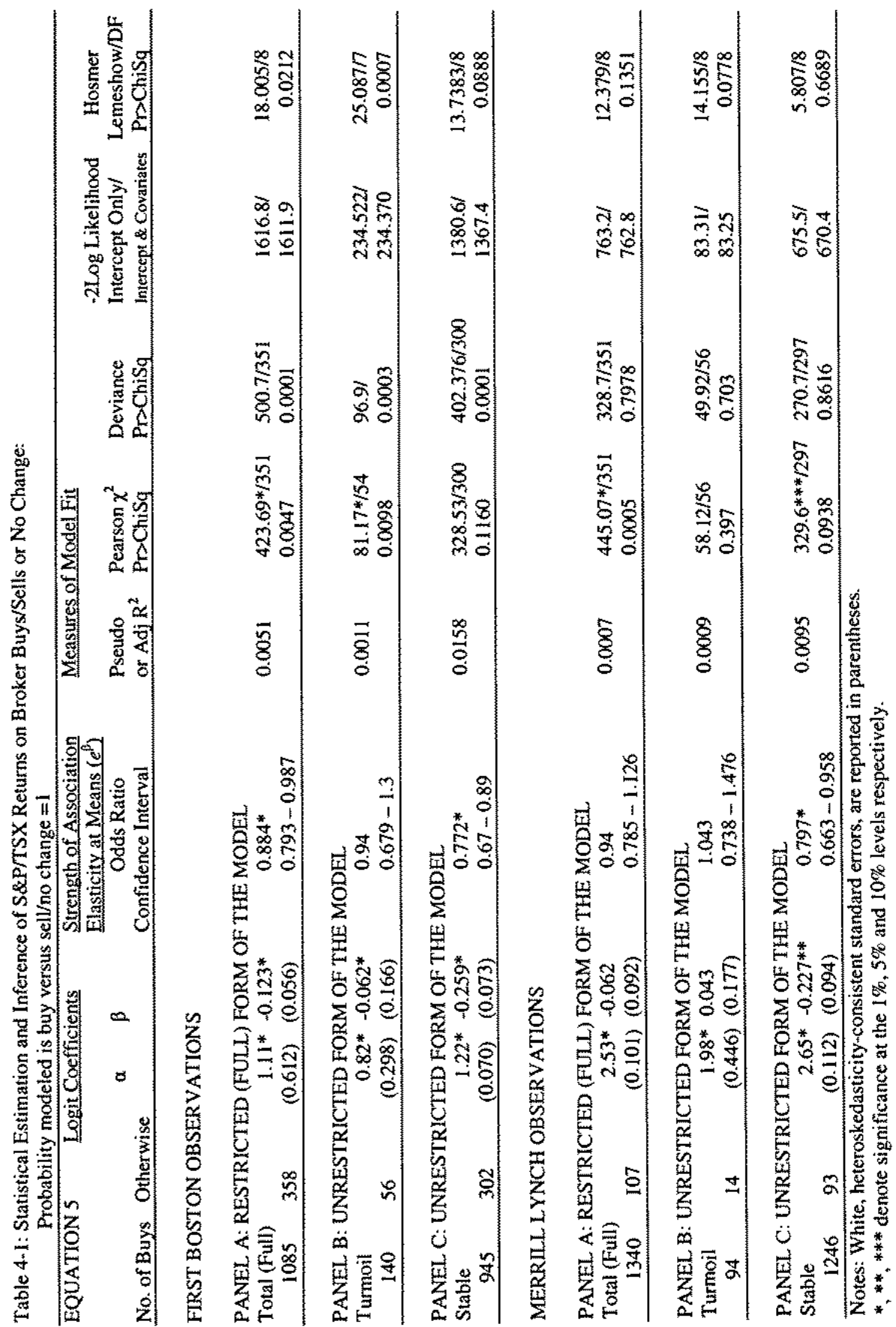


Table 4-2: Tests of Equality between Turmoil and Stable Observations of S\&P/TSX Returns on Broker Buys/Sells or No Change: Probability modeled is buy versus selvno change $=1$

\begin{tabular}{|c|c|c|c|c|}
\hline \multirow[t]{2}{*}{$\begin{array}{l}\text { EQUATION } 5 \\
\text { FIRST BOSTON }\end{array}$} & \multicolumn{2}{|c|}{$\begin{array}{l}\text { Levene Test of } \\
\text { Equality of Means }\end{array}$} & \multicolumn{2}{|c|}{$\begin{array}{l}\text { Welch Test of } \\
\text { Equality of Variances }\end{array}$} \\
\hline & F Value & $\operatorname{Pr}>F$ & F Value & $\mathrm{Pr}>\mathrm{F}$ \\
\hline $\begin{array}{l}\text { Total (Full) observations } \\
\text { Turmoil observations } \\
\text { Stable observations }\end{array}$ & $\begin{array}{l}1.68^{*} \\
2.58^{*} \\
1.68^{*} \\
\end{array}$ & $\begin{array}{l}0.0001 \\
0.0004 \\
0.0001 \\
\end{array}$ & $\begin{array}{l}0.45 \\
1.13 \\
0.45 \\
\end{array}$ & $\begin{array}{l}1.00 \\
0.4132 \\
1.00 \\
\end{array}$ \\
\hline & \multicolumn{2}{|c|}{$\begin{array}{l}\text { Chow Test of } \\
\text { Equality of Coefficients } \\
\text { F Value }\end{array}$} & \multicolumn{2}{|c|}{$\begin{array}{l}\text { Amended Chow Test of } \\
\text { Equality of Coefftcients }\end{array}$} \\
\hline $\operatorname{RSS}($ full $)=268.078$ & noil) $=39$ & RSS (St & $=226.01$ & \\
\hline $\begin{array}{l}\text { PANEL A: } \\
\text { Equality of Intercepts, } \\
\alpha \text { (turmoil) }=\alpha \text { (stable) }\end{array}$ & \multicolumn{2}{|l|}{$10.90^{*}$} & $9.3776 *$ & 0.0022 \\
\hline $\begin{array}{l}\text { PANEL B: } \\
\text { Equality of Slopes, } \\
\beta \text { (turmoil) }=\beta \text { (stable) }\end{array}$ & \multicolumn{2}{|l|}{$3.64 * *$} & 1.1782 & 0.2777 \\
\hline $\begin{array}{l}\text { PANEL C: } \\
\text { Equality of Regressions, } \\
\alpha, \beta \text { (turmoil) }=\alpha, \beta \text { (stable) }\end{array}$ & \multicolumn{2}{|l|}{2.58} & 1.0198 & 0.3127 \\
\hline $\begin{array}{l}\text { EQUATION } 5 \\
\text { MERRILL LYNCH }\end{array}$ & \multicolumn{2}{|c|}{$\begin{array}{l}\text { Levene Test of } \\
\text { Equality of Means }\end{array}$} & \multicolumn{2}{|c|}{$\begin{array}{l}\text { Welch Test of } \\
\text { Equality of Variances }\end{array}$} \\
\hline $\begin{array}{l}\text { Total (Full) observations } \\
\text { Turmoil observations } \\
\text { Stable observations } \\
\end{array}$ & $\begin{array}{l}1.59^{*} \\
0.86 \\
1.59^{*} \\
\end{array}$ & $\begin{array}{l}0.0001 \\
0.594 \\
0.0001\end{array}$ & $\begin{array}{l}0.23 \\
0.11 \\
0.23 \\
\end{array}$ & $\begin{array}{l}1.00 \\
0.9949 \\
1.00 \\
\end{array}$ \\
\hline Stable observations & \multicolumn{2}{|c|}{$\begin{array}{l}\text { Chow Test of } \\
\text { Equality of Coefficients } \\
\text { F Value }\end{array}$} & \multicolumn{2}{|c|}{$\begin{array}{l}\text { Amended Chow Test of } \\
\text { Equality of Coefficients }\end{array}$} \\
\hline $\mathrm{RSS}($ full $)=99.025$ & oil) $=12.1$ & RSS (Stat & 86.028 & \\
\hline $\begin{array}{l}\text { PANEL A: } \\
\text { Equality of Intercepts, } \\
\alpha \text { (turmoil) }=\alpha \text { (stable) }\end{array}$ & $13.62^{*}$ & & $8.0611 *$ & 0.0045 \\
\hline $\begin{array}{l}\text { PANEL B: } \\
\text { Equality of Slopes, } \\
\beta \text { (turmoil) }=\beta \text { (stable) }\end{array}$ & 2.82 & & 2.1817 & 0.1397 \\
\hline $\begin{array}{l}\text { PANEL C: } \\
\text { Equality of Regressions, } \\
\alpha, \beta \text { (turmoil) }=\alpha, \beta \text { (stable) }\end{array}$ & 2.00 & & 0.8467 & 0.3575 \\
\hline
\end{tabular}




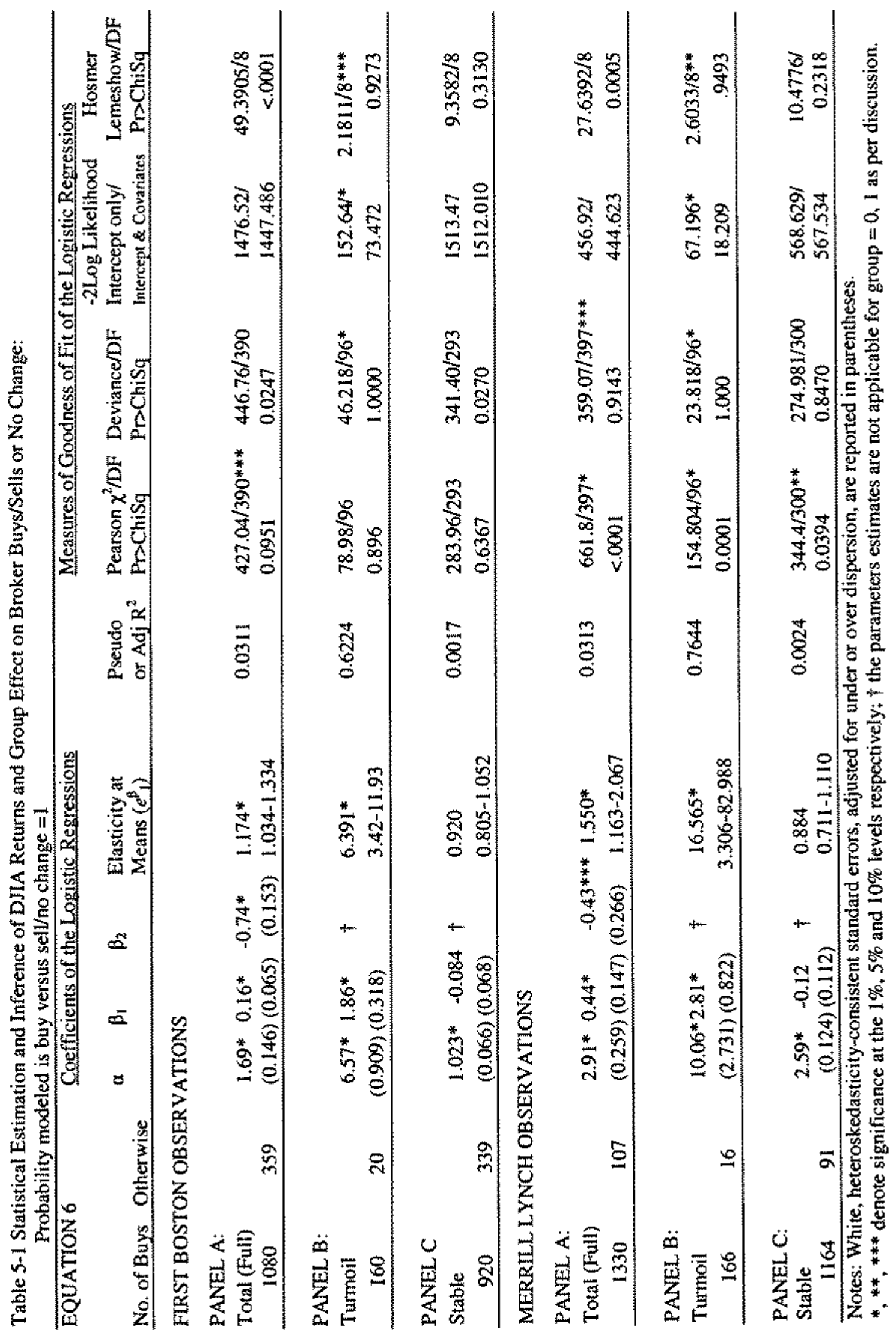




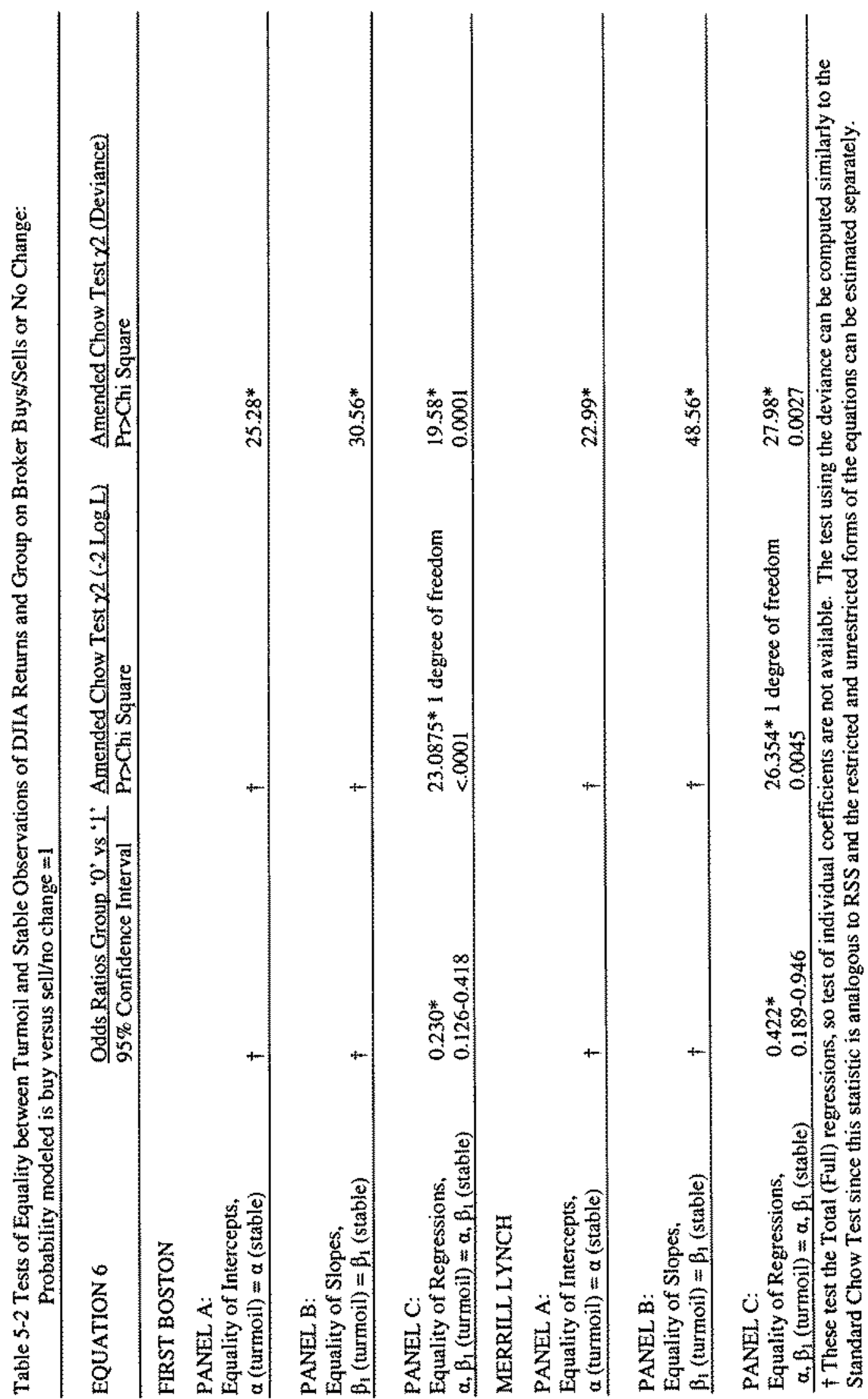




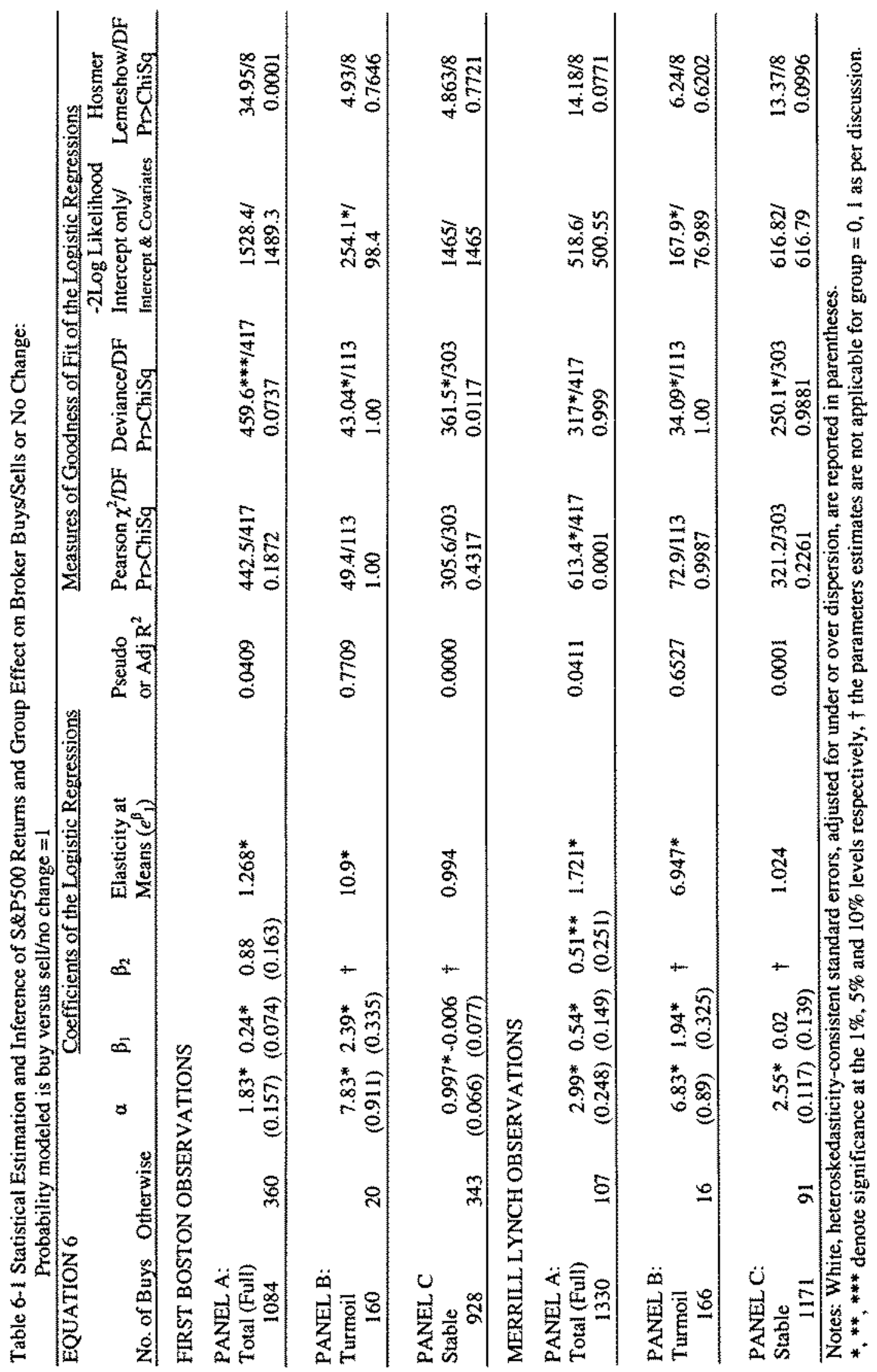




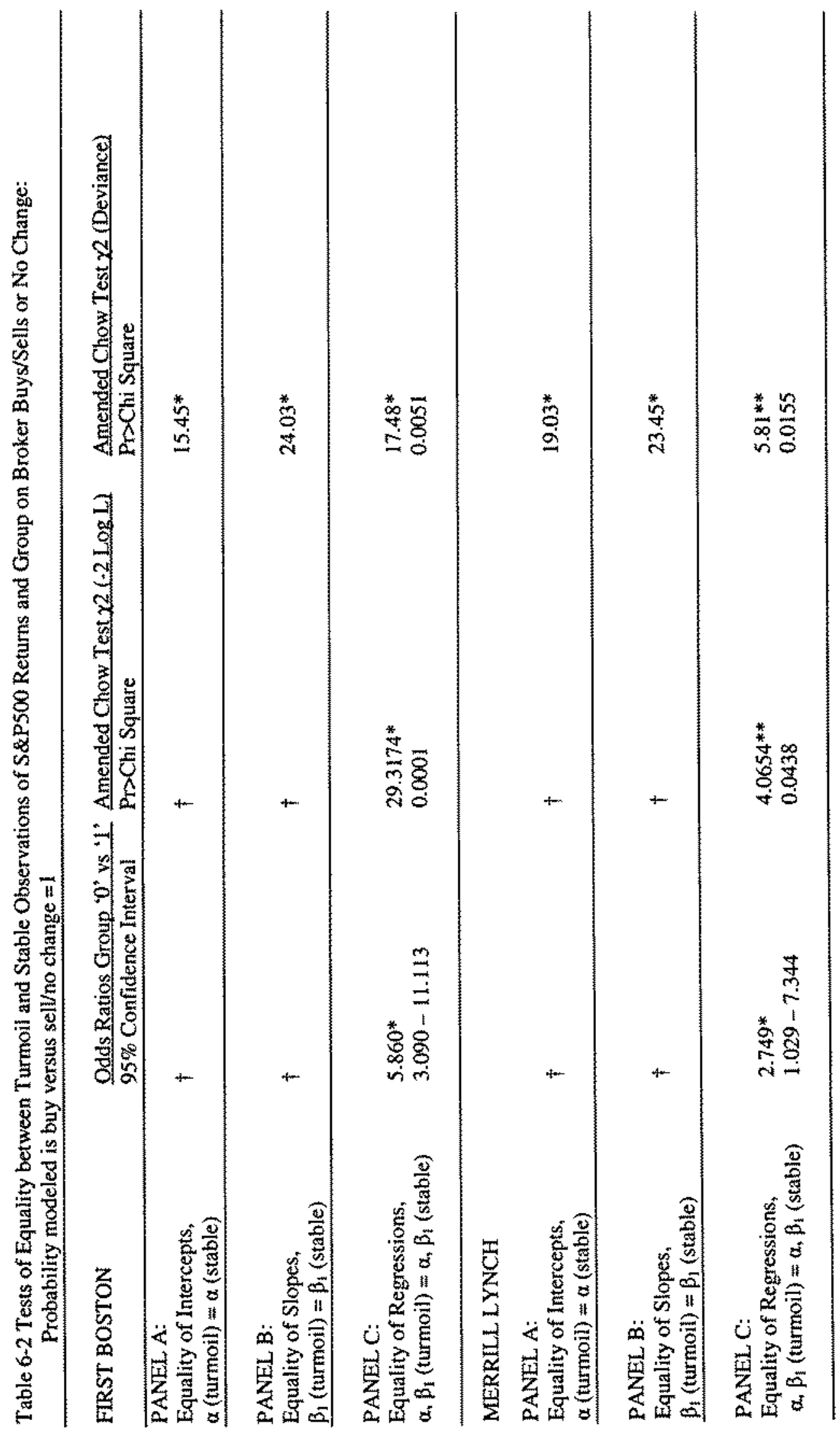

$\alpha$ 


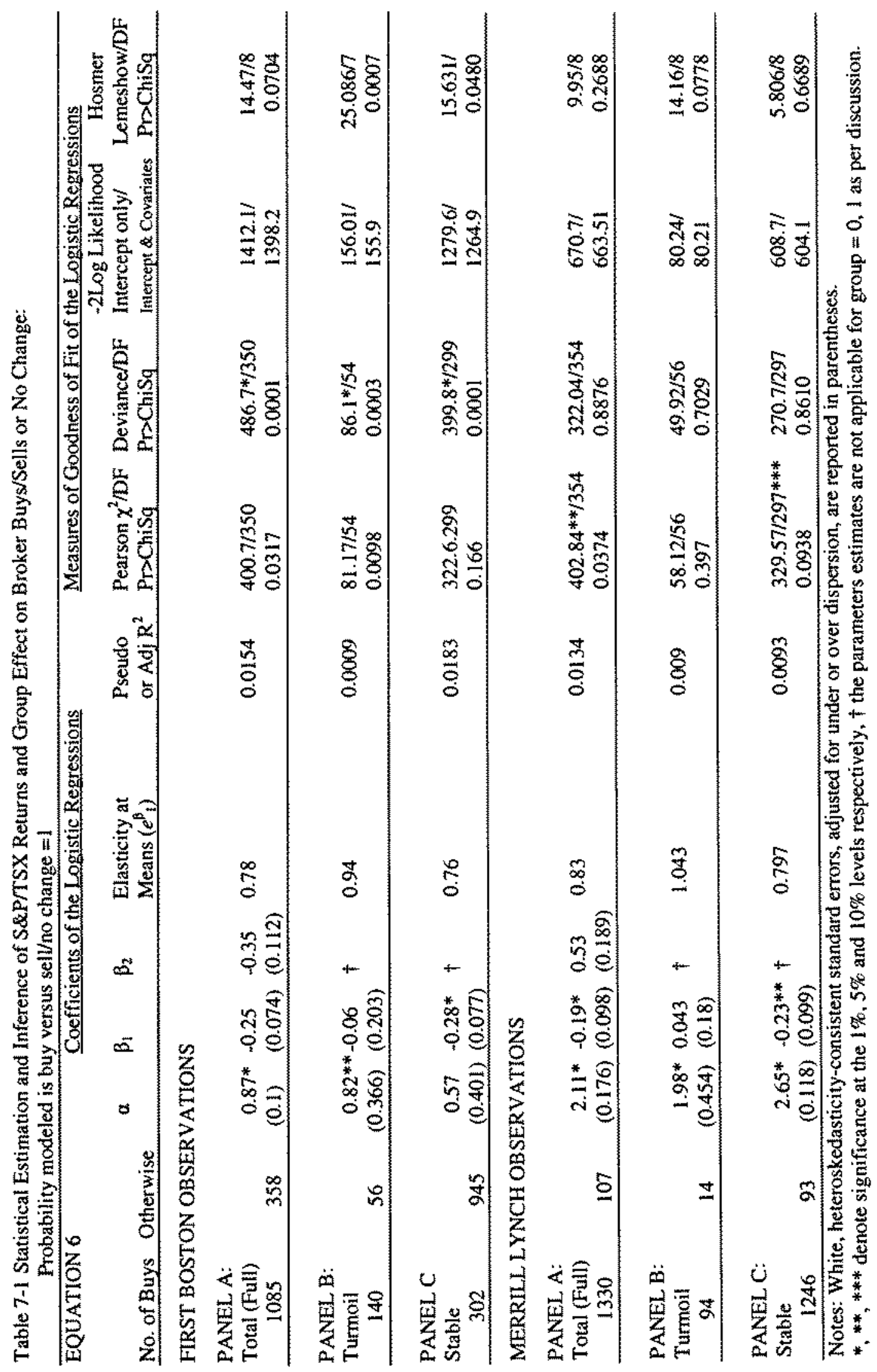




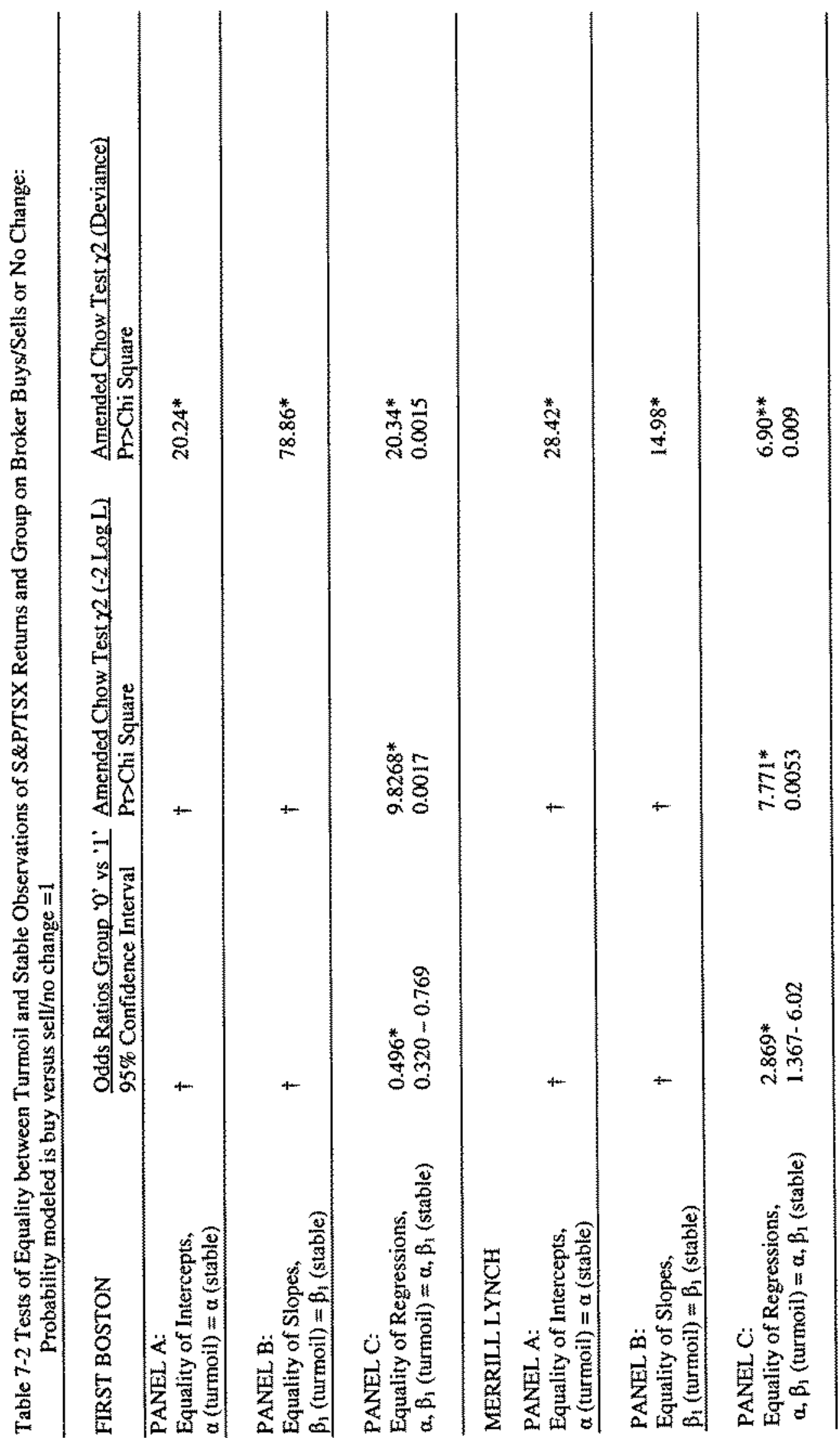




\section{INTERPRETATION OF THE LOGISTIC COEFFICIENTS}

Tests of the Significance \& Influence of the Logistic Regression Coefficients:

The initial assessment of the procedure involved tests to determine whether the independent variables are significantly related to the variable that measures the outcome. Accordingly the parameters of interest are calculated and interpreted. Positive (negative) signs of the estimated coefficients suggest linear increases (decreases) in the log of the odds or probability. Typically the intercept coefficient is of little interest. Many times when it is significant however it suggests missing independent variables. The slope coefficient is of greater interest and "represents the change in the logit corresponding to the change of one unit in the independent variable" (Hosmer \& Lemeshow 2000 p 48). Consequently a positive slope (beta) coefficient estimate of the market index indicates that the events (1) in this case buy, is more likely given a level of return than a $(0)$ or sell/no change. A negative coefficient estimate indicates that buys are less likely given a level of retum. Consequently if turmoil conditions exist as measured by the change in the market index, a positive beta implies a larger probability of buying securities versus selling or no change.

Conventional $t$ statistics for the statistical significance of each estimated coefficient, that is whether the coefficients are statistically different from zero, can be computed. Hypothesis tests for significance of the regression coefficients attempt to determine whether any omitted variables have an effect on the model. The results for Equation (5) show a positive beta for the market index with statistical significance during turmoil conditions for both brokerage houses using the DJIA and S\&P500; the results for the S\&P/TSX, show a significantly negative coefficient during stable periods for both 
sets of traders, and for MER's total set of observations. It has been noted that the S\&P/TSX itself is negatively correlated with the rest of the market because of its beavy weighting in securities of resource-based companies. However, a detailed perusal of the companies whose stock made up the database showed that very few of them were resource based. The results for the coefficients of total observations at MER are probably significant because the turmoil observations have an undue influence. On tests of Equation (6), the coefficients for the total (full) set of observations are all statistically significant, suggesting the group effect is a real one, i.e., market turmoil conditions significantly affect the probability for both brokerages. The coefficients and their significance levels in Equation 6 are slightly different from Equation 5 for two reasons. Some of the model misspecification is reflected in the alphas of Equation 5 and the standard errors are smaller in Equation 6 because of the over-dispersion adjustment.

Strength of the Association - Measures of Marginal Effects:

Estimated coefficients are used to interpret association among explanatory variables in logistic regressions. The logistic coefficients themselves unlike with OLS are not marginal effects. The marginal effect here is the slope of the probability curve relating $x$ to $\operatorname{Pr}(Y=1 \mid x)$, holding all other variables constant. The effect is such that the model will never predict a probability greater than one, and will diminish as the probability gets closer and closer to one. These effects are evaluated by assuming a 
trader has a mean response for every independent variable. The mathematical basis for the marginal effects is available in Greene (1997). ${ }^{30}$

The marginal probability will have the same sign as the coefficient when evaluated at the means. As mentioned previously, proper interpretation of these variables depends on the difference between two logits, the effect on the margin. Marginal effects at the mean are directly built into the coefficients because of the exercise of taking logarithms. An elasticity measure gives the percentage change in the probability of a success in response to a one percentage change in the explanatory variable. Greene (2000, p. 816$)$ notes that the elasticities vary for every observation so it is desirable to report a summary measure by evaluating the expression at every observation and then taking the average. ${ }^{31}$ Since the coefficients of the logistic regressions can be interprcted as the change in the dependent variable associated with a one unit change in the independent variable (Menard 1995), the elasticities can be computed at the mean through the odds ratio and a confidence interval can be computed. The "Elasticity at Means" indicates the percentage change in the probability of a trader buying more of a security as a result of a one-percent change in the relevant explanatory variable (the market index return) when all variables are evaluated at their mean values, the starting or reference point. The result is meaningful when the explanatory variable of interest is roughly continuous, such as return, but not for the dummy variables.

\footnotetext{
${ }^{30}$ Greene, W. Econometric Analysis, Macmillan Publishing Company, New York, 1997.

${ }^{3 t}$ Greene, W. H., (2000) Econometric Analysis, $4^{\text {th }}$ edition, Upper Saddle River, New Jersey: Prentice-Hall.
} 
This test is one of whether the individual odds ratios are significantly different from one (no association) or test whether two odds ratios are different from each other. Some view it as a measure of relative risk (Rothman and Greenland 1998) ${ }^{32}$. These nonparametric tests use the chi square statistic. If the statistic is large relative to the degrees of freedom then the model does not significantly describe the data. Analysis using the odds ratios illustrates the change in the probability of the dependent variable for a unit change in the independent variable. The Elasticity at Means and the Odds ratio show significant levels for the turmoil data using the DJIA and the S\&P500. The coefficients of the return variables are very similar based on estimation of both equations (5) and (6) and suggest a negative relationship especially between the probabilities of "buys versus sells/no change" and returns especially using the DJIA and S\&P500 as representative of the market. While the strength of association is statistically significant for the total observations from MER, the results for the turmoil observations are very obvious for both brokerage houses. The results are also significant for the total as well as the stable observations at FB and MER using the S\&P/TSX. This is probably a result of the negative correlation of mining stocks at the S\&P/TSX and the total market index at S\&P500.

The estimation of the odds ratio using Equation (6) is useful in determining the interaction effects. If there is an interaction effect between a risk factor and another variable, the estimate of the odds ratio of the risk factor will vary. If they are different, it implies the only variables that do not exist in the other specification are significant. In all cases there are differences suggesting that the group effect is important. A direct test is

\footnotetext{
${ }^{32}$ Rothman, K. J. and Greenland, S. (1998). Modern Epidemiology. 2nd ed. Lippincott-Raven, Philadelphia.
} 
on the odds ratio comparing GROUP $=0$ with GROUP $=1$ which is presented as an adapted (since it is also nested) Chow test in the second sections of all the tables and discussed at length in Hosmer \& Lemeshow (2000, pg 75).

\section{5\% Confidence Intervals of the Odds Ratios:}

The interval provides additional information about the parameter. It is useful to measure the likelihood that the odds ratio one is found within the interval, in which case the model does not significantly describe the data. The only consistently statistically suitable odds ratio statistics are for the turmoil observations. The tables using the DJIA data show the odds of buying over selling during the turmoil observations are six times that of the stable observations for FB and 16 times for MER. For the stable and total observations, the probabilities are statistically equally likely that the trader will buy or sell except in the case as mentioned previously for MER. The number one occurs in the confidence intervals for all the remaining regressions except for MER's total observations and in the turmoil observations of the S\&P/TSX data. This lends some support to the postulation that the buy actions of traders are inversely related to the returns on the S\&P/TSX. The tables that present the results of Equation (5) show similar results as those that report on Equation (6) for the individual odds ratios but with a $95 \%$ confidence interval.

Test of Significance of the Model, Influence or Goodness of Fit:

In OLS regressions $r^{2}$, the coefficient of determination can be used to measure overall fit of the model or the strength of association. Several analogous measures of fit 
have been suggested for logit models but none of them supports a straightforward interpretation as $r^{2}$. The adjusted or pseudo $R^{2}$ of logistic methods can be calculated using a variety of methods and are all based on comparisons of the predicted values from the fitted model to those from a model using an intercept only. Ljungqvist and Wilhelm Jr. (2005), in their study of "weather" as providing a behavioral bias use "probit" regressions and consider a "pseudo $R^{2}$ of $23.5 \%$ " in conjunction with a significant Pearson chi-square statistic as providing evidence of a "good" model. Unfortunately low $R^{2}$ values are the norm in logistic regression, a fact difficult to reconcile with the relatively higher $r^{2}$ common in OLS regressions. Consequently it is important to review $R^{2}$ in conjunction with other measures to determine "goodness of fit".

Aldrich and Nelson's (1984) pseudo or adjusted $R^{2}$ measure suggests significant support only for the model during times of turmoil using the DJIA on the data from both brokerage houses. The $R^{2}$ squared for the turmoil set of observations is roughly $60 \%$ at FB and $78 \%$ at MER while it is negligible for the stable set.

The residual sum of squares in logistic regressions is not as useful as in OLS since the deviation of each observation from one will give a negligible result. These are calculated for all the market indices for both brokerage houses and are seen to have only fractional remainders of the sum of the two separate sets from the total set. In logit regressions the equivalent measures of sum of squared residuals are the deviance residuals and the likelihood ratio. The statistics follow a $\chi 2$ distribution rather than an $F$ one, can be calculated and used in adapted Chow tests. Another measure of discrepancy between observed and fitted values analogous to the residual sum of squared errors in OLS is the Pearson residuals. The test statistics are the Pearson $\chi^{2}$ statistic which is the 
sum of the Pearson residuals and the deviance, the sum of squared deviance residuals. The Likelihood Ratio Goodness of Fit statistic (LR) is also based on the comparison of the restricted and unrestricted maximum of the log likelihood function. These tests are described in Mc Cullagh \& Nelder (1989) and follow an asymptotic chi-square distribution with degrees of freedom equal to $(m-1)^{*}(k+1)$, where $m$ is the number of subsamples and $k$ is the number of independent variables in the model. The Pearson statistic on the other hand is a true goodness of fit test since a significant statistic suggests a good fit.

Mc Cullagh \& Nelder $(1989)^{33} \mathrm{pg} 33$ is typically quoted as the standard reference for deviance. The formula for the deviance residual, $d$ is given by

$$
d_{i}(p, y)= \pm \sqrt{-2\left(y_{i} \ln \hat{p}_{i}+\left(1-y_{i}\right) \ln \left(1-\hat{p}_{i}\right)\right)}
$$

The deviance residual for a logistic model is similar to the residual error in ordinary least squares regression for the linear model. A smaller the deviance residual reflects a better fitting logistic model. The deviance is the sum of squared deviance residuals

$$
\chi^{2}{ }_{D}=\sum_{j=1}^{J} d j^{2}
$$

Since the deviance test statistic determines whether a given logit model is worse than a perfectly fitted (saturated or full) model, it is more appropriately known as a "badness of fit" test since non-significant residual deviances or residuals are considered good fit. A "smaller" deviance value given a particular sample size would indicate that the fitted model describes the data as a whole well whereas a "large" value would suggest otherwise. Thus, the deviance can also be used directly to test the goodness of fit of the

\footnotetext{
${ }^{33} \mathrm{Mc}$ Cullagh \& Nelder (1989), Generalized Linear Models, $2^{\text {nd }}$ ed. London: Chapman and Hall.
} 
model. A well fitting model is not significant. The deviance statistic gives support for the model during turmoil conditions for both brokerages using the DIA. It also gives some support for the actions during turmoil conditions at FB using the S\&P500. Surprisingly it also shows statistical significance at MER for all observations and conditions using the S\&P500.

The log-likelihood statistic is adjusted to present the -2 Log Likelihood test that determines the difference between the model with intercept only and the one with all the covariates. The results presented include the total statistic which measures all the covariates and the difference from the model with only the intercept. A good fitting model will have a very significant difference between the two statistics. The absolute value of the statistic is heavily dependent on the number of observations in the sample. Meaningful differences are prevalent for both brokerage house turmoil observations using the DIIA.

A third measure of standardized residuals is provided by the Hosmer-Lemeshow (H-L) Goodness-of-Fit Test (also know as the Lackfit test). Some studies suggest that the deviance statistic is not distributed as chi-square when there are a small number of observed values (less than 400). The Hosmer-Lemeshow fit test is designed to correct for the small sample size (especially when there are continuous predictors). This provides a chi-square-based test that assesses how well the data under analysis perform under the null hypothesis that the model fits the data. Again, when this test is not significant then the model being tested is a good fit to the data because this means the parsimonious model is not significantly worse than the well-fitting saturated model. Mc Cullagh \& Neder (1989) caution against using a single statistic to draw conclusions about goodness 
of fit, so several are presented with a conclusion based on the significance levels of more than one of them. Based on all the mcasures of model fit, it can be concluded that especially using the DJIA for the turmoil data, the model is a good fit (or not a bad fit) to model the probability that a broker will buy securities during a down market versus sell/no change.

\section{TESTS OF STRUCTURAL CHANGE}

Test of Homogeneity of Variances and Tests of Equality of Means:

The test of Homogeneity of Variances, the Levene test and the Test of Equality of Means if the variances are known a priori to be unequal, the Welch test, are typically not measured for logistic regressions since the dichotomous dependable variable is not normally distributed. However, there are benefits to computing these statistics to understand the characteristics of the data. The Levene tests sbow convincingly using the DJIA and various other sets of observations using the S\&P500 and the S\&P/TSX that the variances are not homogeneous. Given the lack of homogeneity, the Welch tests show there are virtually no differences in the means. ${ }^{34}$ Consequently, there are no observed differences in these tests between the stable and total observations. There is however a noticeable difference in these tests in the turmoil observation for all three parts. The null hypothesis of homogeneous variances can be decisively rejected when the DJIA is used on both brokerage house data and only FB with the S\&P/TSX. Given that this is the case in these parts, the Welch test is not mcaningful. However using S\&P500, the null

\footnotetext{
${ }^{34}$ The procedure in SAS automatically drops groups in the Levene test for homogeneity of BUY,SELL variances across different return grotps. In addition, groups are dropped from Welch's ANOVA of return effect for BUY_SELL for no observed variability.
} 
hypothesis that the means are equal once tests show that the variances are not equal, can be rejected.

Tests of Equality of Regressions:

Most statistical tests rely on the assumption of static parameters of the model (or the covariances of the data have remained constant over the sample observation). However during periods of unusual circumstances it is likely this is an unrealistic assumption and that the model can be improved by accounting for structural changes that may have caused the model parameters to change. Chow's $(1960)^{35}$ Breakpoint Test divides the data into two sub-samples. It then estimates the same equation for each subsample separately, to see whether there are significant differences in the estimated equations. A significant difference indicates a structural change in the relationship. The Chow test for ordinary linear squares regression is an $F$ test that involves computing the residual sum of squares of the regression. The $F$ test with $\mathrm{df}=k, N 2+N .3-2 k$ is computed. If the computed $F$ exceeds the critical $F_{k}, N 2+N 3-2 k$, the hypothesis that the two regressions are the same is rejected.

In logistic regression, since the analogy to this residual is the deviance, one test consists of determining the significance probability of the deviance for a given degrees of freedom. If this probability is small, then the null hypothesis of no significant change in the data prior to and after the structural change is rejected, suggesting evidence of a

\footnotetext{
${ }^{35}$ Chow, G. (1960). Tests of Equality Between Sets of Coefficients in Two Linear Regressions, Econometrica, vol. 28: 591-605.
} 
structural change in the data. Toyoda $(1974)^{36}$ shows that the Chow test "is well behaved even under heteroskedasticity as long as at least one of two sample sizes is very large". For logistic regressions, the Chow test can also be adapted using the chi-square value produced by subtracting the $-2 \log$ Likelihood for the two nested models. It has one degree of freedom. ${ }^{37}$

Some studies however believe that the Chow tests can provide wrong conclusions in the presence of heteroskedastic disturbances. Additionally it is not conceptually feasible to use the deviance in exactly the same manner as the residual sum of squares in OLS. This is because a very large denominator (which is comprised predominantly of the number of observations) will produce a large $F$ statistic that may seem to be statistically significant even if the deviance is small. Consequently, this statistic has to be adapted somewhat for a logistic equation. Instead it is more suitable to divide the data into groups depending on the different characteristics, for example turmoil observation versus stable observation and then checking for similarities between the two groups. When the two different methods give the same indications, the result is a robust test for the structural equality of logistic regression parameters, a Chow test that is chi square distributed.

Another definition of the 'Chow test' equivalent to pooling the data, estimating the fully interacted model, and then testing the hypothesis that the Group $l$ coefficients

\footnotetext{
${ }^{36}$ Toyoda, T., Use of the Chow Test under Heteroskedasticy, Econometrica, Vol, 42, No. 3 (May, 1974), pp. 601-608.

${ }^{37}$ Jaccard, J. (2001), Interaction Effects in Logistic Regression, Sage Series: Quantitative Applications in the Social Sciences Sage Publications, Inc. CA.
} 
are significantly different to the coefficients estimated in Group 0 , is a preferential methód for testing for parameter consistency. This is an odds ratio test on Equation (6). ${ }^{38}$

The tests show significant structural change results for both brokerage houses using the DJIA and S\&P500. Consequently, the null hypothesis that the regression slopes, intercepts and total regression for the market turmoil and non-turmoil observations are equal is rejected and supported by all three versions of the Chow test and the odds ratio variation. These statistics show statistically significant structural break points occurred principally for the loss greater than the $0.95 \%$ of the DJIA and S\&P500 indices.

\section{Implication of these Results}

It is noteworthy that the coefficients derived for the variables using logit/probit procedures only have meaning relative to each other, therefore the absolute magnitude of the coefficients is not interpretable like it is in ordinary least squares regression models. The model represents the association of the dependent variable, which represents the probability of a particular choice being made, and the independent variable. Therefore, the regression parameters represent the change in the buys/sells associated with a unit change in the incremental return of the market, and do not necessarily represent causal effects. Hence, the model represents a convenient way to explain relationships or predict the propensity to buy or sell given the known inputs or extreme change in the market conditions.

${ }^{38}$ This Type 3 analysis of effects is reported as part of the logistic procedure in SAS. 
The results reported from the different brokerage houses indicate robustness of the effects because of their similar conclusions. Arguably, the more experienced traders at various brokerage houses may be less prone to behavioral biases. The differential experience levels can account for significantly different trader behavior. An exercise for future exploration can include a test of statistically significant difference between the two brokerage houses.

The results using the DJIA consistently lend support to the null hypothesis that during periods of market turmoil, investors trade differently while the other two indices lend some support. Specifically they buy more securities during down markets. The exercise affirms behavioral biases suggesting that perceptions and sentiment may heavily influence trading patterns. This observation leads to an extension of the methodology of this study. It may also be useful to investigate how the above results change with the inclusion of another indicator of investors' risk preferences, sentiment.

\section{Extensions of the Methodology}

Fama and French (1993) argue that a three-factor asset-pricing model is the appropriate benchmark against which anomalies should be measured. In other words, other factors are priced as risk. In as much as interpretations and robustness of the results are heavily influenced by the type of distributions and sample sizes, the results may be improved through an alternative specification of the model. The results so far indicate that traders in Toronto significantly base their trading decisions on the daily changes in the DIIA. This thesis now attempts to follow Fama and French (1996)'s multifactor approach to Merton's (1973) Intertemporal CAPM to determine whether other factors 
like the return on DJIA, change in Consumer Sentiment and Trader Activity contribute to changes in the market index as a whole as defined by the S\&P500. The framework will however be limited to a behavioral one.

Since there are many more non-turmoil observations than market turmoil, the data can be combined into one sample with the different types of observations being assigned dummy variables. The resulting model specifies these different observations as independent variables.

$$
\text { Model }: \quad \text { RETURN }=\alpha+\beta_{l}\left(B U Y_{-} S E L L\right)+\beta_{2} \text { GROUP }+\varepsilon
$$

The test would be therefore on whether or not the $\beta$ 's are significantly different from zero. If they are, this supports the hypothesis that investor behavior is different because of behavioral factors as well as market conditions (turmoil versus non-turmoil). A major advantage of this specification is the assumptions of ordinary least squares are no longer violated and more robust statistics can be computed. ${ }^{39}$ The caveat here is the interpretation. Is the market return predicted by these behavioral factors, or does market retum predict consumer behavior? It may be argued that the DJIA is also a behavioral factor since it has the capacity to create either euphoria or fear.

In as much as interpretations and robustness of the results are heavily influenced by the type of distributions and sample sizes, the results may be improved through an alternative specification of the model. The results so far indicate that traders in Toronto significantly base their trading decisions on the daily changes in the DJIA. This thesis now attempts to follow Fama and French (1993)'s multifactor approach to Merton's (1973) ICAPM to determine whether other factors like the return on DJIA, change in

\footnotetext{
${ }^{39}$ Unfortunately the endogeneity issue remains.
} 
Consumer Sentiment and Trader Activity contribute to changes in the market index as a whole as defined by the S\&P500. The result is a multi-factor model as suggested by Fama and French (1996). The framework will however be limited to a behavioral one.

Since the previous section noted that the results based on the DJIA showed a bigh correlation between trader behavior and market retums it is a good candidate for inclusion in an extension of the methodology. In this specification of the model, the dependent variable is the market return. The dummy variable GROUP is defined as 1 for the group of market turmoil observations, and 0 for the non-turmoil ones. The other independent variable is as defined as the brokerage data from the previous section, the BUY_SELL responses of the traders. This methodology serves a two-fold purpose, since the number of market turmoil observations is far less than the non-turmoil ones, it eliminates biases that may be caused by inferences made from extreme differences in sample size. Secondly, it allows for testing of sub-hypotheses that check for the effect of several behavioral factors. Since the return of the market is the new dependent variable, sub-hypotheses include whether the lagged returns of the DJIA or other behavioral factors like the traders' buy or sell activities and investor sentiment are parsimonious predictors. Adding lags may also enhance the plausibility of the assumption of normalcy in the error term, with mean zero and constant variance.

Since the dependent variable is no longer binary a logit or probit specification is no longer necessary and predictive tendencies can be discemed using OLS. Lakonishok and Smidt (1988), in a test for seasonal patterns in rates of return on 90 years of data, also specified the predicted variable as the retum on the market. An $F$-test is conducted on 
the joint significance of the regression coefficients. The general model is presented as follows:

Model: $\quad$ RETURN $=\alpha+\beta_{1}\left(x_{1}, x_{2}, x_{3}\right)+\beta_{2}$ GROUP $+\varepsilon$

Where $x_{1}, x_{2}, x_{3}$ may be any independent variables that can determine buy/sell activity for example sentiment, bankruptcies, volume of stock traded, buys or sells. The dummy variable (GROUP) will again be one during market turmoil and zero otherwise. The caveat here is the interpretation. Is the market return predicted by these behavioral factors, or does market retum predict consumer behavior? It may be argued that the DJIA is a behavioral factor since it has the capacity to create either euphoria or fear. Lagged endogenous and/or exogenous variables are typically introduced in order to reduce the autocorrelation and endogenous regressors problems. The lagged retum is especially useful since anecdotally and empirically it has been noted that based on mean reversion of retums, traders first over-react and then eventually pull back (Shefrin 2001). Therefore, it can also be used as a behavioral factor in this multi-factor model. Hence, an altemate index like the S\&P500 can be classified as the market retum as is the norm in empirical studies.

Lagged DJIA, Consumer Sentiment \& Trader Activity as Predictors of the Market Return $(S \& P 500)$

There is a large difference in sample sizes among the market turmoil and nonturmoil observations. Consequently, the implications may be skewed if the data is tested separately. Therefore, by aggregating the data one large sample can be tested with the observations from the turmoil and non-turmoil environments being categorized using 
dummy variables. Since the model no longer involves estimating a discrete choice dependent variable, the estimation is no longer constrained to calculating probabilities. Hence, the model can be estimated using ordinary least squares achieving the benefits of coefficients with special meanings; however, it is important to determine that the assumptions of normality and equal variances are not violated. In regression models, when the data are time-series in nature, there is a possibility that the error terms follow an autoregressive process. An autoregressive error model corrects for serial correlation. Since ordinary least-squares regression assumes constant error variance, heteroskedasticity problems cause the OLS estimates to be inefficient. Another problem that arises is the OLS forecast error variance is inaccurate since the predicted forecast variance is based on the average variance instead of the variability at the end of the series. Therefore, the estimation has been adjusted for heteroskedasticity and serial correlation in this section. ${ }^{40}$

The specification of this model suffers from a drawback. The DJIA is serially correlated with the S\&P500. Even though it is not an extremely large component of this market, the results may be compromised. Using a lagged return of the S\&P500 should solve this problem. Additionally, the lagged retum will check for evidence of herding.

Herding occurs when a group of investors trades the same stock in the same direction over time, while feedback trading occurs when lagged returns act as the common signal that the investors follow. The analysis will begin by presenting a general model, which incorporates other economic variables that could possibly be predictors of

\footnotetext{
${ }^{40}$ The estimation procedure in SAS, PROC AUTOREG accounts for changing variance and as a member of the family of GARCH models provides a means of estimating and correcting for the changing variability of the data. The GARCH process assumes that the errors, although uncorrelated, are not independent and models the conditional error variance as a function of the past realizations of the series.
} 
the retum on a market index. If it is assumed that investors' buy/sell decisions are exogenous to the daily retum of a market index and are one of the priced factors that can successfully be used in "assessing the information processing ability of financial markets" (Roll 1992) ${ }^{4 !}$, then the following specification is useful.

$$
R E T U R N=\alpha+\beta_{l}\left(R E T U R N_{t-l}\right)+\beta_{2}(S E N T)+\beta_{3}\left(S E N T_{t-f}\right)+\beta_{4} B U Y_{-} S E L L_{1}+\beta_{S} \text { GROUP }+\varepsilon
$$

The variables are defined as follows:

RETURN $N_{i}=$ return on $\mathrm{S} \& \mathrm{P} 500$

$\alpha=$ intercept

$\beta_{1}=$ coefficient estimate of the impact of the lagged $S \& P$ retum

$R E T U R N_{t-1}=$ the one-day lagged return on the S\&P500

$\beta_{2}=$ coefficient estimate of the impact of change in sentiment

$S E N T$ = change in sentiment, as measured by the change in the consumer sentiment index $\beta_{3}=$ coefficient impact of the one period lagged change in sentiment

$S E N T_{t-1}=$ lagged change in sentiment

$\beta_{4}=$ coefficient impact of trader activity

$B U Y$ SELL = dummy variable defined as one for trader "buys" and zero otherwise

$\beta_{\xi}=$ coefficient impact of "market turmoil" versus "non-turmoil" condition

GROUP = dummy variable defined as one for market turmoil observations and zero otherwise

$\varepsilon=$ Error term

All the variables have been defined before except for the sentiment data. ${ }^{42}$ During the period under investigation, this index was only collected quarterly. Therefore, it was essentially the same over a three-month period. The results are also treated for heteroskedasticity. Another confounding effect as mentioned before is, while investors may over-react one day, they may re-think their behavior and compensate the following

\footnotetext{
${ }^{4 !}$ Roll, R. W., 1992, Weather, in Peter Newman, Murray Mllgate, and John Eatwell, ed.: The New Palgrave Dictionary of Money and Finance 3, 789-790 (Macmillan Press, London).

${ }^{42}$ The measure of sentiment used here is the Index of Consumer Confidence (ICC). The monthly Index of Consumer Confidence is constructed from responses to four attitudinal questions posed to a random sample of Canadian households. The Index has been accumulated monthly since December 2001 but quarterly since 1971.
} 
day, eventually leading to mean-reversion. Since the behavioral bias of over-reaction is not being investigated in this thesis the DJIA can be removed from this specification and replaced with a lag of the S\&P500. Table 8 presents results using DJIA and its lag and the specification reported in Table 9 utilizes the S\&P500 and its lag to verify that the results produced by the two indices are similar. Intuitively the specification in equation (9) using the DIIA in lieu of the S\&P500 undoubtedly leads to high predictive capacity based on the results from the first set of equations that show that the DJIA was a good predictor of the brokers' buy/sell or change decisions during this time frame. Estimation results are presented first for FB and subsequently MER.

$$
\begin{aligned}
& R E T U R N=0.058+0.20 R E T U R N_{t-l}+0.001 S E N T+0.003 S E N T_{t-l}+0.2315 B U Y_{m} S E L L-1.8209 G R O U P \\
& (0.058)^{*}(0.0228)^{*}(0.004) \quad(.004)(.06)^{*} \quad(0.10)^{*} \\
& \text { RETURN }=0.072+0.1978 R E T U R N_{t-1}-0.001 S E N T+0.003 S E N T_{\mathrm{t}-1}+0.1683 B U Y_{-} S E L L-1.7613 \text { GROUP }
\end{aligned}
$$

\begin{tabular}{|c|c|c|c|}
\hline FIRST BOSTOI & & & \\
\hline Total R-square C & for heteroske & city & 0.3594 \\
\hline Durbin Watson & 1.9381 & & \\
\hline Total R-square & 0.7502 & & \\
\hline Test of the Mods & $=(-0001)$ & $7.45^{*}$ & \\
\hline Tests of Structur & Chow Test & $42.28^{*}$ & Structural Break Point 173 \\
\hline MERRLLL LYN & & & \\
\hline Total R-square C & for heteroske & city & 0.3520 \\
\hline Durbin Watson & 1.9337 & & \\
\hline Total R-square & 0.7486 & & \\
\hline Test of the Mode & $=<.0001)$ & $6.35^{*}$ & \\
\hline Tests of Structur & Chow Test & $32.25 *$ & Structural Break Point 175 \\
\hline
\end{tabular}

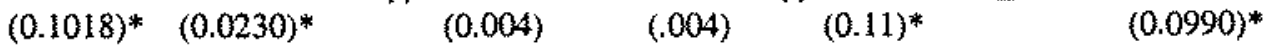

Table 8: Regression Results of DJIA on lagged DJIA, Sentiment, Lagged Sentiment and Buy/Sell Statistics

Table 9 reports regression results for the estimated models on FB and then MER using the S\&P500 and its lag. 


$$
\begin{aligned}
& \text { RETURN }=0.037+0.2827 \text { RETURN }_{t .1}-0.002 S E N T+0.001 S E N T_{t-1}+0.1704 B U Y_{-} S E L L-1.2754 \text { GROUP } \\
& \begin{array}{llllll}
(0.054)^{*} & (0.0238)^{*} & (0.004) & (.004) & (.06)^{*} & (0.09)^{*}
\end{array} \\
& \text { RETURN }=0.27+0.2652 \text { RETURN }_{t, l}-0.0015 S E N T+0.001 S E N T_{t-1}+0.4826 B U Y_{-} S E L L-1.3167 G R O U P \\
& \begin{array}{lllll}
(0.0967)^{*}(0.0233)^{*} & (0.004) & (.004) & (0.10)^{*} & (0.0920)^{*}
\end{array}
\end{aligned}
$$

\begin{tabular}{|c|c|c|}
\hline \multicolumn{3}{|l|}{ FIRST BOSTON } \\
\hline Total R-square Corrected for heteroskedasticity & 0.3144 & \\
\hline Durbin Watson & 1.9061 & \\
\hline Total R-square & 0.7740 & \\
\hline Test of the Model $(\operatorname{Pr}>\mathrm{F}=<.0001)$ & $8.47^{*}$ & \\
\hline Tests of Structural Change Chow Test & $35.37 *$ & Structural Break Point 173 \\
\hline \multicolumn{3}{|l|}{ MERRILLL LNCH } \\
\hline Total R-square Corrected for heteroskedasticity & 0.3280 & \\
\hline Durbin Watson & 1.9051 & \\
\hline Total R-square & 0.7688 & \\
\hline Test of the Model $(\mathrm{Pr}>\mathrm{F}=<.0001)$ & $8.22 *$ & \\
\hline Tests of Structural Change Chow Test & $32.25 *$ & Structural Break Point 175 \\
\hline
\end{tabular}

Table 9: Regression Results of S\&P500 on lagged S\&P500, Sentiment, Lagged Sentiment and Buy/Sell Statistics

Another Specification of the Model: Consumer Sentiment \& Trader Activity as Predictors of the Market Return (S\&PSO0)

Since the DJIA and S\&P500 produce similar results, the analysis using the DJIA can be dropped henceforth. The previous model can provide a reference point to see how much predictive power is lost by removing the lagged $\mathrm{S} \& \mathrm{P} 500$ as a regressor.

The new model to be estimated therefore is:

$$
R E T U R N=\alpha+\beta_{l}(S E N T)+\beta_{2}\left(S E N T_{t \cdot l}\right)+\beta_{3} B U Y_{-} S E L L+\beta_{4} \text { GROUP }+\varepsilon
$$

The variables are defined as previously described but excludes the lagged S\&P500. Table 10 reports regression results for the specification in Equation (10) for the estimated models on FB and then MER. 


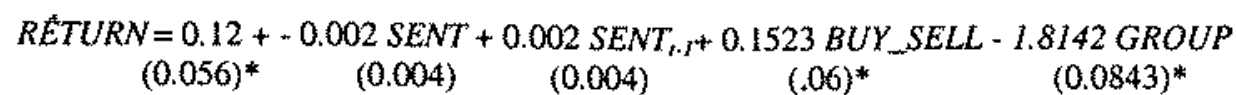

RETURN $=-0.26-0.002$ SENT +0.002 SENT.++0.5374 BUY SELL -1.839 GROUP
$(0.1009)^{*}$
$(0.004)$
(0.004)
$(0.1037)^{*}$
$(0.0833)^{*}$

Table 10 Regression Results of S\&P500 on Sentiment, Lagged Sentiment and Buy/Sell Statistics

FIRST BOSTON

Total R-square Corrected for heteroskedasticity

Durbin Watson

Total R-square

Test of the Model $(\mathrm{Pr}>\mathrm{F}=<.0001)$

Tests of Structural Change

MERRILLLYNCH

Total R-square Corrected for heteroskedasticity

Durbin Watson

Total R-square

Test of the Model ( $\operatorname{Pr}>F=<.0001)$

Tests of Structural Change
Chow Test
0.2442

1.2781

0.2702

23.88*

$44.07 *$

0.2672

1.3247

0.3374

32.84

$28.62 *$
Structural Break Point 178

Structural Break Point 175

\section{Implication of these Results}

From Tables 8 and 9 we can see that the behavioral factors lagged $S \& P 500$, lagged $D J I A$ and the BUY_SELL dummy variables are significant in this multi-factor model. During turmoil times when the GROUP dummy is 1 , return is shown to be significantly negative since it outweighs the coefficient for BUY_SELL. Sentiment is not a significantly priced factor. This is probably reflective of the fact that during the period under consideration in this chapter the Canadian Consumer Sentiment data was aggregated only quarterly. Consequently, much of the daily effects may have been lost by dated information. In an analysis of $r$ squared, it did show some small contribution to the general strength of the regression. Therefore, a further exercise could be to utilize a better measure of consumer sentiment than this quarterly data. This is investigated in the 
subsequent chapter. It is noteworthy that the lagged value of the $S \& P 500$ and the DJIA are significantly priced risk factors, lending support to herding behavior.

It is useful here to test whether the power of the specification is greatly reduced by removing all explanatory factors except for the buy-sell dummy variable. While this specification may be nonsensical since it is presumptuous to believe that the trader activity of two small brokerage houses can significantly affect the return on the market, the spirit of the argument is motivated by a study by Hirshleifer \& Shumway (2003) ${ }^{43}$ This study seeks exogenous factors like the sunshine effect, rain and snow conditions to determine the probability that stock market returns in New York are positive. They determine that the sunshine effect consistently predicts positive daily returns, and investors can improve their Sharpe ratios by trading on morning weather conditions. They conclude that after accounting for transactions costs, the benefit of this information is greatly diminished but "sunshine is just one of the many influences on mood". The implications of this study make reconciliation with fully rational efficient markets difficult and suggest that a traders' reference point (i.e. whether he has experienced wealth losses or not) plays an important role in market returns. Consequently, if it is assumed that investors' buy/sell decisions are exogenous to the daily return of a market index and are one of the priced factors that can successfully be used in "assessing the information processing ability of financial markets" (Roll 1992) ${ }^{44}$, then the above specification is useful. It is noteworthy however that this specification is entirely

\footnotetext{
${ }^{43}$ Hirshleifer, David \& Shumway, Tyler (2003), Good Day Sunshine: Stock Returns and the Weather, The Journal of Finance 58 (3), 1009-1032.

${ }^{44}$ Roll, R. W., 1992, Weather, in Peter Newman, Murray Milgate, and John Eatwell, ed.: The New Palgrave Dictionary of Money and Finance 3, 789-790 (Macmillan Press, London).
} 
different to the original specification in this thesis, which suggests that the buy/sell decisions depend on the state of the market. The resultant estimation gives the following equation and Table 11 reports the results:

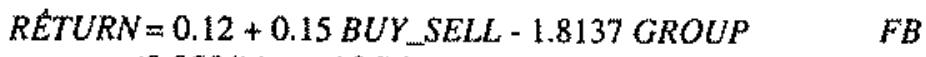

$$
\begin{aligned}
& (0.0554)^{*} \quad(.06)^{*} \quad(0.0842)^{*} \\
& \text { RETURN }=-0.26+0.538 \text { BUY SELL }-1.839 \text { GROUP } \quad \text { MER } \\
& (0.10)^{*}(.10)^{*} \quad(0.0801)^{*}
\end{aligned}
$$

\begin{tabular}{|c|c|c|}
\hline \multicolumn{3}{|l|}{ FIRST BOSTON } \\
\hline Total R-square Corrected for heteroskedasticity & 0.2439 & \\
\hline Durbin Watson & 1.2769 & \\
\hline Total R-square & 0.2439 & \\
\hline Test of the Model $(\mathrm{Pr}>\mathrm{F}=<.0001)$ & $232 *$ & \\
\hline Tests of Structural Change & $59.20^{*}$ & Structural Break Point 178 \\
\hline \multicolumn{3}{|l|}{ MERRILL LYNCH } \\
\hline Total R-square Corrected for heteroskedasticity & 0.2670 & \\
\hline Durbin Watson & 1.3234 & \\
\hline Total R-square & 0.2670 & \\
\hline Test of the Model $(\operatorname{Pr}>F=<.0001)$ & $262^{*}$ & \\
\hline Tests of Structural Change $\quad$ Chow Test & $70.84^{*}$ & Structural Break Point 175 \\
\hline
\end{tabular}

Table 11 Regression Results of S\&P500 on Buy/Sell Statistics

Table 12 reintroduces the DJIA since it was a better contributing factor in the initial logit specification. These results are similar. Apart from the estimations using the lagged return index, the serial correlation problem remains.

$$
\begin{aligned}
& \text { RETTURN }=0.12+0.22 \text { BUY_SELL }-2.2815 \text { GROUP } \quad F B \\
& (0.0560)^{*} \quad(.0651)^{*} \quad(0.0867)^{*} \\
& \text { RETURN }=0.06+0.242 \text { BUY_SELL }-2.2138 \text { GROUP MER } \\
& (0.10)^{*}(.11)^{*} \quad(0.0860)^{*}
\end{aligned}
$$




\section{FIRST BOSTON}

Total R-square Corrected for heteroskedasticity

Durbin Watson

Total R-square

Test of the Model $(\operatorname{Pr}>\mathrm{F}=<.0001)$

Tests of Structural Change

MERRILL LYNCH

Total R-square Corrected for heteroskedasticity

Durbin Watson

Total R-square

Test of the Model $(\mathrm{Pr}>\mathrm{F}=<.0001)$

Tests of Structural Change
Chow Test

Chow Test
0.3248

1.4943

0.3248

$347 *$

81.97* Structural Break Point 173
0.3182

1.4996

0.3182

$336^{*}$

16.76* Structural Break Point 175

Interpreting the Results

The results are consistent with the initial specification presented in this thesis. Even though it is not practical to model the return on a major index as being predicated by the buy/sell activities of two small brokerage houses, the relatively high $r$ squared and the significance of the coefficients show that they are highly correlated. Additionally structural change as measured by the Chow statistic is statistically significant at the point where the turmoil versus non-turmoil break in observations occurred.

While we expect that institutional investors will generally sell when markets are down and buy during up markets since there is an expectation that their mutual fund clients and other investors would require redemptions, the activity does not have to be repeated in the brokers' "own" accounts. Several considerations may play a role here, traders/brokers may buy since they see value or they see potential for arbitrage profits during periods when markets deviated from normal trading patterns according to Merton's (1987) zero arbitrage risk-return relation. Unfortunately the data cannot clarify 
these ambiguities. However, during times of extreme wealth altering conditions these considerations may play less of a role in investor behavior.

There is an ongoing argument regarding market anomalies. One theory suggests that anomalies exist and are currently being exploited as sources of alpha (the constant) in the regression, while some note that anomalies disappear over time. Therefore it is useful to incorporate a multi-factor model to search for factors that compensate investors for risk as suggested by Fama and French (1993).

\section{Limitations and Robustness of this Methodology}

This methodology, while it can not formulate utility functions, places loss aversion as opposed to risk aversion as defined in rational expectations theory, as being prevalent during periods of extreme wealth altering circumstances or "market turmoil". A limitation of this methodology occurs because we are unable to obtain risk preferences or risk aversion directly, which is a necessary component of Prospect Theory. ${ }^{45}$ A detailed survey of the literature showing attempts to measure risk aversion directly in included in Starmer (2000) ${ }^{46}$ Therefore, the assumption that risk aversion or loss aversion is reflected in the buy/sell decision is reasonable.

Since the coefficients in the sample of non-turmoil data as well as the total sample of both market turmoil and non-turmoil data were found to be insignificant (Equations 5

\footnotetext{
${ }^{45}$ Benartzi, Shlomo \& Thaler, Richard H, (1995) Myopic Loss Aversion Myopic Loss Aversion and the Equity Premium Puzzle, The Quarterly Journal of Economics, MIT Press, vol. 110(1), pages 73-92.

${ }^{46}$ Starmer, C, Developments in Non-Expected Utility Theory: The Hunt for a Descriptive Theory of Choice under Risk, Journal of Economic Literature, Vol. XXXVIII (June 2000) pp. 332-382.
} 
and 6), suggesting other variables may be more important, it is necessary to check for robustness of the econometrics and the specification of the model.

\section{Potential Extensions}

Checks of robustness may include tests for heteroskedasticity, with arbitrary within-year correlation (cluster by year) and arbitrary between firm correlation (cluster by brokerage). Another question that can be asked is, can some set of other independent variables that determine buy/sell activity be able to predict the buying or selling (no change) behavior? Subsequently, an expanded version of the full model with additional independent variables can be considered.

Similarly, tests can be conducted as to whether year or brokerage fixed effects in the regressions affect the results. Whether results are sensitive to variations in the cutoff values for small and large trades can also be investigated. The regression can be repeated for each year in the sample, and for various other sub-samples including cut-offs for "market turmoil" definitions.

Special situations that bear further investigation include events that occur when the market increased by specified percentage levels. This is an attempt to formalize Mr. Greenspan's observation of "Irrational Exuberance". There is also a possibility that the changes in positions (i.e. bought or sold) are not accurate since the data only details the change in percentage of the security in the portfolio. Thus, the portfolio as a whole may have gone down in value more than the security in question, or vice versa. An additional test can then be performed on the data under a "binary dependent" variables approach. 


\section{Conclusions}

A logit specification was employed to predict the probability that traders at the Toronto branches of two large multinational brokers would buy securities during periods of wealth reducing periods. This specification was chosen in lieu of OLS because of nonnormality concerns, heteroskedasticity and the constraints that predicted values were constrain between zero and one. Alternative specifications using OLS were also employed to check for robustness of the effect.

Consistent with Thaler \& Johnson's (1990) survey and Shefrin's (2001) anecdotal account, but in contrast to Barberis, Huang and Santos (2001), the probability of traders buying stock after a period of wealth losses as defined by a substantial fall in the returns of a major index increases. From the pcrspective of expected utility theory, behavioral biases should have no explanatory power. However, empirical investigation of the buy/sell actions of institutional traders at the Toronto branches of two large brokerage houses show that the traders seem to be able to withstand significant losses to their portfolios until they reach some threshold of intolerance, or reflection point in the jargon of Prospect Theory. At this threshold point, they reacted differently.

Anccdotal evidence suggests that individual investors evaluate their portfolio performance at the end of every quarter and react or make changes to the portfolio, after reviewing its efficacy. The performance of professional traders is also evaluated against some benchmark at the end of every quarter. This study seeks answers from a more frequent assessment period, daily evaluation of a trader's portfolio. Evidence supporting different behavior under market turmoil conditions was found especially with returns based on the DJIA and to a lesser extent the S\&P500. A strong relationship between 
these market indices and traders' purchases, sales and no change in their market making and proprietary accounts was found. If trader behavior can be connected to consumer behavior and assuming traders make changes to their portfolios based on these characteristics, then it would be feasible to investigate aggregate behavior at an economy wide level. A definitive characterization of trader behavior and the applicability for generalization remains a meaningful challenge for future research. 


\section{Chapter IV - EFFECT OF SENTIMENT IN THE CONTEXT OF PROSPECT THEORY Introduction}

De Long, Shleifer, Summers and Waldmann (1990) devised a model which incorporated irrational traders with erroneous stochastic beliefs to explain the equity premium puzzle. Unfortunately however researchers have been unable to precisely obtain empirical evidence of a sentiment factor that reflects fluctuations in the opinions of these traders regarding the future prospects for the stock market. If sentiment could be measured directly, the model could be tested and implications could be devised.

By constructing a sentiment index Baker and Wurgler (2003) find that large highly profitable firms, with large dividend payouts earn lower subsequent returns once sentiment starts falling. This suggests sentiment is a lagged predictor. This chapter's motivation is to determine how consumer sentiment and investor propensity to buy/sell together interact with market conditions to give rise to behavior that is observed.

\section{Research Hypothesis and Methodology}

To the extent that consumer sentiment is an indicator of investors' risk taking behavior, in this section, consumer sentiment is used to test the hypothesis that risk aversion (or risk preferences) is affected by stock market returns as is implied by the assumptions of Prospect Theory. A further exercise may incorporate a discussion as to whether consumer sentiment predicates Investor Confidence as is suggested in the previous Chapter. However, in as much as the average consumer today invests in the markets both directly and indirectly, it is a fair assumption. In the spirit of the previous 
section, the empirical work is first performed on US data and then extended to the Canadian case.

The US case is reflected in data from the Dow Jones Industrial Average (DJIA) as an index that draws the most attention among investors and the financial press, and the University of Michigan's Index of Consumer Sentiment Index (CSI). Another widely followed survey which measures how consumers feel about the upcoming six months and their plans to make purchases (or not) is the Conference Boards' Consumer Confidence Index (CCI). While both indices measure consumer-spending expectations, the $\mathrm{CCI}$ is more heavily weighted towards business. Both surveys try to measure consumer spending and saving behavior. The Consumer Confidence Index comes from a nationwide sample of 5,000 households, $60 \%$ based on future expectations and 40 percent on current conditions. The University of Michigan's Index of Consumer Sentiment covers three broad areas: personal finances, business conditions and buying conditions. The university surveys at least 500 households each month and asks about 50 core questions. Households are included that represent all U.S. households, except Alaska and Hawaii. The University of Michigan's Expectations Index is included in the Conference Board's U.S. Leading Economic Indicator Index, formerly compiled by the U.S. Department of Commerce. Each month Michigan releases a preliminary index on the second Friday and a final index on the fourth Friday.

On May 1 2002, Standard and Poor agreed to take over management of the Toronto Stock Exchange 300 Composite Index and renamed it the S\&PTSX. Previously it was known as the TSX. The Canadian return data is measured by this index. Since May 2002, the index is reviewed quarterly and companies that do not meet the criteria for 
size and liquidity are dropped from the index and replaced ones that do. However, the S\&P/TSX does not make up the universe of a typical Canadian investor's holdings. Registered retirement savings plans (similar to $401 \mathrm{ks}$ ) are permitted to contain $30 \%$ of foreign ownership. In fact as of February 2005, Canadian pension plan investors no longer have these constraints. Part of the reason for this as suggested in Chapter III is because of the nature of the Toronto Stock Exchange and its heavy weighting in sectors which exhibit negative correlation to the global stock market principally mining and oil and gas industries. Data on the Canadian Consumer Confidence ${ }^{1}$ Index are used to represent Canadian economic agents" mood or sentiment. This data is published quarterly since 1978 , and monthly since September 2001 by the Conference Board of Canada. An index, which uses the same methodology and is analogous to the University of Michigan's Consumer Sentiment Index, is the Decima-Investor's Group Index of Canadian Consumer Confidence. However, this has only been collected quarterly since September 2001. Since a relationship between consumer's sentiment and stock market retums has not been tested for Canadian data this section contributes to the literature, especially in light of a possible correlation in the returns for industrialized countries.

To test the assumption (from Barberis, Huang, and Santos (2001) and Falato (2003)) that consumer sentiment is affected by the stock market, the following linear

\footnotetext{
'The Index of Consumer Confidence, the Conference Board's survey of Canadian households has been ongoing since 1960. It measures consumers' levels of optimism regarding current economic conditions. This is a crucial indicator of near-term sales for companies in the consumer product sector. It is constructed from responses to four attitudinal questions posed to a random sample of Canadian households. Those surveyed are asked to give their views about their households' current and expected financial positions and the short-term employment outlook. They are also asked to assess whether the present time was a "good" or a "bad" time to make a major purchase such as a house, car or other bit-ticket items.

Source: http:/www.conference-board.org/economics/methodology.cfm.
} 
relationship between the percentage change in the sentiment index and the stock market return may be estimated:

$\Delta \ln M C S I_{t}=\beta_{0}+\beta_{l} \Delta \ln S_{t o c k_{t}}+\beta_{2} \Delta \ln \operatorname{Stock}_{t-1}+\beta_{3} \Delta \ln M C S I_{t-1}+\varepsilon_{t}$

\section{Variables Defined}

MCSl is the Michigan index of consumer sentiment,

Stock is the Dow Jones Industrials Average stock market index

$\beta_{0}$ is a constant, $\beta_{l}, \beta_{2}, \beta_{3}$ are coefficients to be estimated, and $\varepsilon$ is a random error.

The case for the American variables is eventually extended for the Canadian variables as defined below.

TSX is the S\&P/TSX Composite Index, formerly known as the TSE 300

$C C I$ is the Canadian Index of Consumer

Equation (1), similar to the one estimated by Otto $(1999)^{2}$, assumes that the relationship between stock market returns and consumer sentiment is constant overtime. Intuitively, one would expect large swings in market returns to have a greater impact on consumer sentiment since they imply more significant changes in consumer wealth. Therefore, the coefficients in Equation (1) would be expected to be different depending on the magnitude of the change in stock market returns (Chapter III investigated the effect of the direction of change).

Regime switching models provide a systematic approach to test for multiple breaks and regime shifts in the data generating process. Regime shifts in the literature are considered to be governed by exogenous stochastic processes rather than singular,

\footnotetext{
${ }^{2}$ Otto (1999) uses the Wilshire 5000 index and estimates equation 1 from June 1980 to June 1999 . She finds the coefficients on the stock index and its lagged value to be $0.33(0.09)$ and $0.19(0.08)$ respectively with an $R^{2}=0: 11$ and $S: E=4.3$. In our equation, we also include the lagged value of the sentiment index variable in order to account for potential autoregressive behavior in $\triangle$ in $M C S I_{t}$.
} 
deterministic ones. A Markov chain hypothesizes that information from the distant past is irrelevant given knowledge of the recent past. In Markov switching models it is important to secure long data samples so that the time-variability of the parameters could be properly identified.

Hanson (1996) proposed a formal test of Markov switching models against the linear alternative of no-switching, or no structural change. This method, which produces valid inferences, evaluates the $\log$-likelihood function for a grid of different values for the regression coefficients, standard deviation and the transitional probabilities.

The threshold effect is tested against a null hypothesis of linearity in Equation 1. Hansen's Lagrange Multiplier (LM) test is used to test for heteroskedasticity if it is suspected and is robust in its presence. The LM threshold test tells if the null hypothesis of no threshold can be rejected, but it does not tell which variable is the threshold. Hansen (2000) suggests computing $p$ values using a bootstrap by fixing all the regressors individually and generating a bootstrap dependent variable from the normally distributed OLS residuals. After 1000 replications, a low p-value suggests a significant threshold variable, and a high one, an insignificant variable. It is performed by regressing the squared residuals against all the independent variables. The null hypothesis of no heteroskedasticity $\gamma_{1}=\gamma_{2}=0$ and the LM statistic converges to a chi-square. If the threshold is known the standard $F$-test could be used, otherwise the bootstrap procedure should be used.

In order to allow for consumer sentiment to react differently to the stock market depending on the level of returns, the relationship between the variables is modeled using the following threshold specification, which draws heavily on Hansen's (2002) model: 
$\Delta \ln M C S I_{t}=\beta_{0 I}+\beta_{I I} \Delta \ln S t o c k_{t}+\beta_{2 I} \Delta \ln S t o c k_{t \cdot l}+\beta_{3 I} \Delta \ln M C S I_{t \cdot I}+\varepsilon_{\mathrm{t}}$ for $q_{t} \leq \gamma(2)$

$\Delta \ln M C S I_{t}=\beta_{02}+\beta_{12} \Delta \ln S t o c k_{t}+\beta_{22} \Delta \ln S t o c k_{t-1}+\beta_{32} \Delta \ln M C S I_{t-1}+\varepsilon_{t}$ for $q_{t}>\gamma$ (3)

The threshold variable $q_{t}$ is an endogenous variable that will be determined on the basis of $\Delta \ln S t o c k_{t}$. Therefore, it is deducted from the data. According to this model, if the return on the stock market index increases above a certain level $\gamma$, the relationship between sentiment and the stock market is described by the coefficients in equation (3). For example, the coefficient $\beta_{l l}$ describes the contemporaneous relationship between sentiment and stock returns when returns are below the threshold level, $\gamma$, whereas the coefficient $\beta_{12}$ is relevant when returns are above $\gamma$. The model in (2) and (3) can be written more compactly in one equation as follows:

$\Delta \ln M C S I_{t}=\underline{B}_{0}+\underline{B}_{1} \Delta \ln S t o c k_{t}+\underline{B}_{2} \Delta \ln S t o c k_{\mathrm{s} \cdot 1}+\underline{\beta}_{3} \Delta \ln M C S I_{\mathrm{t} \cdot \mathrm{I}}+\varepsilon_{\mathrm{t}}$

Where:

$\underline{\beta}_{0}=\beta_{0 I} l\left(q_{t}\right)+\beta_{02}\left(1-l\left(q_{t}\right)\right)$

$\beta_{L}=\beta_{11} I\left(q_{\mathrm{s}}\right)+\beta_{I 2}\left(1-I\left(q_{1}\right)\right)$

$\underline{\beta}_{2}=\beta_{21} I\left(q_{t}\right)+\beta_{22}\left(1-I\left(q_{t}\right)\right)$

$\beta_{3}=\beta_{31} l\left(q_{t}\right)+\beta_{32}\left(1-l\left(q_{t}\right)\right)$

The indicator function is $l\left(q_{t}\right)=1$ when the threshold variable $q_{s} \leq \gamma$ and is equal to zero otherwise. Equation (4) can be thought of as a restricted version of Equation (1). Since it is not known a priori whether the threshold model is a good description of the data, it is possible to test the hypothesis that sentiment reacts differently to the stock market during unusual periods by testing whether the unrestricted model in (4) is significantly better than the linear model (1) using the Likelihood Ratio statistic developed in Hansen (1996). Note: One major difference between this model and the one 
in the previous chapter is that here the threshold (or turmoil) value of market returns is determined by the data whereas it is set a priori in the analysis for Chapter III. Therefore, while the hypothesis here is that when market returns reach a certain level, consumer sentiment/mood will be affected more than at other times, it is not assumed to be known beforehand but instead, the data reflects this information. This feature of the model is an important characteristic and is part of the motivation for this analysis.

To estimate the model, it is necessary to find the optimal value for the threshold variable $q_{t}$ along with estimating the rest of the parameters in the model. The distribution theory relevant for constructing confidence intervals for the threshold parameter and testing the validity of the threshold specification versus the linear model are all developed in Hansen $(1996,1999$, and 2000). The basic steps are:

1) Estimate equation (2) and compute the residual sum of squares (RSS) for various levels of $q_{t}$ ranging from $\gamma_{\mathrm{L}}$ to $\gamma_{\mathrm{H}}$. Following Hansen (2000), the lower and upper bounds for $q_{t}, \gamma_{\mathrm{L}}$ and $\gamma_{\mathrm{H}}$, are set such that the highest and lowest $15 \%$ of the observations are excluded from the search space for the threshold variable. The threshold estimate is the one that minimizes the sequence of RSS.

2) Compute the following likelihood ratio test of the hypothesis that the coefficients are the same in the restricted and unrestricted models using the following likelihood ratio:

$L R_{0}=\left(S_{0}-S_{1}\right) / \hat{\sigma}^{2}$

Here $S_{0}$ and $S_{1}$ are the RSS under the following $\mathrm{H}_{0}$ and $\mathrm{H}_{1}$ respectively:

$\mathrm{H}_{0}: \beta_{01}=\beta_{02} ; \beta_{1 I}=\beta_{12} ; \beta_{2 I}=\beta_{22} ; \beta_{31}=\beta_{32}$ and $\hat{\sigma}^{2}$ is the residual variance under $\mathrm{H}_{5}$. 
3) Since the distribution of this LR statistic is non-standard, it is necessary to bootstrap ${ }^{3}$ the critical values as described in Hansen (1999).

4) Assuming the hypothesis $\mathrm{H}_{0}$ can be rejected, supporting the existence of a threshold effect, the best estimate of $q_{t}$ is chosen as the value that minimizes the LR computed as a function of the threshold value.

Sample \& Data

Unfortunately, the Canadian data is not as extensive as the US equivalents. However, the indices show a $53 \%$ correlation with the quarterly data from 1978 to the present and a $42 \%$ correlation with the monthly data since 2001 . The Decima-Investor's Group gives an $88 \%$ correlation with the 14 data points that overlap with the quarterly University of Michigan's data. Again, meaningful considerations cannot be made with this few data points. In as much as quarterly data may lose its explanatory potential since it will not capture the spontaneous responses, the study focuses on monthly data in both the US and Canadian cases. The Appendix to this chapter shows summary statistics for the percentage change in monthly consumer sentiment and the return of the market.

These variables under investigation follow a stochastic process where all the values are drawn from a discrete set. A Markov chain hypothesizes that information from the distant past is irrelevant given knowledge of the recent past. In a first-order Markov process only the most recent draw affects the distribution of the next one; all such processes can be represented by a Markov transition density matrix. A special

\footnotetext{
${ }^{3}$ In statistics, bootstrapping is a method for estimating the sampling distribution of an estimator by resampling with replacement from the original sample.
} 
complex statistical case of Markov switching models useful as a parsimonious strategy for nonparametric function estimation is a threshold model. Bruce Hansen generously provided his Gauss Procedures to estimate and test this threshold model.

\section{Empirical Applications}

Part I: US data

The analysis began by estimating a simple Ordinary Least Squares regression (OLS) of the relationship in equation (1) in order to establish benchmark results comparable to the previous literature. Using monthly data on the Michigan index of Consumer sentiment and the Dow Jones Industrials Average for the period January 1978 to December 2004, the following equation is estimated:

$$
\Delta \ln M C S I_{t}=\begin{array}{lll}
-0.351 \\
(0.25)
\end{array}+\begin{array}{ll}
0.193 \Delta \ln S t o c k_{t}+0.284 \Delta \ln S t o c k_{t-1}-0.065 \Delta \ln M C S I_{t \cdot I} \\
(0.054)^{*}
\end{array}
$$

$R^{2}=0.1099 ;$ S.E $=4.35$

In the presence of heteroskedasticity, correlation coefficients are biased so heteroskedasticity corrected standard errors are shown in parentheses. The coefficients on the stock index variables are both highly significant (at a $1 \%$ level of significance) indicating a strong positive relationship between consumer sentiment and stock returns. A positive correlation is consistent with the assumption of Prospect Theory that positive changes in wealth improve investors' mood or sentiment. Although the equations are estimated over different sample periods and use a different variable for the stock index, the coefficient estimates shown above are very close to those found in Otto (1999). This 
suggests that the relationship between the stock market and consumer sentiment has been relatively stable and is not highly dependent on the choice of data used for estimation.

In order to test for the existence of a threshold effect, it is necessary to test the null hypothesis that the coefficients in equations (2) and (3) are equal. That is the following hypothesis was tested:

$$
\mathrm{H}_{0:} \beta_{0 I}=\beta_{02} ; \beta_{1 I}=\beta_{12} ; \beta_{2 I}=\beta_{22} ; \beta_{31}=\beta_{32}
$$

Since the threshold level $\gamma$ is not identified under the null hypothesis, standard tests are not applicable. Hansen (1996) suggests using the likelihood ratio statistic in equation (6) which has a nonstandard asymptotic distribution. Hansen (2000) develops asymptotic methods to construct confidence intervals for the least squares estimate of the threshold parameter. Hansen (1996) shows that the bootstrap $p$-values are asymptotically valid when the number of replications in the bootstrap procedure is large. The basic steps for computing the bootstrap $p$-values shown in Table I are as follows:

- Estimate the model under the null hypothesis (equation 1) with least squares and obtain the residuals $(\hat{\varepsilon})$ and sum of squared residuals. Given the estimated threshold parameter (obtained by minimizing the RSS over a range of threshold values), compute the LR statistic in equation (6).

- Randomly selecting from the distribution $\mathrm{N}(0, \hat{\varepsilon})$, and fixing the regressors in equation (1), create a bootstrap sample of size $\mathrm{n}$ for the dependent variable using equation (1). Using this bootstrap sample, estimate the model under the null (equation 1) and the alternative (equation 4) and calculate the bootstrap values of LR (equation 6). 
- Repeat this procedure 1000 times and calculate the percentage of draws where the simulated LR exceeds its actual value (found in step 1). This is the asymptotic pvalue for LR under the null of no threshold. The null of no threshold is rejected if this value is smaller than the desired critical value.

Table 1: Estimation Results of the Threshold Effect on Monthly US Data

\begin{tabular}{lll}
\hline Threshold Variable & Stock Index & Lagged Stock Index \\
\hline Threshold Estimate & -0.44671055 & 1.0938499 \\
Lagrange-Multiplier & & \\
Test of No Threshold & $6.845881^{*}$ & $17.919628^{*}$ \\
Bootstrap P-Value & 0.694 & $0.003^{*}$ \\
& \\
\hline
\end{tabular}

As can be been seen in Table 4-1, the null hypothesis of no threshold can be rejected at the $1 \%$ significance level when the threshold variable is the lagged stock market index return but the bootstrap pwvalue is not significant for the threshold variable stock market index return. This means that when the previous month's stock market returns reach a certain threshold value, consumer sentiment reacts differently to the stock market variables. Table 4-2 shows the full estimation results from the threshold model.

The threshold value, $\gamma$, is estimated to be 1.09 . The $95 \%$ confidence interval is $[0.888128,1.858924]$. The confidence region shows that the threshold estimate is not significantly different from a large of other potential threshold levels, which implies that the threshold value is estimated with reasonable certainty. The confidence region is obtained by finding the set of values of $\gamma$ for which the likelihood ratio lies below the asymptotic critical values for $L R(\gamma)$ that are Tabulated in Hansen (2000). 
Table 2: Full Estimation Results of the Threshold Effect in Both Regimes on Monthly US Data

Threshold Variable

Threshold Estimate

PCSTOCKL

95\% Confidence Interval:

1.0938499

Sum of Squared Errors

$[0.888128,1.858924]$

Residual Variance

5895.3520

Joint R-Squared

18.775006

0.15945333

Heteroskedasticity Test (p-value)

0.94636834

Parameter Estimates for Regime 1: PCSTOCKL $\leq 1.093849$

\begin{tabular}{lll} 
Variable & Estimate & Standard Error \\
\hline & & \\
Constant & -0.75142500 & 0.43418522 \\
PCSTOCK & 0.18085839 & $0.065785365^{*}$ \\
PCSTOCKL & 0.29371237 & $0.081114404^{*}$ \\
PCCSENTL & -0.19481092 & $0.079617479^{*}$
\end{tabular}

Number of Observations $\quad 165$

Degrees of Freedom $\quad 161$

Sum of Squared Errors $\quad 3110.476$

Residual Variance $\quad 19.31973$

R-Squared 0.114653

Parameter Estimates for Regime 2: PCSTOCKL > 1.093849

\begin{tabular}{llc} 
Variable & Estimate & Standard Error \\
\hline & & \\
Constant & 1.5939085 & 0.59570868 \\
PCSTOCK & 0.22074039 & $0.086336756 *$ \\
PCSTOCKL & -0.10431936 & 0.13014208 \\
PCCSENTL & 0.131844444 & 0.076979080 \\
\hline
\end{tabular}

Number of Observations $\quad 157$

Degrees of Freedom $\quad 153$

Sum of Squared Errors $\quad 2784.876$

Residual Variance $\quad 18.20183$

R-Squared $\quad 0.050807$

Notes:

PCSTOCK is defined as $\Delta \ln$ Stock

PCSTOCKL is defined as $\Delta$ in Stock.

PCCSENTL is defined as $\triangle \ln M C S I_{\text {s.l }}$

* and ** denote $1 \%$ and $5 \%$ significance levels, respectively 


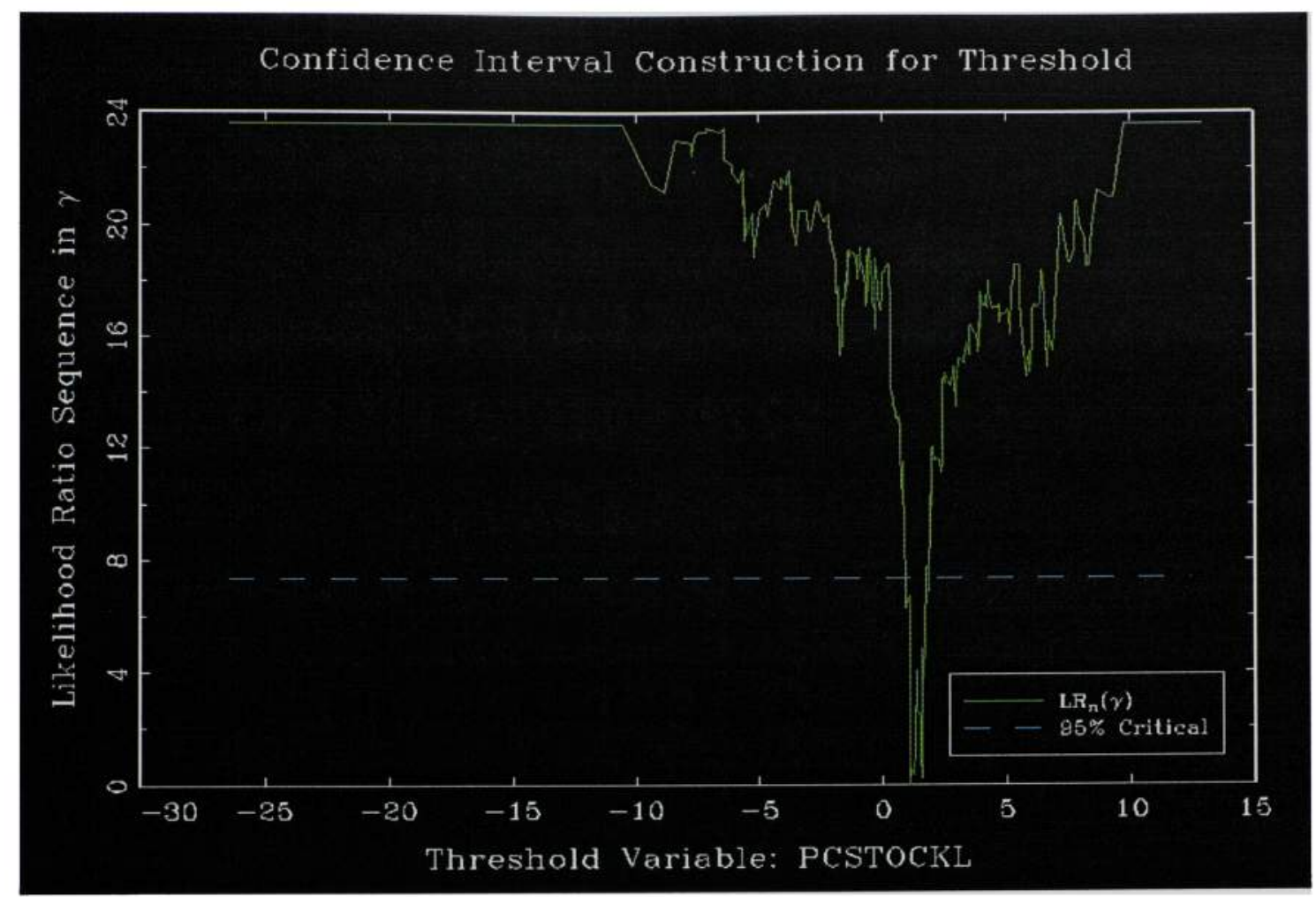

Figure 1 shows a graph of the LR statistic as a function of the threshold variable, $\gamma$, the lagged stock market index. The least squares estimate of $\gamma$ is 1.09 , the value that minimizes the graph ${ }^{4}$. While the asymptotic distribution is non-normal, it is free from nuisance parameters and it is closed form so $p$-values can be generated as in Hanson (2000). The broken line plots the $95 \%$ critical value of 7.35 , which is obtained from Table 2 of Hansen (2000). The graph shows that the LR crosses the dotted line at the values 0.88 and 1.86 , which gives us the asymptotic $95 \%$ confidence interval of the estimated value of $\gamma$. As can be seen in the graph, the interval is relatively tight by comparison with those obtained in the growth equation application that is discussed in

\footnotetext{
${ }^{4}$ Hansen (2000) notes that one may equivalently plot the residual sum of squared errors $\mathrm{S}(\gamma)$ against $\gamma$. In that case, the dotted line is drawn at $\mathrm{S}(\gamma)+\mathrm{c} \hat{\sigma}^{2}$, where $\mathrm{c}$ is 7.35 for the $95 \%$ interval.
} 
Hansen (2000). According to this estimate, when stock market retums reach a level of $1.09 \%$ per month, the relationship between consumer sentiment and stock market retums changes from regime 1 to regime 2 where the coefficient on the contemporaneous correlation between sentiment and retums (PCSTOCK) changes from 0.18 to 0.22 . Given that over our sample period, the mean and median monthly change in the stock market index are $0.81 \%$ and $0.94 \%$, respectively, these results are consistent with the idea that individuals sentiment or feelings about the state of tbe economy are affected by the stock market during times when stock market retums are higber than average ${ }^{5}$. Consistent with the result that the linear model was rejected in favor of the threshold specification, it can be seen that the threshold model joint R-squared of $16 \%$ (Table 4-2) is higher than that found for equation $1(11 \%)$. Note that the coefficient estimates for regime 1 (lowvolatility regime) are very similar to those obtained from the linear model with the exception of the lagged sentiment variable, which became significant in the threshold model. It is interesting that in regime 2 , when tbe stock market return is above its threshold value (high volatility); the only variable that remains significant is the current stock market retums variable (which is also why the $R$-squared is low in regime $2,5 \%$ ). The fact that the recent history of the sentiment index variable, as captured by the lagged sentiment variable, $\triangle \ln M C S I_{t-1}$, loses its predictive power in regime 2 indicates that other variables that are not reflected in our equation become more important to current sentiment during times of unusually high changes in stock market retums. Developing a

\footnotetext{
"Note that in our sample period monthly market returns are highly variable with a standard deviation of 4.47. The result that the threshold variable is not much higher than the average monthly return suggests that consumers discount outlier values.
} 
model that incorporates additional explanatory variables is an interesting subject for future research as will be discussed in the next section.

Given that, the dependent variable in equation (7) is highly variable and to improve the fit of the model, the study attempted to capture more dynamics in the data by including an additional lag of the stock variables in the equation ${ }^{6}$. The full threshold model results for this extension are shown in Table 4-3.

As can be seen in Table 4-3, the results from this estimation are virtually the same as those obtained in Table 4-2, with a slightly better fit due to the additional explanatory power of the stock market variable in $t-2$. The joint $r$-squared increased from 16 to $18 \%$ but the threshold level of 1.09 and the associated $95 \%$ confidence level of $[0.88,1.8]$ remain unchanged. In empirical work, it is rare to get a much higher fit as measured by $r$ squared. This indicates that the results are not very sensitive to the number of lags that are included in the model. Again here the coefficient on the current stock variable is positive and significant in both regimes but is higher in regime $2(0.18$ in regime 1 and 0.23 in regime 2). Note however, that the other coefficients in this case behave slightly differently when the two regimes are compared. Specifically, the twice-lagged stock variable and the lagged sentiment variable remain significant at the $5 \%$ level in regime 2 . This may indicate that the additional lags have captured some of the omitted variables effect that was exhibited in Table 4-2. Potential future research to deal with these and other modeling issues are discussed in later sections.

\footnotetext{
${ }^{6} \mathrm{~A}$ version of the model with additional lags of the dependent variable was also estimated but these were not found to be significant.
} 
Table 3: Full Estimation Results of the Threshold Effect in Both Regimes with a second lag of the Stock Index

Threshold Variable

Threshold Estimate

95\% Confidence Interval:

Sum of Squared Errors

Residual Variance

Joint R-Squared

Heteroskedasticity Test (p-value)

\section{PCSTOCKL}

1.0938499

$[0.888128,1.858924]$

5702.0957

18.334713

0.18160977

0.70895534

Parameter Estimates for Regime 1: PCSTOCKL $\leq 1.093849$

\begin{tabular}{lll} 
Variable & Estimate & Standard Error \\
\hline & & \\
Constant & -1.0486017 & 0.45850716 \\
PCSTOCK & 0.17922154 & $0.066506694^{*}$ \\
PCSTOCKL & 0.25476950 & $0.078477151^{*}$ \\
PCSTOCKL2 & 0.19521815 & 0.11402066 \\
PCCSENTL & 0.23606049 & $0.074950741^{*}$ \\
\hline & & \\
Number of Observations & 164 & \\
Degrees of Freedom & 159 & \\
Sum of Squared Errors & 2972.6833 & \\
Residual Variance & 18.696121 & \\
R-Squared & 0.14648825 & \\
\hline
\end{tabular}

Parameter Estimates for Regime 2: PCSTOCKL > 1.093849

\begin{tabular}{lll} 
Variable & Estimate & Standard Error \\
\hline & & \\
Constant & 1.3854162 & 0.59863352 \\
PCSTOCK & 0.23784354 & $0.085009188^{*}$ \\
PCSTOCKL & 0.069031825 & 0.13074396 \\
PCSTOCKL2 & 0.13912996 & $0.063026296^{* *}$ \\
PCCSENTL & 0.09326651 & $0.077100459^{* *}$ \\
\hline
\end{tabular}

Number of Observations $\quad 157$

Degrees of Freedom $\quad 152$

Sum of Squared Errors $\quad 2729.4124$

Residual Variance $\quad 17.95660$

R-Squared $\quad 0.069711405$

Notes:

PCSTOCK is defined as $\Delta \ln S t o c k_{t}$

PCSTOCKL is defined as $\Delta$ in Stock $_{\text {r- }}$

PCSTOCKL2 is defined as $\Delta \ln S t o c k_{t-2}$

PCCSENTL is defined as $\triangle \ln M C S l_{t-1}$

${ }^{*}$ and ${ }^{* *}$ denote $1 \%$ and $5 \%$ significance levels, respectively 


\section{Part 1l: Canadian data-monthly}

Similar to the U.S. data, the analysis began by estimating a simple Ordinary Least Squares regression (OLS) of the relationship between sentiment and retums. Using monthly data on the Canadian Consumer Sentiment Index (CCl) and the Toronto Stock Exchange index (TSX) for the period from September 2001 to December 2004, the following equation is estimated:
$\Delta \ln C C I_{t}=\quad 0.184+0.081 \Delta \ln T S X_{t}+0.078 \Delta \ln T S X_{t-1}$
(0.399) $(0.100)$
$(0.096)$

$R^{2}=0.035 ; \mathrm{S} . \mathrm{E}=2.78$

Heteroskedasticity corrected standard errors are shown in parentheses. The insignificant coefficient estimates and low $R$-squared in equation (8) suggest that there is no relationship between the stock market index and sentiment in Canada. The linear model estimated above shows that the stock market does not help predict consumer sentiment. The possibility that the relationship between sentiment and returns undergoes regime shifts and thus is not well described by a linear model such as in equation (8) was considered. Following the methodology outlined in the previous section, the study tested for the existence of a threshold using the stock market variable and its lagged value as potential threshold variables. The results are shown in Table 4-4:

Table 4: Eslimation Resulls of the Threshold Effect on Monthly Canadian Data

\begin{tabular}{|c|c|c|}
\hline Threshold Variable & Stock Index (TSX) & Lagged Stock Index (TSX) \\
\hline $\begin{array}{l}\text { Threshold Estimale } \\
\text { Lagrange-Multiplier }\end{array}$ & -0.0953 & -0.60547 \\
\hline Test of No Threshold & 8.069442 & 9.597595 \\
\hline Bootstrap P-Value & 0.099 & 0.024 \\
\hline
\end{tabular}


Table 4-4 shows that the null hypothesis of no threshold when the threshold variable is the lagged stock market index return can be rejected at the $5 \%$ significance level. However it can only marginally be rejected at the $10 \%$ level bootstrap for the threshold variable stock market index retun. This result, which is similar to what was found for the U.S. data, implies that the relationship between sentiment and returns is not linear and that it changes depending on the level of stock market retums. Table 4-5 shows the full estimation results from the threshold model.

The threshold value, $\gamma$, is estimated to be $-0.605 \%$ with a $95 \%$ confidence interval of: $[-0.60546,-0.09530$.$] The confidence region shows slightly more uncertainty$ about the value of the threshold as compared to the results obtained for the US monthly data. 
Table 5: Full Estimation Results of the Threshold Effect in Both Regimes on Canadian Monthly Data

Threshold Variable

Threshold Estimate

PCSTOCKL

95\% Confidence Interval:

$-0.60546921$

Sum of Squared Errors

$[0.60546,-0.09530]$

Residua! Variance

261.87109

Joint R-Sq̨uared

6.5467772

Heteroskedasticity Test (p-value)

0.24336425

0.22727185

Parameter Estimates for Regime 1: PCSTOCKL $\leq-0.60546$

Variable

Estimate

Standard Error

Constant

$-1.7013226$

0.92753969

PCSTOCK

0.41081134

$0.13252473^{* *}$

PCSTOCKL

$-0.24355180$

0.15575428

Number of Observations

17

Degrees of Freedom

14

Sum of Squared Errors

123.89396

Residual Variance

8.8495685

R-Squared

Parameter Estimates for Regime 2: PCSTOCKL > -0.60546

\begin{tabular}{lll} 
Variable & Estimate & Standard Error \\
\hline & & \\
Constant & 1.3360669 & $0.52218041^{* *}$ \\
PCSTOCK & -0.11905985 & 0.084838141 \\
PCSTOCKL & -0.15580132 & 0.18382528
\end{tabular}

Number of Observations

29

Degrees of Freedom

26

Sum of Squared Errors

137.97713

Residual Variance

R-Squared 0.063350834

Notes:

PCSTOCK is defined as $\triangle \ln T S X t_{i}$ PCSTOCKL is defined as $\triangle \ln T S X t_{t \cdot 1}$

PCCSENTL is defined as $\triangle \mathrm{in} C C I_{t-1}$

${ }^{*}$ and ${ }^{* *}$ denote $1 \%$ and $5 \%$ significance levels, respectively 


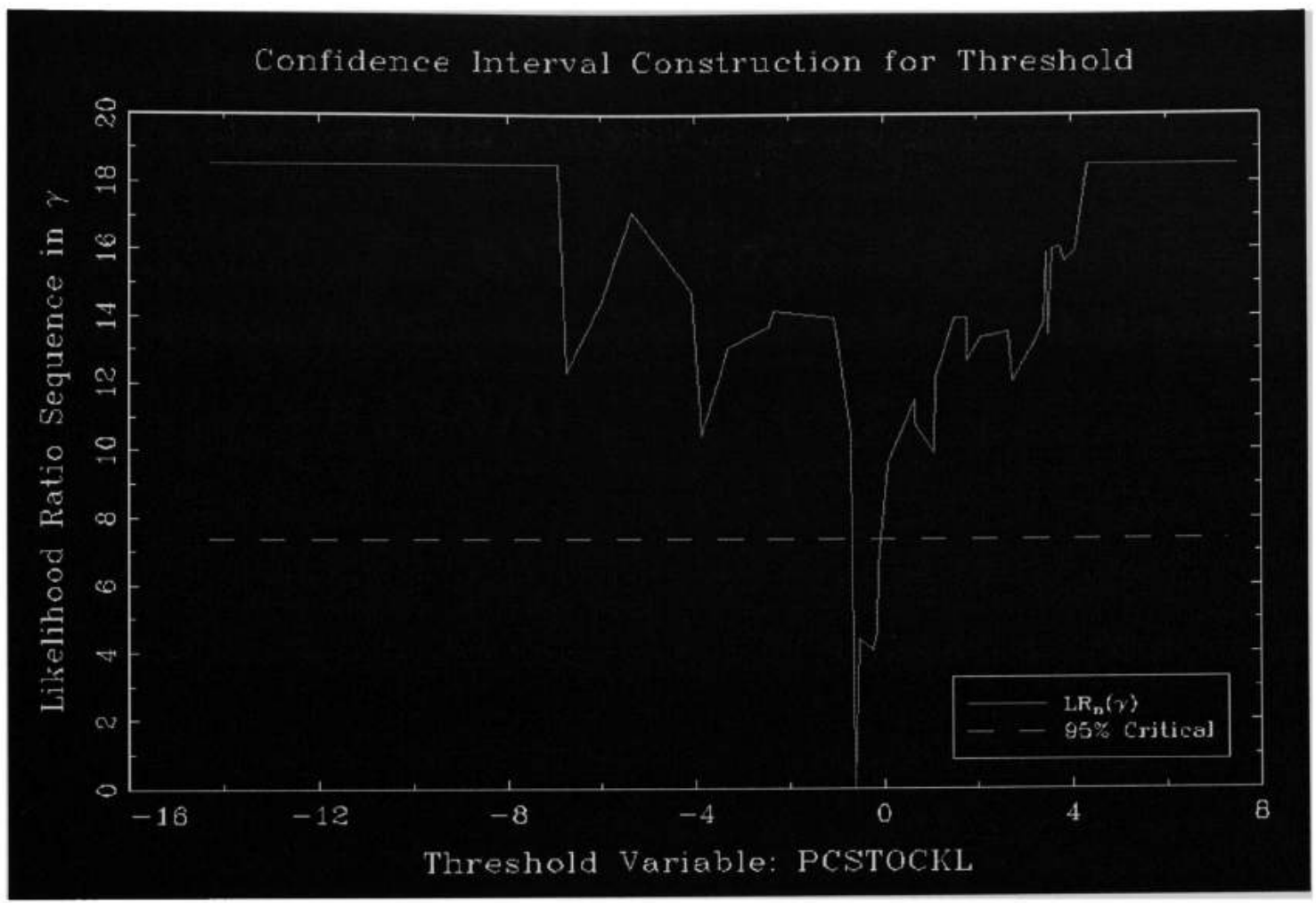

Figure 2 shows a graph of the LR statistic as a function of the threshold variable, $\gamma$, the lagged stock market index. It can be seen from the graph that the estimated threshold value occurs at the lower bound of the 95\% confidence region (the region where the LR is below the dotted line). Comparing the coefficients from the two regimes, it can be seen that the stock market variable is positive and highly significant in regime 1 , when then the lagged stock market index is below its threshold value of $0.60 \%$, a value greater than the mean value of $-0.01 \%$ (see Appendix A). A positive and significant coefficient on the stock market variable is consistent with the assumption of Prospect Theory that higher returns are associated with better consumer sentiment. The predictive power of the stock market variable is also reflected in the dramatically higher 
$r$-squared in Regime 1 and in the joint $r$-squared for the overall threshold model, ( $r$ squared is $24 \%$ as compared to $0.034 \%$ for the linear model). The results in this section highlight the importance of modeling the relationship between sentiment and returns in a regime-shifting framework since our conclusions regarding the results would be completely reversed had the study relied solely on the linear (OLS) model.

\section{Part III: Canadian data-Quarterly}

In order to examine the relationship between sentiment and returns in Canada over a longer time span, our model is estimated using quarterly data on the $\mathrm{CCI}$ and the TSX that covers the period from the first quarter in 1978 to the fourth quarter of 2004. The OLS estimates are as follows:

$$
\begin{aligned}
& \Delta \ln C C I_{t}=-0.79+0.16 \Delta \ln T S X_{t}+0.27 \Delta \ln T S X_{t-1}-0.19 \Delta \ln C C I_{t-1} \\
& \begin{array}{lll}
(0.579)(0.063)^{*} & (0.072)^{*} \quad(0.100)^{* *}
\end{array}
\end{aligned}
$$

$\mathrm{R}^{2}=0.179 ; \mathrm{S} \cdot \mathrm{E}=6.16$

Equation (9) shows that the coefficients on the stock market variable are positive and significant consistent with the assumption from Prospect Theory that better returns are associated with improved investor mood. The model has relatively good fit with an $r$ squared of approximately $18 \%^{7}$. Another version of equation (9) with the DJIA as the stock market variable instead of S\&P/TSX is estimated to see this improves the fit of the model. The estimated OLS equations are:

\footnotetext{
${ }^{7}$ Although the coefficient on the lagged dependent variable is only significant at the $10 \%$ level, we found the r-squared drops to $15 \%$ if we remove this variable from the set of regressors.
} 
$\Delta \ln C C I_{t}=-0.107+0.082 \Delta \ln D J I A_{t}+0.404 \Delta \ln D J I A_{t \cdot 1}-0.126 \Delta \ln C C I_{t \cdot 1}$
(0.583) $(0.086)$
$(0.087)^{*}$
(0.096)

$\mathrm{R}^{2}=0.201 ; \mathrm{S} . \mathrm{E}=6.12$

Interestingly, the fit of the linear model improves slightly when the US stock market is used as the regressor as in equation (10). In this case, the contemporaneous relationship between sentiment and the DJIA returns is not significant but the coefficient on the lagged stock market index is positive and significant, consistent with expectations. In addition, the coefficient on the lagged dependent variable is negative and highly significant indicating that the model is capturing autoregressive behavior in the data. Given these encouraging results, the LR test is performed to see if the relationship between sentiment and returns undergoes regime shifts. Table $4 m 6$ shows the LR statistic and the corresponding $p$-values for the various potential threshold variables.

Table 6: Estimation Results of the Threshold Effect on Quarterly Canadian Data

\begin{tabular}{lllll}
\hline Threshold Variable & Stock Index (TSX) & Lagged TSX & DIIA & Lagged DJA \\
\hline Threshold Estimate & 5.81017 & -0.51457 & -2.22486 & -2.5347 \\
LagrangewMultiplier Test & & & \\
of No Threshold & 8.147961 & 9.017356 & 7.639175 & 7.008075 \\
Bootstrap P.Value & 0.405 & 0.305 & 0.515 & 0.581 \\
& & & \\
\hline
\end{tabular}

The results show that the null hypothesis of no threshold cannot be rejected for both equations (9) and (10), indicating that the relationship between sentiment and returns does not depend on the level of stock market returns. This result is inconsistent with our findings for the monthly Canadian data from 2001 to 2004 and with those from the US data. A closer look at the full estimation results from the threshold model is useful for exploring why it was rejected in favor of the linear model. Interestingly, the fit 
of the threshold model is usually better than the linear model. By looking at $95 \%$ confidence regions, it is apparent that the model cannot find an estimate of a threshold value with any degree of reasonable certainty. This can be seen in the extremely wide range for the confidence levels, and may partially explain why this specification is rejected in favor of the linear model. The only exception to this is seen in the instance where the threshold variable is the current value of the DJIA return. In that case, the threshold estimate is $8.9 \%$ and occurs at the lower bound of the $95 \%$ level. Consistent with our previous results, the coefficients on the stock market variable increase in significance when the DJIA return is above the threshold value (regime 2).

The results presented in this section suggest that the stock market is an important determinant of consumer sentiment and that their relationship varies depending on the level of stock market returns. The implications here are that investors' propensity to buy/sell changes during times when stock market returns are above average, consistent with the assumptions of Prospect Theory. The assumption here is that the investor's propensity to buy/sell is represented by consumer sentiment. The model used in this section is based on a simple equation relating sentiment to returns.

These results are consistent with the results from Chapter III and again may be a result of the possible negative correlation between the S\&P/TSX and the DJIA because of the heavy inclusion of resource based companies. Additional potential explanations for these results is of course, the fact the true model is one where the relationship between consumer sentiment and stock returns in Canada does not undergo regime shifts.

It is significant that the results from the US case show a definite threshold effect whereas the equivalent Canadian variables do not. This supports the findings from 
Chapter III that given its defensive nature the TSE 300 alone cannot be utilized as a good representative of a market index. Consequently alternative factors will have to be considered in the Canadian case in case the model is mis-specified, if not the US market data from the DJIA, S\&P500, possibly other economic variables like bankruptcy numbers, automobile purchases or employment data.

\section{Limitations and Robustness of this Methodology}

The benefit of this (general) threshold model, one which relates a dependent variable, $y$ to a set of independent variables, $x$ 's which allows the intercept and slopes of the relationship between the $y$ and $x$ to vary with the level of one of the $x$ 's, is its ability to parsimoniously develop asymptotic confidence intervals for the parameters a model. This methodology also lends itself to the use of data in identifying regime changes or in the terminology of this study, "tumoil" versus "non-turmoil" periods. Unfortunately, there are some concerns with this methodology. Some limitations are that it is only possible to have one threshold variable at a time and that the model does not allow for endogenous threshold variables. Additionally this particular formulation of the model does not allow for endogenous regressors. While another paper by Hansen does allow for an endogenous regressor it cannot also be the threshold variable and would not have been viable for the purposes of this study.

Potential steps in Empirical Analysis

This section describes the steps necessary to improve the model and address the relevant econometric issues. Equation (4) assumes that the stock market retum is 
exogenous with respect to sentiment. Since sentiment can also affect stock market returns, it is necessary to consider a model that allows for the potential endogeneity of the stock market variables. If the two variables are cointegrated as described previously, then the ECM considers this. If the cointegration model does not apply, then the variables need to be modeled in a simultaneous equations framework.

Evaluating the Economic Significance of Sentiment as a determinant of trading behavior - an extension

In applied research, Granger causality (1969) is a well-known concept. The meaning of causality in the Granger sense is based on the idea that the past cannot be caused by the present or future. Hence, if an event takes place before another event, causality can only come about from the first event to the second one. Granger formulated a test statistic to test whether movements in one variable systematically precede movements in another variable. In a regression framework, this means running a regression of one variable on the past values of itself and the past values of any potentially eausal variable, and testing the significance of coefficient estimates associated with the potentially causal variable. A uni-variate auto-regression model is a single equation, single-variable linear one where the lagged variables are used to predict the current value of a variable. Sims (1980) formulated a system of $n$ equations and $n$ variables as an extension of the uni-variate case where each variable could be explained by the lags of its own variable and the lags of the other $n-1$ variables. This model was defined as vector auto-regressions (VAR). VAR performs vector auto regressions, which are a set of unrestricted "reduced form" linear regressions with lags of the dependent 
variables on the right hand side. Sims et al. $(1990)^{8}$ sbowed that the asymptotic distribution theory could not be used to test for causality if the variables in the VAR model are integrated.

To remedy this, Toda and Yamamoto (1995) introduced a modified Wald test statistic that asymptotically has a chi- square distribution irrespective of the order of integration or co-integration properties of the variables in the model. This test is based on adding additional unrestricted lags. An extension of the dissertation can use a Granger causality procedure as well as the Toda and Yamamoto modification to investigate the relationship between retums, sentiment, as well as several other measures of financial development and economic growth. The advantage of this approach is to provide a model of descriptive capabilities that lead to structural inferences by determining cause and effect in trading activities and enhanced policy analysis.

\section{Conclusions}

Chapters III and IV share a common theme and show decisively that trader behavior depends on whether the market is in a period of turmoil/crisis or whether it is in a relatively stable period. The fact that a definite difference is exbibited shows support for the Prospect Theory hypothesis that during periods of extreme wealth altering conditions (losses), the behavior of market participants is different.

\footnotetext{
${ }^{8}$ Reference given in Toda, Hiro Y and Peter C. B. Phillips, (1993) "Vector Autoregressions and Causality," Econometrica Volume: 61, Issue: 6.
} 


\section{Chapter V - 1S THERE EVIDENCE OF CONTAGION? \\ Introduction}

The process of globalization has reinforced the various linkages among open economies, thereby making these interdependent. To this extent, observations of economic disturbances across regions are inevitable. The pertinent question however is whether the strength of the transmission mechanism remains stable over time. Empirical tests on the question of contagion in the returns of financial markets have focused on the changes in the correlations of the affected markets between the 'crisis' versus 'non-crisis' or tranquil periods. Arbitrary, impulsive (or irrational) trading following a disastrous event can prove costly. Consequently, investigations into these "knee jerk" reactions can prove economically beneficial.

In a series of innovating papers, Forbes and Rigobon (2001, 2002) (FR hereafter) suggest that looking at unadjusted correlation coefficients is not appropriate. The calculated correlation coefficient is an increasing function of the variance of the underlying asset return, so that when coefficients between a tranquil period and a crisis period are compared, the coefficient in the crisis period is biased upwards as volatility rises and must be adjusted before conclusions can be made on the existence of contagion.

Studies that measure systematic risk during high volatility regimes are based on the computation of cross-country correlations that exist beyond any fundamental links between countries and common shocks. In their interpretation of the evidence, many authors have argued that excess co-movement of stock returns may be explained by the price impact of correlated investor demand, or common liquidity shocks (e.g. Pindyck and Rotemberg, 1993; Lee, Shleifer and Thaler, 1991; Froot and Dabora, 1998) 
Through this type of analysis, it is possible to infer whether sizeable losses occur. The broad definition of contagion defines it as the cross-country or cross-market transmission of shocks or any general cross-country/market spillover effect - whether real, financial, or from exogenous sunspots. Contagion can therefore take place both during the tranquil and crisis periods; accordingly, contagion does not need to be related to crises.

However, studies on contagion have tended to emphasize crisis periods. FR (2002) point out that the exercise of measuring the correlation coefficients over different time periods may introduce bias into the measured correlation coefficients due to heteroskedasticity in asset returns. The asset return variance of the crisis period is higher than that of the stable period. They assert that once the data is adjusted for heteroskedasticity, there is no longer any statistically significant evidence of contagion, only interdependence or spillover effects. It is noteworthy that an increase in correlation is not necessarily caused by contagion but may be a result of higher volatility of returns since correlation depends on the volatility of returns during a market in crisis. Contagion exists if a shift in cross-market correlation occurs even after even the volatility effects on return correlation are controlled.

FR uses the definition of contagion as the significant excess conditional correlation among the asset returns of different countries above what could be explained by economic fundamentals (systematic risks). They define a slightly more restrictive definition of contagion, interdependence as the transmission of shocks to other countries or, more generally, significant cross-country correlations that exist beyond any 
fundamental links between countries and beyond common shocks." This definition is usually referred to as excessive co-movement, and is commonly explained by herding behavior leading to sunspots. ${ }^{2}$ Sunspot equilibrium is a stochastic balance uncorrelated with economic fundamentals. ${ }^{3}$ FR asserted that once the data is adjusted for heteroskedasticity, there is no longer any statistically significant evidence of contagion, only interdependence or spillover effects. Theirs is a test on the parameters. It is noteworthy that an increase in correlation is not necessarily caused by contagion but may be a result of higher volatility of returns since correlation depends on the volatility of returns during a market in crisis.

The aim in this chapter is to determine whether investor trading behavior is influenced by market conditions in an individual country, in other words is there evidence of contagion or interdependence in stock market co-movements. While there have been numerous studies on the contagious natures of currency crises, the 1987 US stock market crash and the $9 / 11$ disaster, there has not been too much interest in the massive fraud case perpetrated by the principals at Bre-X Minerals. The incidence of the fraud has been a cause of embarrassment for the venerable Toronto Stock Exchange and has led to

\footnotetext{
'Forbes, K. \& R. Rigobon (1999b), Measuring Contagion: Conceptual and Empirical Isstues', Proceedings
} of the World Bank Conference on International Financial Contagion, Washington D.C., Feb 3-4, 2001.

${ }^{2}$ Devenow, A., Welch, I, Rational herding in financial economics, European Economic Review 40 (1996) 603-615.

${ }^{3}$ Pericoli, Marcello \& Sbracia, Massimo (2003), A Primer on Financial Contagion, Journal of Economic Surveys 17 (4), $571-608$. 
numerous changes in the reporting standards of mining companies on the Exchange. ${ }^{4}$ In this chapter, this incident was used as an example to investigate the possible existence of contagion on the returns of the G9 countries and Indonesia. Since the demise of the USSR, Russia has been included in the group of G7 countries and they are collectively known as the G8. ${ }^{5}$ Analysis on the G9 countries includes Australia. Indonesia is included in the analysis since the event was geographically focused there. China is excluded because its markets have not been as open as the other industrialized countries especially during the period under consideration.

\section{Research Hypothesis and Methodology}

The null hypothesis is: no contagion, only interdependence in the market returns of the countries under investigation. The following steps were undertaken.

1) For the G9 and Indonesia, daily returns denominated in US currency were retrieved on the major stock market indices, and short-term (overnight) interest rates. For daily data, FR use two-day average returns to iron out time-differences between the various countries. This study used a lagged return for Australia, Indonesia, Japan and Russia to account for the time-differences.

2) The methodology required defining an event that could be tracked for the contagion question. This event is defined by the data. The variance of returns before and after this event was reviewed to see if it fulfilled the definition of a

\footnotetext{
${ }^{4}$ Speech presented at the Traders Association Annual Meeting by Barbara Stymiest CEO, TSX Group in Boca Raton, Florida October 8, 2004.

http:/www.tsx.com/en/tradingServices/docs/7704STAAnnualMeeting_Oct8-04_StymiestSpeech.pdf.

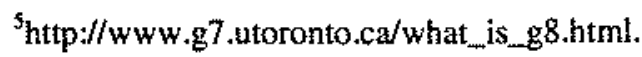


"crisis". The literature considers returns greater than two standard deviations from the mean as being unusually variable.

3) Following FR, this study began by defining the turmoil period as the 3 months after the event, from March 24,1997 to June 251997 , and the stable period as the 7 months before the event, July 9,1996 to March 23, 1997. The full period is the sum of the turmoil and stable periods. To test for contagion, correlation coefficients from the turmoil and full period are compared using a t-statistic. FR implies that their results are robust to the choice of turmoil/stable periods. According to Dungey and Zhumabekova (2001), FR's results regarding contagion from the US $1987 \mathrm{crash}$, vary based on the number of observations in the turmoil period. Consequently, results are shown for 3 months, 6 months, and 9 months after the event. Experimentation with this window was done to check for robustness in the results. The analysis included a comparison of the correlation coefficients from the prewevent and post event periods. This differed from the FR study where the non-crisis period correlation coefficient was obtained from the full sample ${ }^{7}$.

4) The next step calculated the heteroskedastcity-corrected (or unconditional) correlation coefficient ( $\rho$ in Equation 11 in FR). Rather than calculate the correlation coefficient on the stock index returns data directly, FR start by

\footnotetext{
${ }^{6}$ Excess stock market returns from the crisis country during the turmoil period are represented by residuals from the estimated VAR models. Since our data sample starts in July 2, 1996 and the VAR analysis requires using the first 5 observations for lags, the observations used to compute the correlations start in July 9. 1996. Lags are used to adjust for serial correlation in stock market returns and external shocks.
}

${ }^{7}$ This follows a study by Hon, Srauss, and Yong in the Journal of Financial Research (vol 27(1), pp 95114), Spring 2004) which tests for contagion in financial markets after September 11 by comparing correlation coefficients from the prevevent and post-event periods. 
filtering their stock market returns data by estimating a (bi-variate) Vector

Autoregression (VAR) of the stock returns conditional on the following variables:

a) short-term interest rate of crisis country (in this case Canada),

b) short term interest rate for the US, and

c) short-term interest rate for the other country being investigated for contagion.

The US Interest rate is included to control for economic shocks (fundamental factors) and/or monetary policy co-ordination. The study begins by looking at pairs of countries; one of the pair is the country where the initial event occurred, for example Canada and Italy. In this case, for simplicity only, the VAR with 2 lags is given ( $Y$ 's stock returns and $R$ 's are LIBOR 1 month interest rates of the relevant countries undergoing analysis):

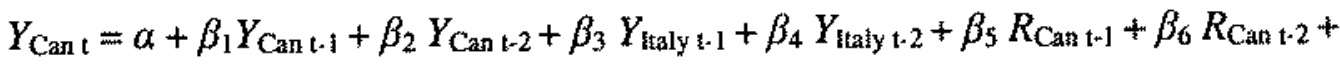

$$
\begin{aligned}
& \beta_{5} R_{\mathrm{US} \mathrm{t}+1}+\beta_{6} R_{\mathrm{US}-2}+\beta_{7} R_{\mathrm{taly} \mathrm{t}-\mathrm{t}}+\beta_{8} R_{\mathrm{ttaly} \mathrm{t}-2 \mathrm{t}}+\varepsilon_{\mathrm{tt}}
\end{aligned}
$$

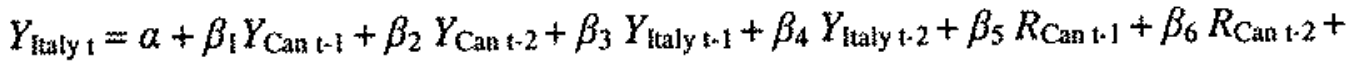

$$
\begin{aligned}
& \beta_{5} R_{\text {US } t-1}+\beta_{6} R_{\text {US }:-2}+\beta_{7} R_{\text {taly }:-1}+\beta_{8} R_{\text {taly }: 2}+\varepsilon_{2 t}
\end{aligned}
$$

This methodology simulates FR and the equations above closely resemble FR's Equations $12,13,14{ }^{8}$ Following FR, the analysis begins with five lags to account for within week variations. After estimating this VAR system for the full period

\footnotetext{
${ }^{8}$ FR Equations 12: $\left.X_{t}=\varphi(L) X_{t}+\varphi(L) X_{t}+1\right)$, FR Equation 13: $X_{t}=\left\{x_{t}^{C}, x_{t}^{j}\right\}$, FR Equation 14: $I_{t} \equiv\left\{i_{t}^{C}\right.$, $\left.i_{i}{ }^{U S .} i_{i}{ }^{j}\right)$ where $x_{i}^{c}$ is the stock market return in the crisis country; $x_{t}^{j}{ }^{j}$ is the stock market return in another market $j ; X_{i}$ is a transposed vector of returns in the same two stock markets; $\varphi(L)$ and $\Phi(L)$ are vectors of lags; $i_{t}{ }^{c}, i_{i}{ }_{i s .} i_{i}{ }^{j}$ are shortterm interest rates for the crisis country, the United States and country $j$, respectively; and $\eta$ is a vector of reduced-form disturbances.
} 
(stable plus turmoil periods), the $\varepsilon^{\prime}$ s are the filtered data to which the correlation formula will be applied (equation 11 in FR paper) ${ }^{9}$.

The covariance matrix of the estimated VAR gives the necessary ingredients for the formulas. These are the covariance of $\varepsilon_{1}$ and $\varepsilon_{2}$ in the various sub-periods and their individual variances. In this case, the variance of $\varepsilon_{1}$ is the variance of the 'crisis' country retum, which is needed to calculate $\delta$ in equation 10 of FR that is the relative increase in the variance of the crisis country from the stable to the turmoil period. The uncorrected or conditional correlation coefficient, $\rho^{*}$ in equation 11 , is given by the usual correlation coefficient formula $\left(\rho^{*}=\sigma_{\varepsilon l \varepsilon 2} / \sigma_{\varepsilon l} \sigma_{\varepsilon 2}\right)$ but applied to the residuals from the $\operatorname{VAR}, \varepsilon_{1}$ and $\varepsilon_{2}$.

5) Given the estimates of $\rho$ (the corrected correlation coefficient) for the sub-periods: turmoil and full, FR test the following null hypothesis of no contagion, only interdependence:

$$
\begin{aligned}
& \mathrm{H}_{0}: \rho_{\text {turmoil }} \leq \rho \text { futl } \\
& \mathrm{H}_{1}: \rho_{\text {urmoil }}>\rho_{\text {full }}
\end{aligned}
$$

The critical value for the one-sided t-test for differences in means at the $5 \%$ significance level is 1.65 . Therefore if the t-statistic $>1.65$, then $\mathrm{H}_{0}$ is rejected indicating 'Contagion'.

6) For the case of Canada as the country where the event originated, steps 4 and 5 were repeated for the other pairs of countries (Can/US, Can/Germany,

\footnotetext{
9RR Equations 10: $\delta=\left(\sigma_{x x}^{h} / \sigma_{x x}^{\prime}\right)-1$, this parameter represents the relationship between variances of excess stock market returns from the crisis country during the turmoil period, and during the stable;

Equation $11: \rho=\rho^{*} /\left(1+\delta\left[1-\left(\rho^{*}\right)^{2}\right]\right]^{1 / 2}$, this is the correlation coefficient between the crisis and the non-crisis market observed during the crisis period.
} 
Can/France, Can/Japan, Can/Britain, Can/Australia, Can/Russia, and Can/Indonesia).

The crisis investigated is not a big one, especially compared to some of the others mentioned in the literature. Therefore, it may be argued that the effects are contained to the industry under question. In as much as the event under consideration occurred in the gold mining industry, this methodology is repeated first to determine the effect of the Canadian total market on the mining returns across the regional indices and secondly the effect of the Canadian Gold Mining Index on the mining returns around the world.

Sample \& Data

The methodology required defining a notable crisis that originated in Canada and may have caused similar market volatility elsewhere. The 1997 finding that the Busang gold discovery in Indonesia was a massive fraud caused a major sell-off on all the Canadian exchanges including the Toronto Stock Exchange, Canada's oldest and most respected.

The relevant important dates pertaining to this event are:

1. Chief geologist 'fell' from a helicopter in the Indonesian jungles, a suicide note was found on March 19, 1997.

2. Temporary Halt on S\&PTSX on Friday Mar 21

3. Halt reported on WSJ on Mon Mar 24. On that day, the company put forth a news report claiming it still had confidence in the gold find. 
4. Longer halt (overnight) on S\&P/TSX on Wed Mar 26 reopened for trading on the afternoon of Thursday Mar 27.

5. All these reports met with denials from the company until May 3 "when Bre-X thereafter acknowledged that the numerous public statements it had made touting the tens of millions of ounces of gold resources at Busang were completely baseless, the product of outright fraud supported by bogus testdrilling reports". That conclusion was confirmed in a final report from Bre-X's independent mining consultant, which became known to the market on May 3 , $1997 .^{10}$

Other reports have implied dissemination of information since March 1, 1997 and confirmation by independent auditors sent to do due diligence work on March $10 .^{11}$ While most empirical research use the date of most widely dissemination as the date published by the Wall Street Journal our goal is to determine whether it was a crisis AND whether it spread. Consequently, 'instantaneous' volatility of returns following the methodology of Corsetti et al (2001 footnote 4$)^{12}$ are computed and graphs are generated to confirm that excess volatility of returns existed during the period the crisis is suspected. Following this methodology, an exponentially weighted moving average (EWMA) of a 1 -month or 20 trading days moving average window size with a EWMA

\footnotetext{
${ }^{50}$ These dates are referenced in the class action suit brought against the principals of the case: http:/www.brexclass.com/graphics/docs/complaint.pdf.

${ }^{11}$ E-M - Engineering \& Mining Journal; 8/1/1998.

${ }^{12}$ Corsetti, G. Pericoli, M. \& Sbracia, M. 2001, 'Correlation analysis of financial contagion: What one should know before running a test', Economic Growth Centre, Yale University, Center Discussion Paper No. 822 .
} 
smoothing constant, $\lambda$ of 0.96 , is graphed and shown in Figure 1 for the eighteen-month period between July 1, 1996 and December 31, 1997. EWMA is a special case of Integrated GARCH. ${ }^{13}$ The $\lambda$ parameter is called the persistence measurement, a smaller one implies higher reaction of the volatility to the market info in yesterday's return. Larger window sizes show the volatility more clearly. $\lambda=.96$, is very persistent but not highly reactive. These finding were also robust to changes in the volatility model (using a different constant of the exponentially weighted moving averages, or a GARCH $(1,1)$ estimate).

In these models, unconditional variance tends to infinity so it is undefined. This maximum likelihood technique returns the annualized volatility of an asset based on a sample of historic prices. The graphs are generated using an Excel add-in. ${ }^{14}$ Based on this methodology and a one-month ( 20 days moving average), volatility changes from $10.6 \%$ on March 21, 1997 to $16.3 \%$. The graph is shown in Figure 1. The volatility change was not as dramatic after May 2, 1997. These readings can be compared on this graph with an event well recognized as a crisis throughout the world, which originated in Hong Kong. This crisis nicknamed the "Asian Flu" culminated on October 27, 1997 when short-term interest rates increased by thirty percent. Here the volatility of October 24 through October 30 changed from $10.6 \%$ to $27.8 \%$. While the volatility change was

\footnotetext{
${ }^{13}$ The Exponentially weighted moving average (EWMA) model uses exponential smoothing to give more weight to recent closing prices than to older prices. The Standard EWMA estimator is a special case of generalized autoregressive conditional heteroskedasticity, or a GARCH model (Engle, 1982; Bollerslev, 1986). When $\alpha=0$ and $\beta=1-\alpha$, the GARCH model reduces to the Standard EWMA estimator, alternatively known as Integrated GARCH or IGARCH. Volatility has been tested for with a GARCH (1,1) process using Hoadley's excel add-in. The stationary condition for GARCH $(1,1)$ is $\alpha+\beta<1$. These graphs used EWMA smoothing constant $\lambda=0.96, \alpha=0.232$ and $\beta=0.761$.
}

${ }^{14}$ http:/www.hoadley.net/options. 
not as dramatic as for the Hong Kong crisis, it was still a significant one and one of the few crises originating in Canada in recent times. ${ }^{15}$ The EWMA model is improved for longer time-periods and the graph is less volatile using a longer moving average window size. Figure 2 shows the data one year before and after the event with a three-month moving average. Additionally the chart in Figure 3 is produced which shows the changes in the index levels over the two years.

Figure 1: Volatility of the S\&P/TSE: Event date March 21, 1997

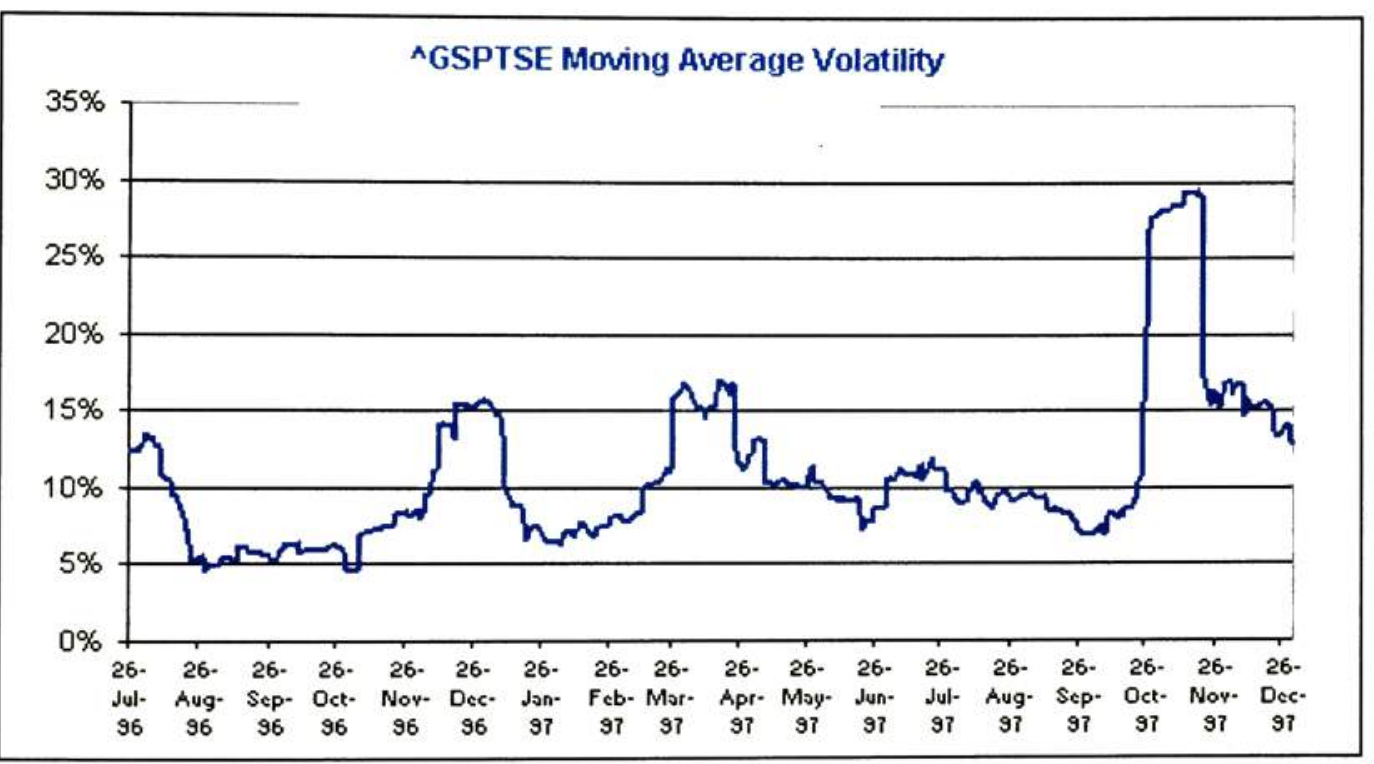

${ }^{15}$ http://www.micromedia.ca/Timeline/1990-1999.htm. 
Figure 2: Volatility of the S\&P/TSE with 3-Month Moving Average: Event date March 21, 1997

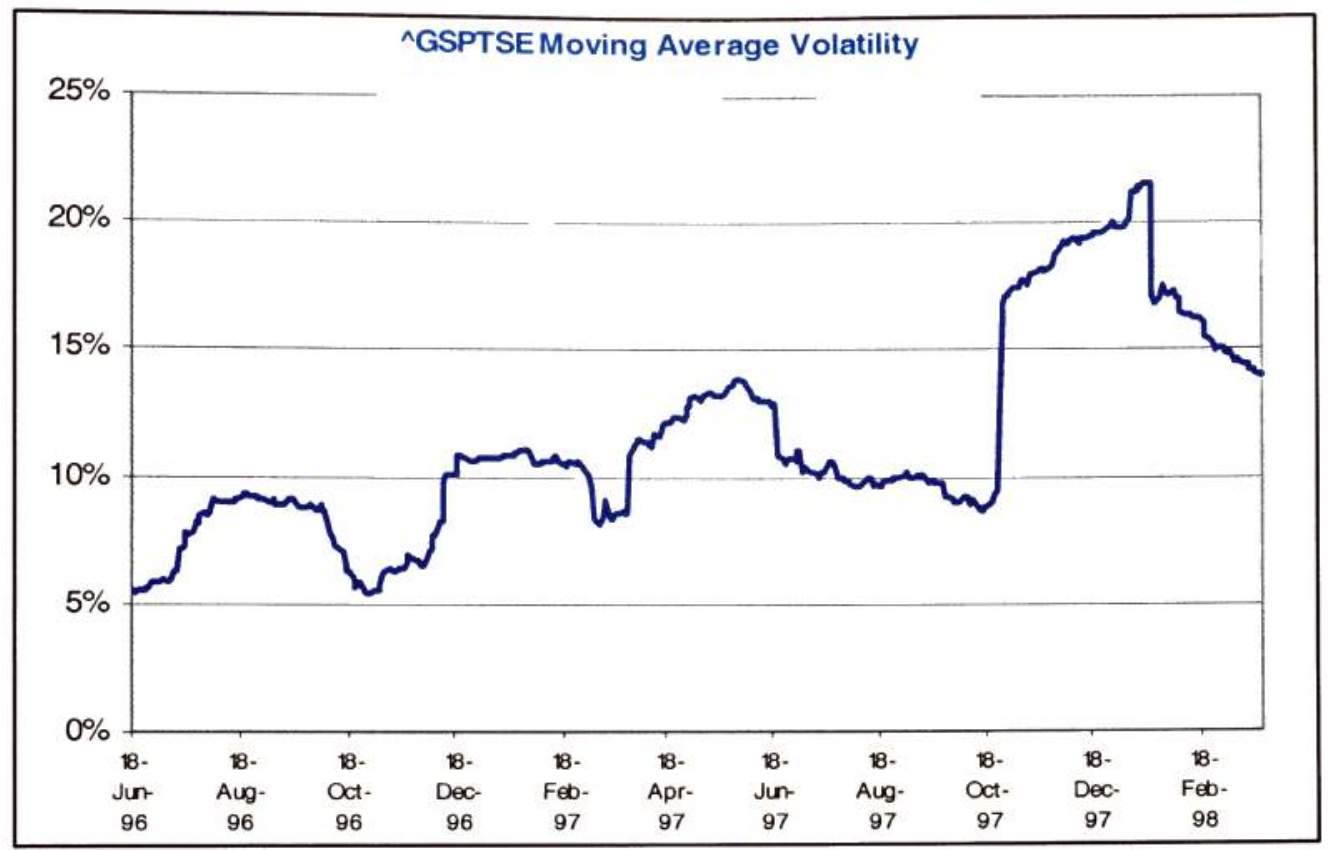

Figure 3: Price Chart of the S\&P/TSX from June 1996 to June 1998

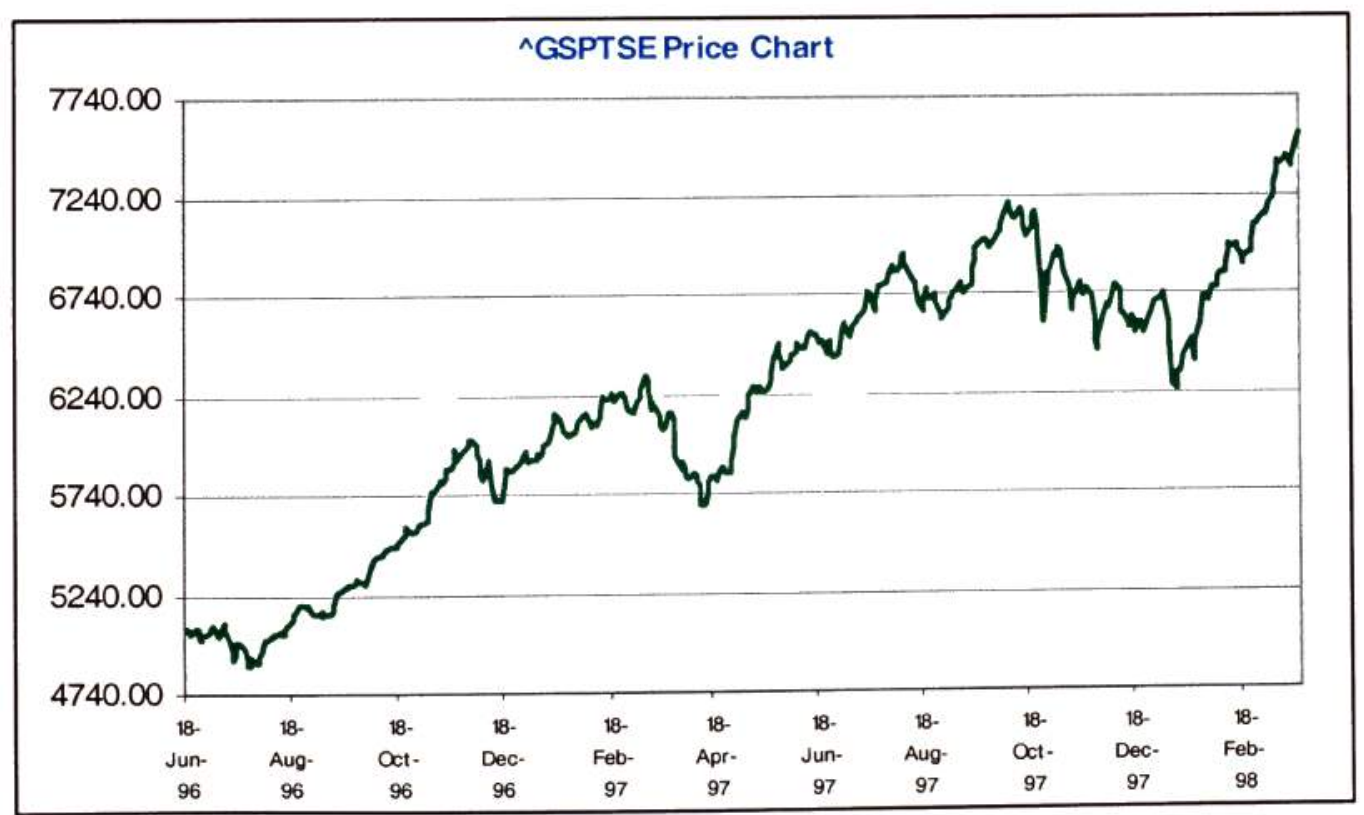


Figure 4: Volatility of the S\&P500 with 3-Month Moving Average: Event date March 21, 1997

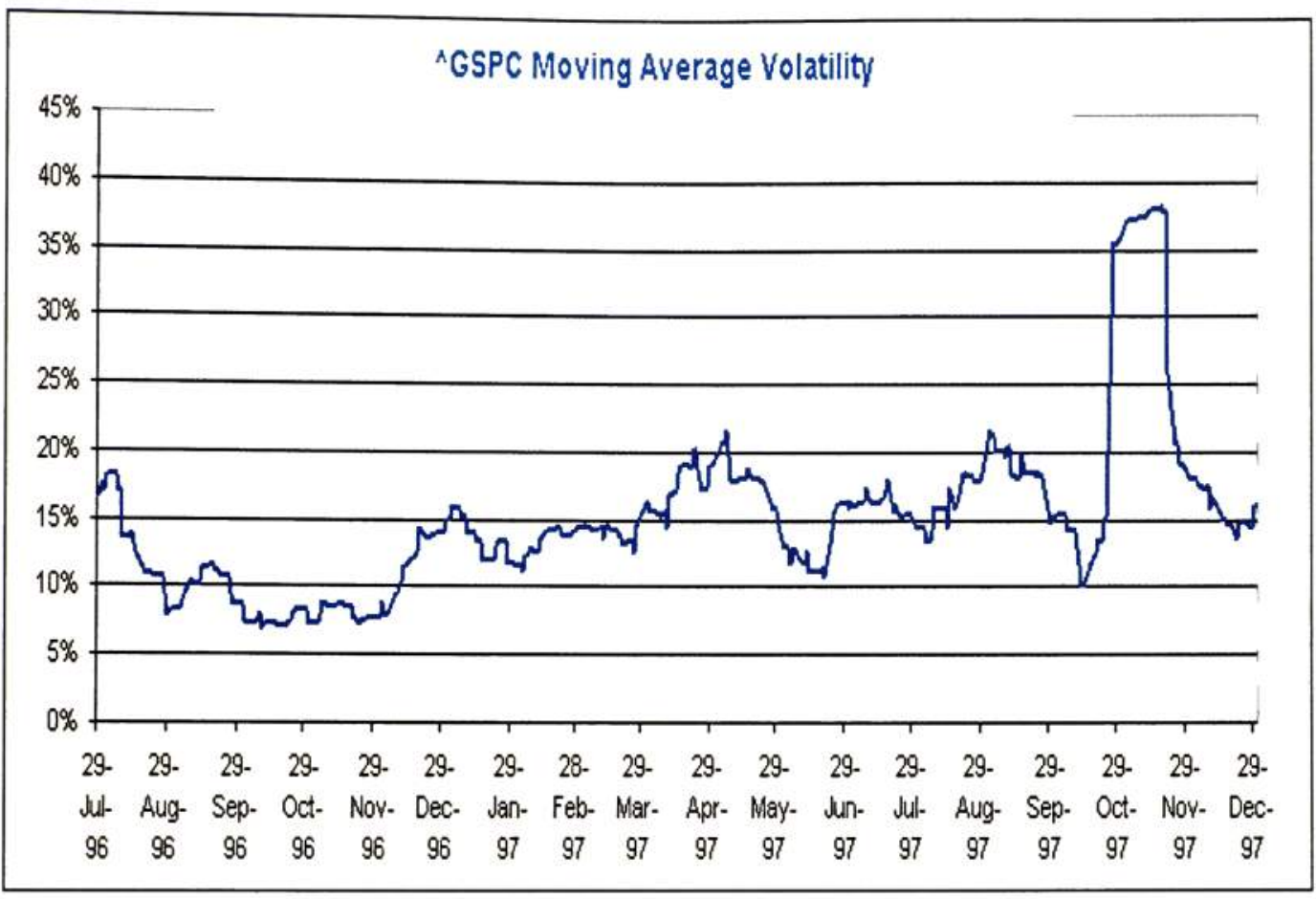

Figure 5: Price Chart of the S\&P500 from July 1996 to December 1997

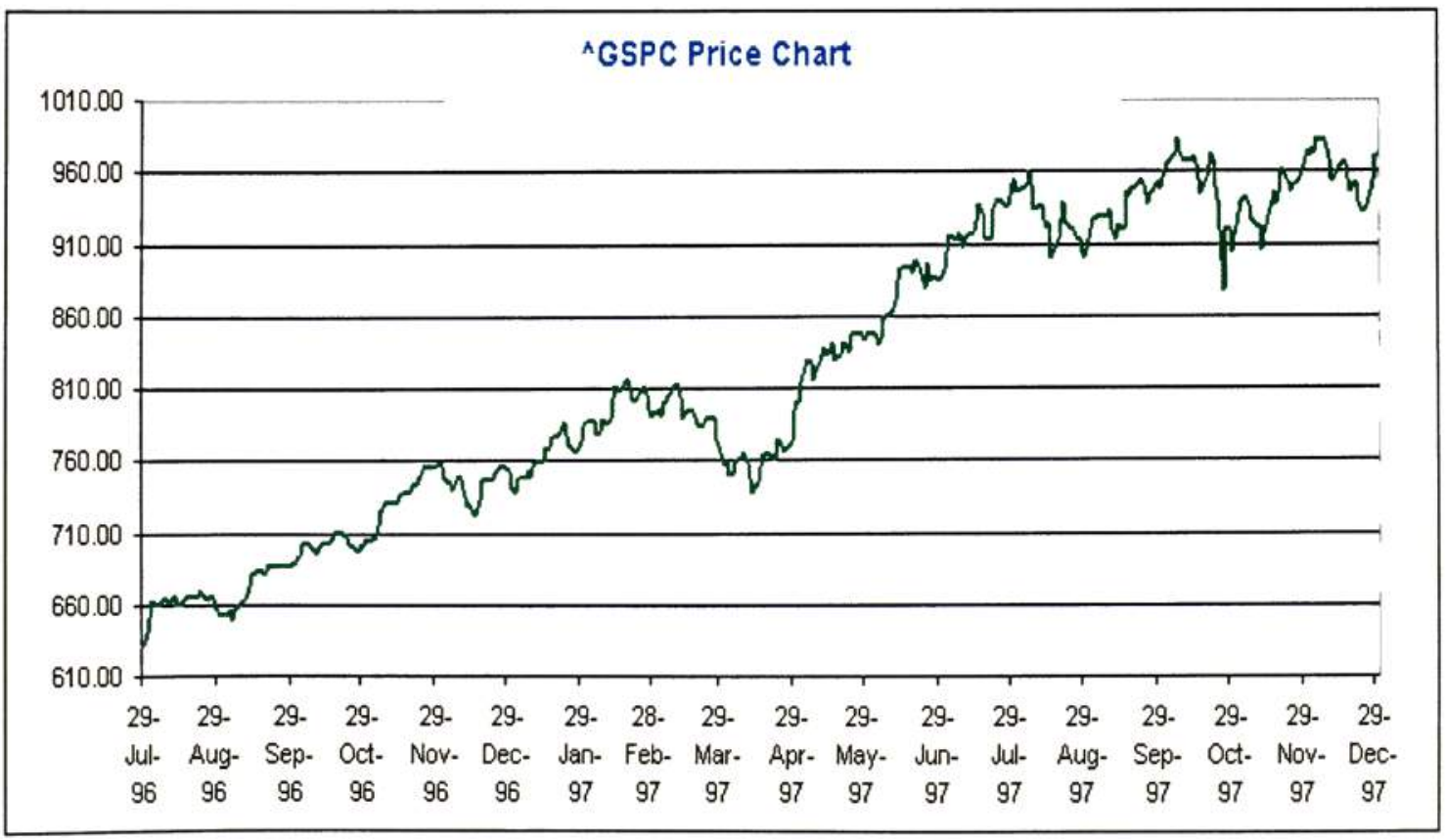


Figures 4 and 5 give corresponding volatility charts for the S\&P500 Index in the United States. While the moves are not magnanimous, there is clearly some change in volatility, approximately $13.3 \%$ to $16.3 \%$ during the course of the week beginning March 24, 1997. This motivates further investigation into evidence for contagion. Because of the documented home country bias ${ }^{16}$ domestic buyers and sellers dominate most stock market activity so the data was first analyzed in each local currency. While this made it free from exchange rate fluctuations, the data suffered from the lack of a common unit. Additionally because the main goal is to test contagion in the context of international diversification, the tests are performed in U.S. currency. The data is collected from each country's total market index in Thomson Financial International Datastream. In as much as the incident occurred in the mining arena the analysis is duplicated for Datastream's collection of gold indices accumulated by region. However, since the Canadian gold industry is included in the Index for the Americas that comparison is excluded and replaced by a comparison with the US gold index.

Research has shown that maximum benefits from portfolio diversification occur from truly global diversification but investors' home country bias predisposes them to investing in developed markets rather than developing ones, (Lewis 1999 provides a survey of this literature). ${ }^{17}$ Consequently, the study will focus on the G9 countries. Indonesia is included in the analysis since the event was geographically focused there.

\footnotetext{
${ }^{16}$ See French and Poterba (1991), Cooper and Kaplanis (1994) Tesar and Werner (1995) and Karolyi and Stulz, 2002), for papers that document this phenomenon.

${ }^{17}$ Karen K. Lewis, (1999), Trying to Explain Home Bias in Equities and Consumption, Journal of Economic Literature, American Economic Association, vol. 37(2), pages 571.608.
} 
China is excluded because its markets have not been as open as the other industrialized countries especially during the period under consideration.

\section{Empirical Applications}

\section{The total country Indices}

The initial analysis applies the methodology to evaluate whether the event in Canada had any impact on each of the remaining nine country indices. Table 1 displays the indices and the Datastream codes for the data analyzed.

Table 1: Total Country Indices from Datastream

\begin{tabular}{ll}
\hline Price Index in US Curtency & Datastream Code \\
\hline & \\
CANADA-DS MARKET & TOTMCN\$ \\
S\&PSOO COMPOSITE DS CALCULATED & S\&PCOMZ \\
AUSTRALIA-DS MARKET & TOTMAU\$ \\
FRANCE-DS MARKET & TOTMFR\$ \\
GERMANY-DS MARKET & TOTMBD\$ \\
TTALY-DS MARKET & TOTMIT\$ \\
JAPAN-DS MARKET & TOTMIP\$ \\
RUSSIA-DS MARKET & TOTMKRS \\
UK-DS MARKET & TOTMUK\$ \\
INDONESIA-DS MARKET & TOTMID\$ \\
\end{tabular}

Table 2 presents the correlation tests for contagion by adjusting for heteroskedasticity following FR and Table 3 does not. Panels A and B differ in the methodology of computing correlations. Panel A follows FR's methodology. Panel B computes correlations when the non-crisis period is defined as approximately 6 months before the event and the crisis period is defined as various time intervals after the event occurred. The hypothesis that contagion existed is based on the measurement of 
correlation in the turmoil period being higher than that of the non-crisis period. A negative large t-statistic indicates that the correlation coefficient in the turmoil period is significantly lower than in the non-crisis period. Consequently, the hypothesis that contagion occurred is not rejected (there is contagion) if the t-statistic is positive and significant. The results show overwhelmingly no contagion occurred. These conclusions depend heavily on FR's methodology. The literature review of Chapter II shows that FR's methodology is biased against finding contagion. Thus the results may be subject to these limitations. According to FR, the unadjusted correlation coefficient will increase in the turmoil period because the variance of returns increases as well. This is compensated for by computing the adjusted correlation coefficient, which corrects for the increase in variance (or heteroskedasticity). As can be seen in Table 3 Panel B, without this adjustment, contagion is found for Russia six months after the event, and Germany, Japan, Russia and USA nine months after the event. The results are different once the correlations are adjusted for heteroskedasticity. Additionally three months after the event the results are approximately the same whether the variances are adjusted or not. In Table 3 Panel B, only Russia and USA exhibit contagion nine months after the event. This scenario supports FR's main point, that if contagion is measured by unadjusted correlation, evidence of contagion would be found when in fact there was only interdependence. There is a possibility however that these nine month results are reflecting Hong Kong's October crash since using a smaller window gives a different answer. A separate framework is required to test this possibility and will not be addressed here. 


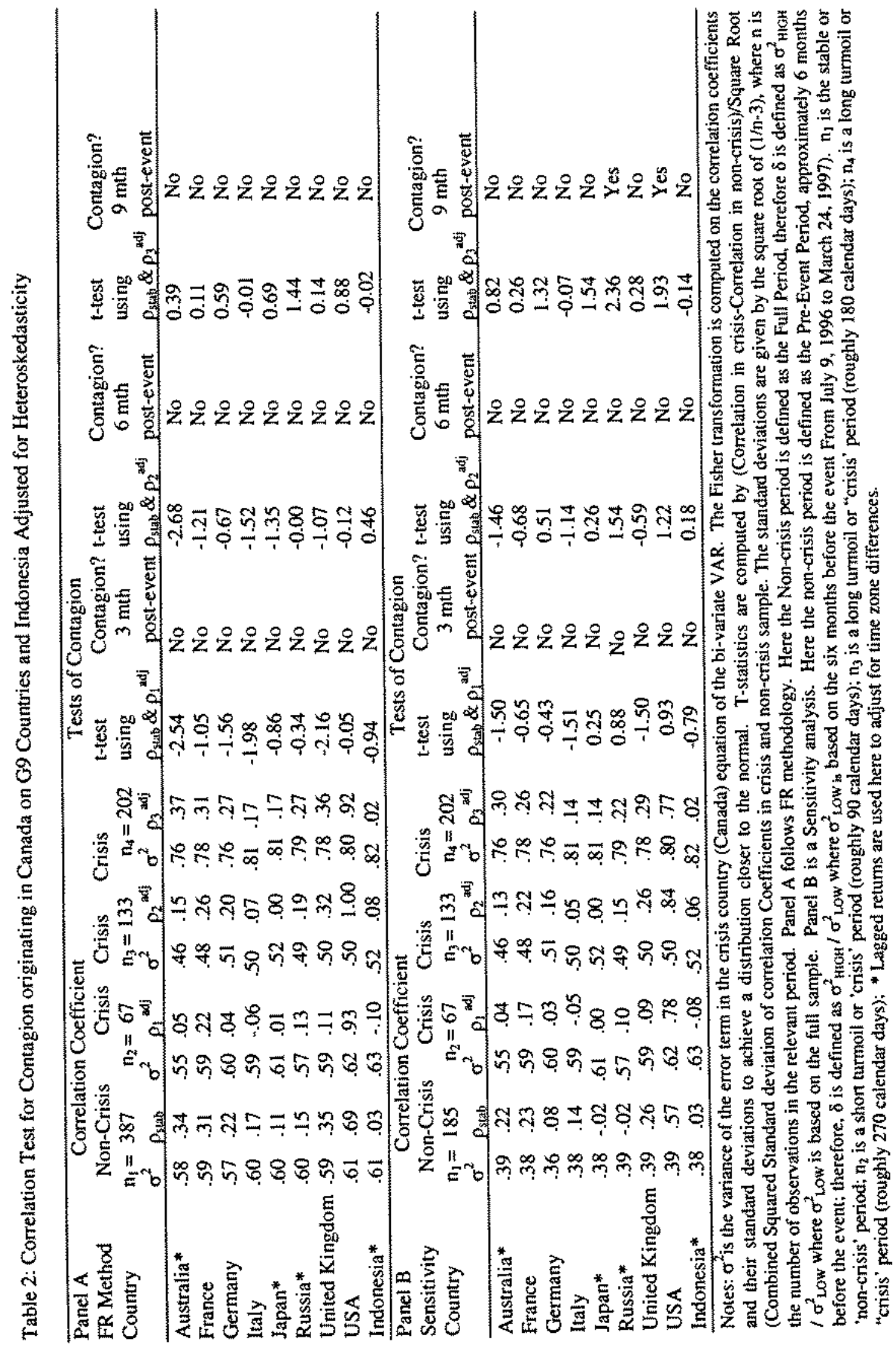




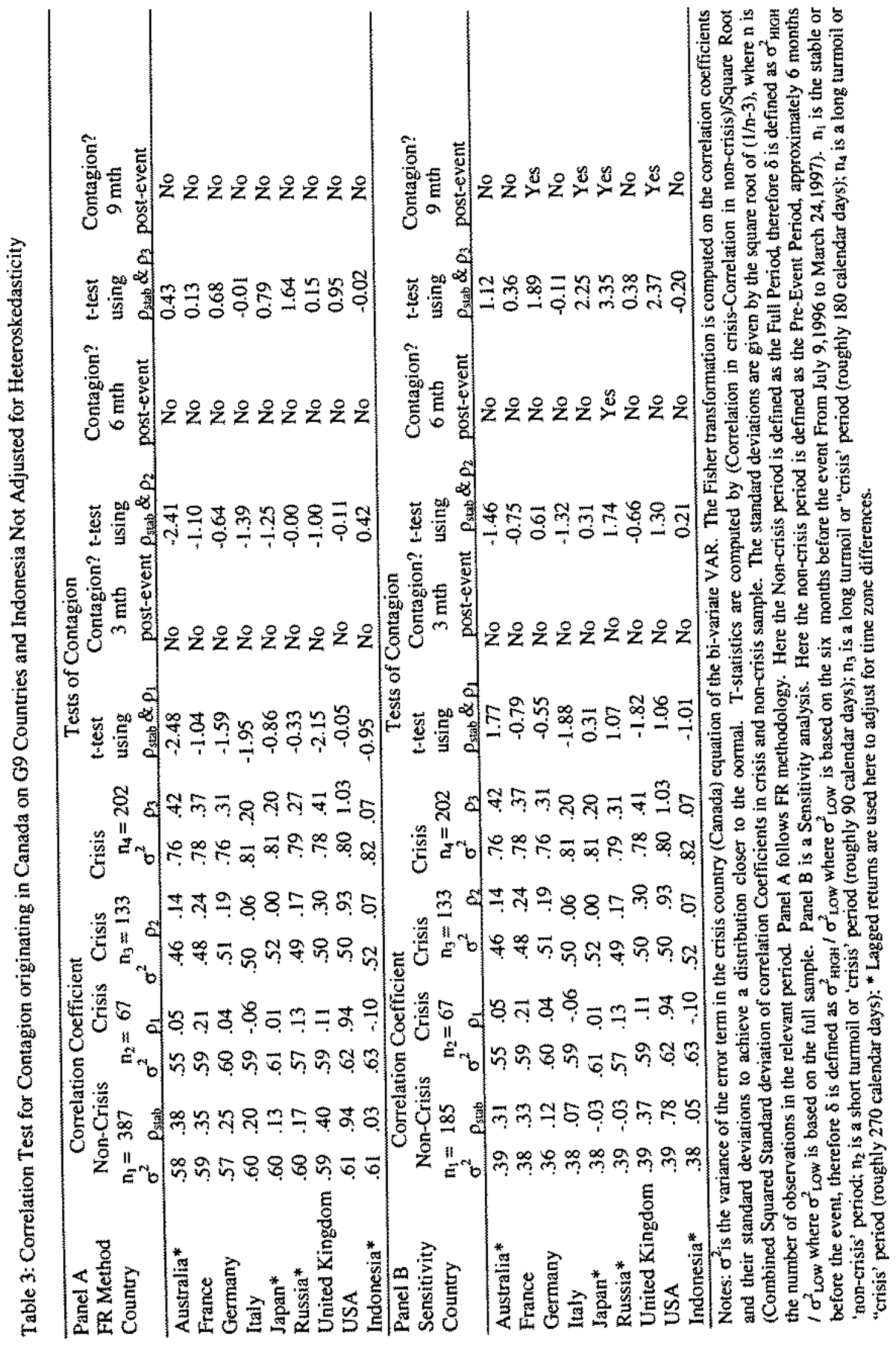


The methodology is extended for the total Canadian indices versus the regional mining industries. Table 4 presents the Datastream codes.

Table 4: Total Canada Index from Datastream versus Gold/Basic Resources of the Regional Indices

Price Index in US Currency

CANADA-DS MARKET

AMERICAS - DS GOLD MINING

DITM CANADA GOLD MINING

FT GOLD MINES TOTAL

AUSTRALASIA-DS GOLD MINING

EMERGING MARKETS-DS GOLD MINING

PACIFIC BASIN-DS GOLD MINING

DITM INDONESIA BASIC MATS

RUSSIA-DS RESOURCES
Datastream Code

TOTMCN\$

GOLDSAM

D4CNGL\$

FTGMTO\$

GOLDSAZ

GOLDSEK

GOLDSPC

DIINBM\$

RESORRS(PI) 


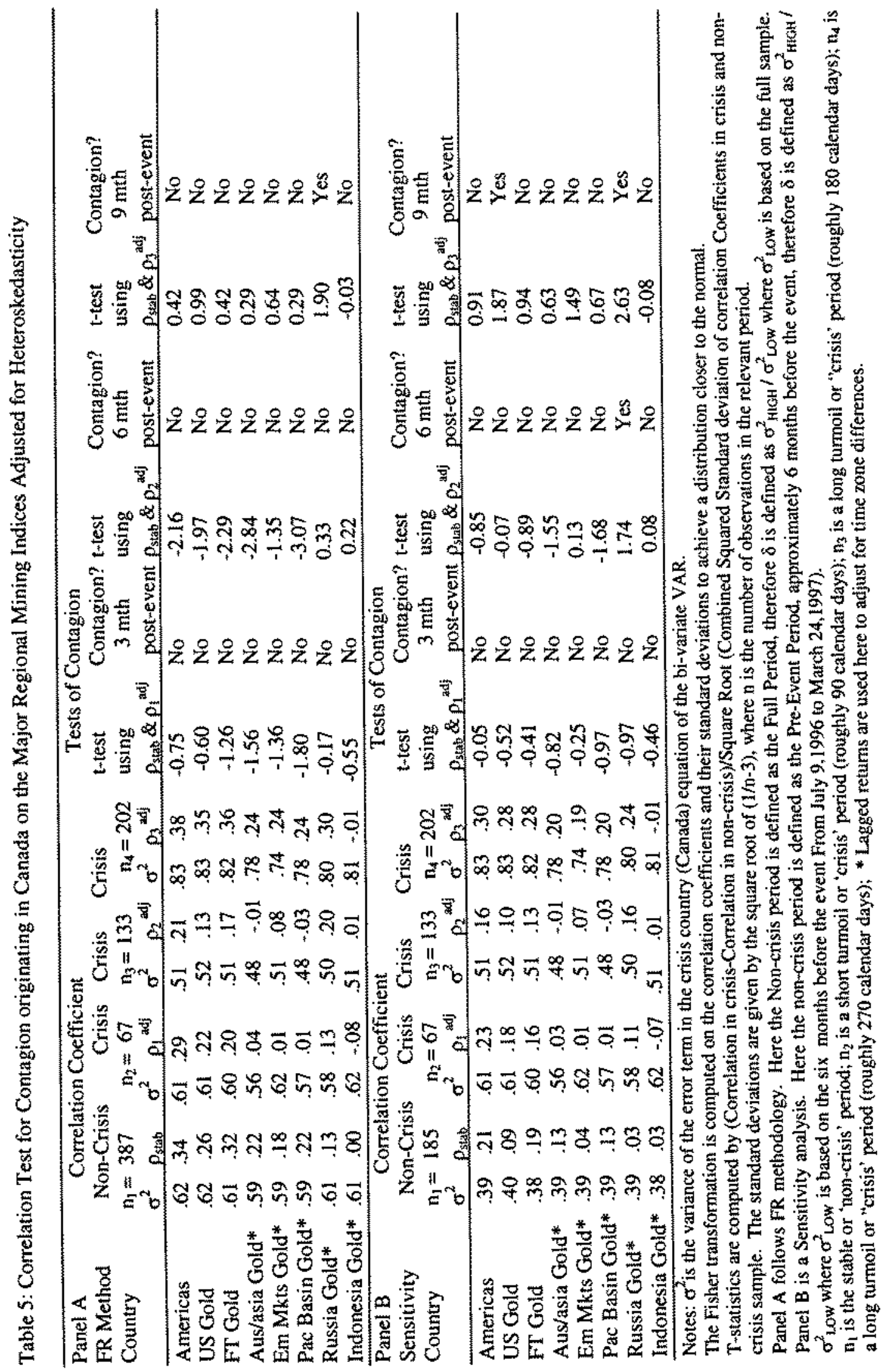




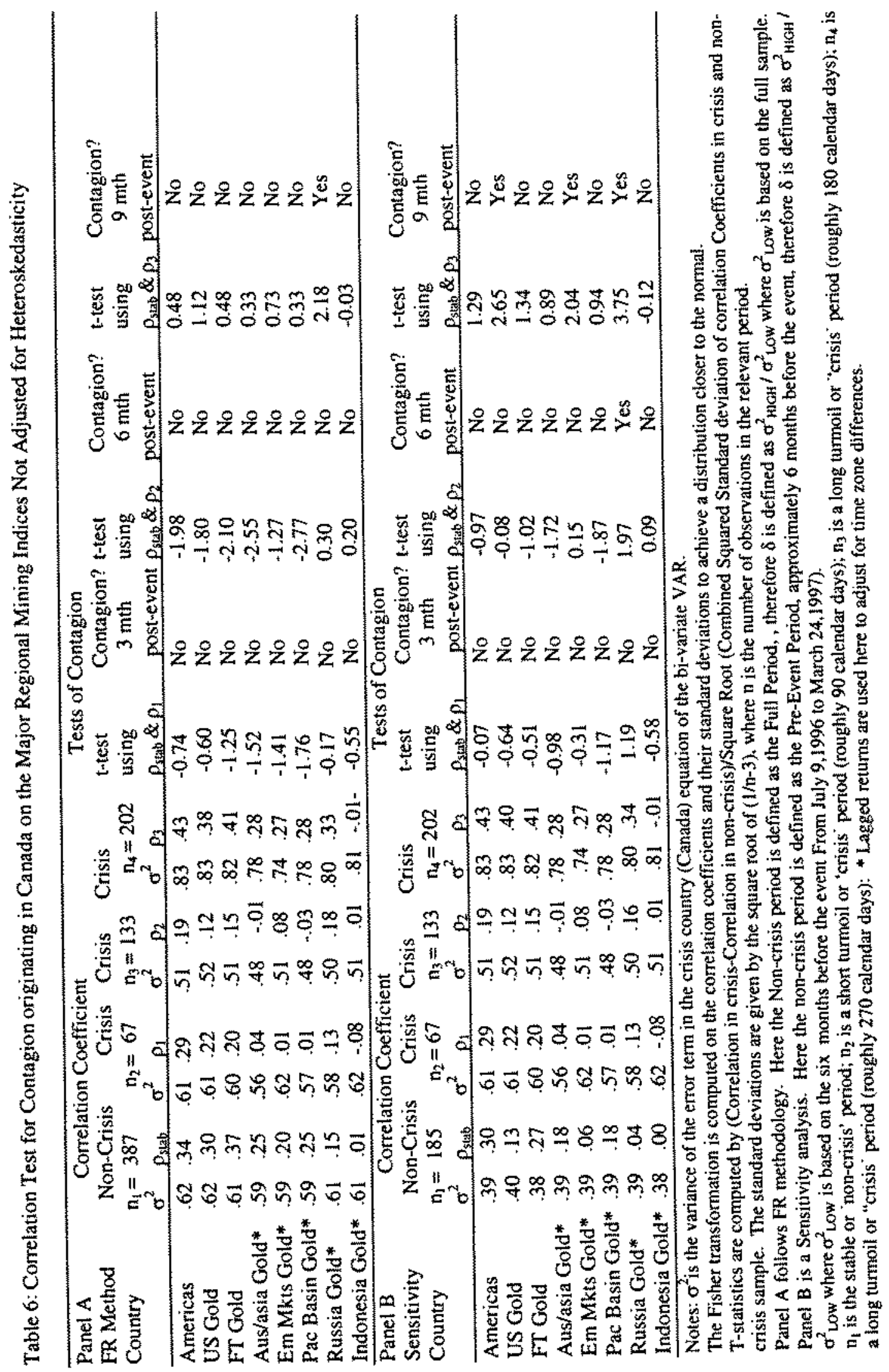


Again, the results show little evidence of contagion once the correlations are corrected for heteroskedasticity. Based on Table 5 Panel B, contagion is only visible in the Russian Gold Index, within six months of the event. Once again, there is some evidence for contagion in the adjusted as well as unadjusted correlations nine months after the event.

Canada's Mining Industry and the Rest of the World

The methodology is extended for the Canadian gold mining index versus the mining industries around the world, In as much as the Canadian gold index is a significant portion of the Index for the Americas the analysis here eliminates the Canada Gold Index against the Americas Gold Index. Table 7 presents the codes used.

Table 7: Total Canada Gold Market from Datastream versts Gold/ Basic Resources around the World

\begin{tabular}{ll}
\hline Price Index in US Currency & Datastream Code \\
\hline & \\
DJTM CANADA GOLD MINING & D4CNGL\$ \\
US-DS GOLD MINING & GOLDSUS \\
FT GOLD MINES TOTAL & FTGMTO\$ \\
AUSTRALASIA-DS GOLD MINING & GOLDSAZ \\
EMERGING MARKETS-DS GOLD MINING & GOLDSEK \\
PACIFIC BASIN-DS GOLD MINING & GOLDSPC \\
DJTM INDONESIA BASIC MATS & DIINBM\$ \\
RUSSIA-DS RESOURCES & RESORRS(PI)
\end{tabular}




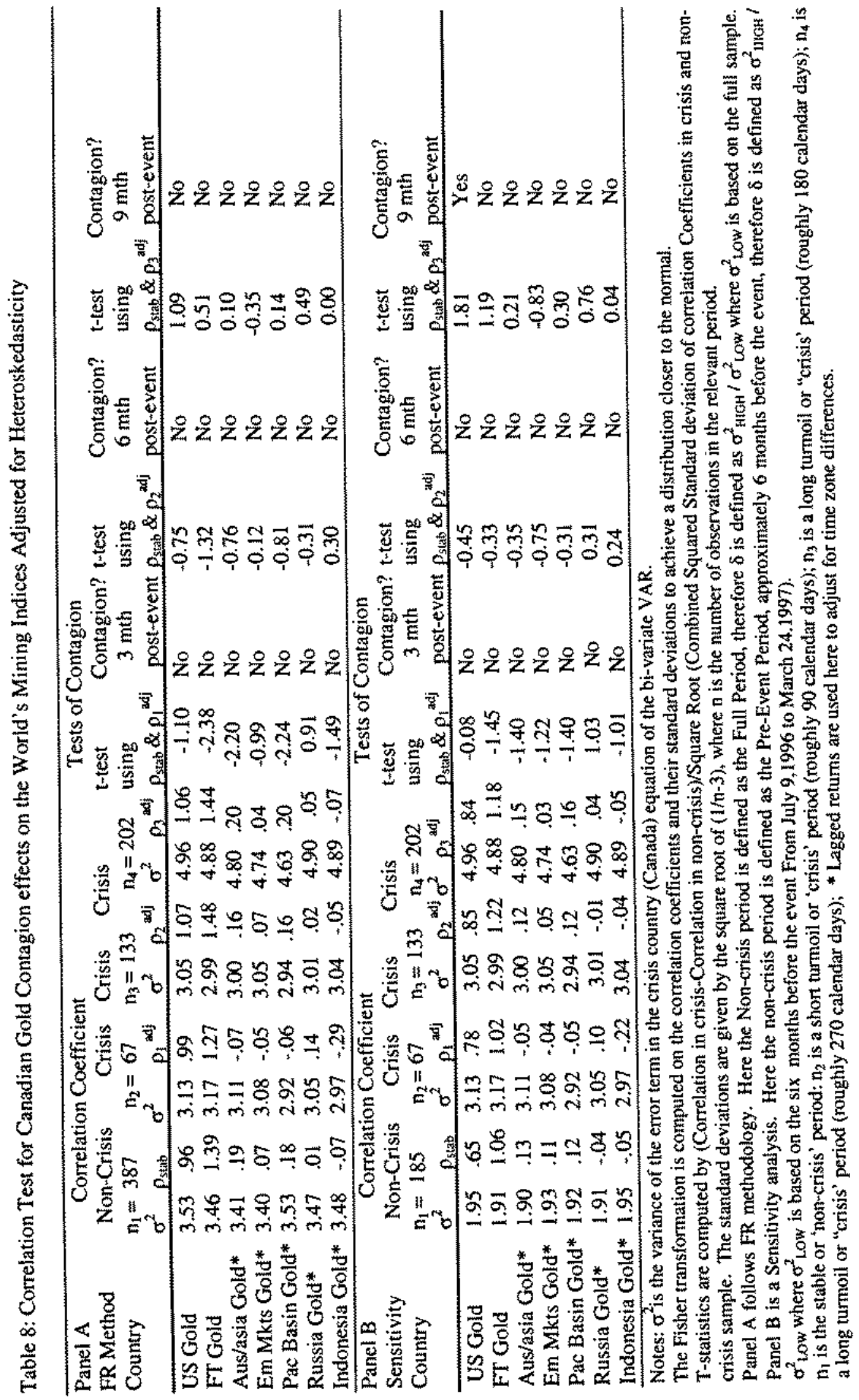




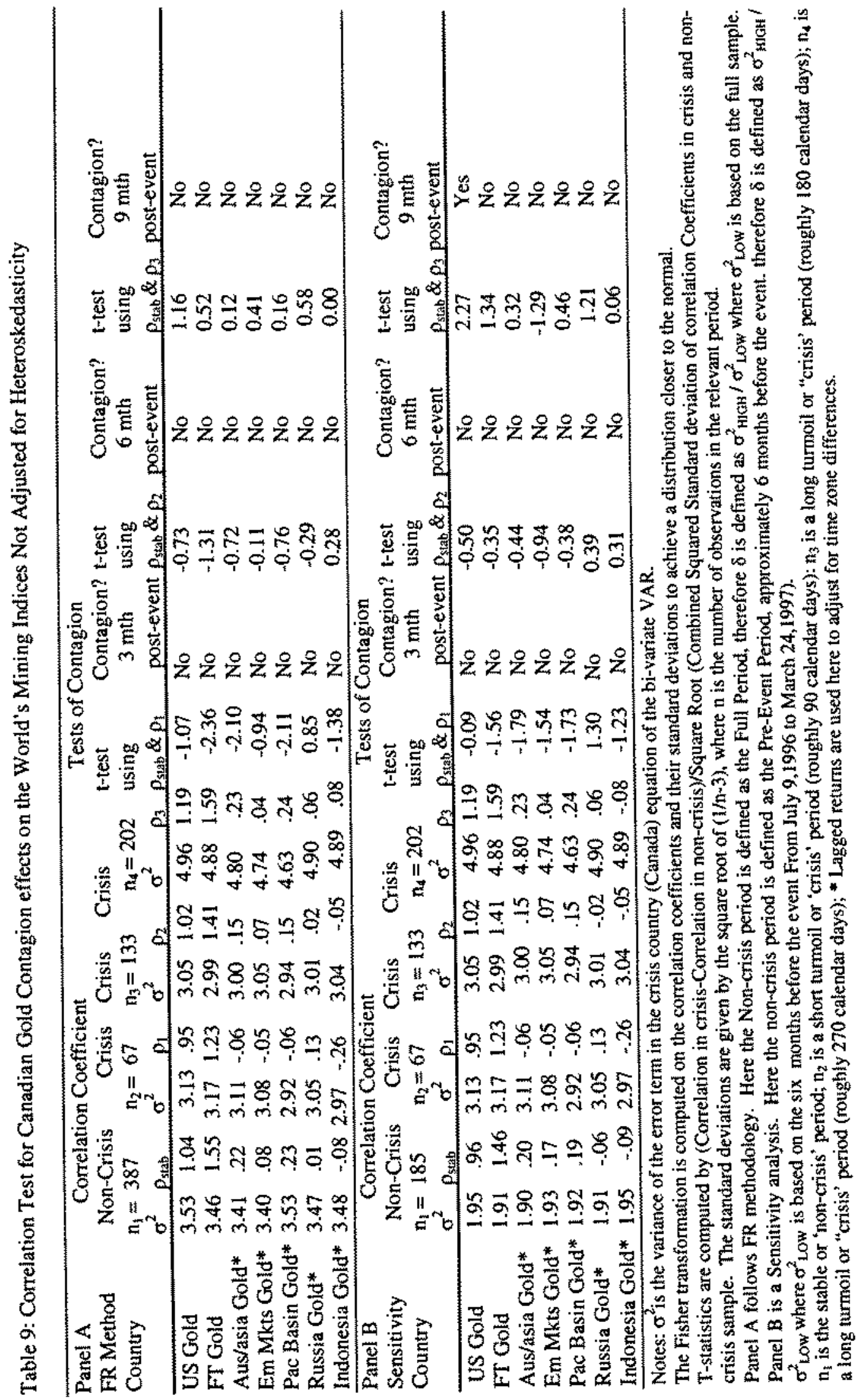


In this section the only evidence of contagion spread from the Canadian gold mining industry is to the US Gold mining industry nine months after the event both for the data adjusted for heteroscedasticty and that unadjusted. It is noteworthy however, that contagion occurred on data where the pre-event is defined as the stable period and not using FR's metbodology of using the entire sample period as the stable one. The implication here is that even though the fraud concocted by Bre-X was felt in the Canadian gold industry it did not significantly spread to the other countries of the world since the null hypothesis of contagion was rejected.

\section{Conclusions}

The benefits from diversification are achieved if returns from global stock markets are stable and not correlated. Many times mutual funds focus on a region or an industry while still expecting benefits from diversification. Therefore, significant structural changes across different regimes can be damaging to the economic well-being of investors' portfolios. These advantages dissipate if these markets exhibit interdependence or contagion. The increase in cross-market linkages must be significant to be called contagion rather than simply interdependence. Contagion is an excessive transmission of shocks from one market undergoing a crisis to another one beyond any specific disturbance and fundamental links. If there are only fundamental financial spillovers then there is evidence of interdependence but not contagion.

Evidence of contagion implies that over and above fundamental reasons, investors follow massive selling in one region with equivalent selling in another region that is related in some fashion to the initial one. Since there was little evidence found for 
contagion in this chapter the implications are that the herding behavior exhibited by investors typical in the literature was not exhibited in a situation of fraud in a well respected Canadian Corporation. Consequently no support for the assumption that after periods of losses investors attempt to seek risk is exhibited in this situation. Some of reasons for this may be because the incident was company specific as well as specific to a particular industry.

This chapter shows that world markets did not follow the Canadian market after correcting for heteroskedasticity. An exponentially weighted moving average chart was used to identify the potential crisis originating in Canada. Results are robust to specifications in the three, six and nine-month sample periods after March 24 . The analysis shows that a few of the gold markets throughout the world took their cues from the Canadian markets and fell after the event investigated.

The results imply that investigations on correlations of global markets that examine contagion may have produced spurious results because of their failure to correct for substantial within-sample heteroskedasticity. Results indicate that the markets were able to distinguish among countries that were able to successfully regulate their financial markets for incidence of fraud. The conclusions are that contagion is rare and that the magnitude and type of crisis can influence interdependence of financial markets. This study contributes to the literature through its extension into the mining industry and in validating Forbes and Rigobon (2002) contention of no contagion following the heteroskedasticity corrections even though evidence was found without these corrections. Further investigations can include a determination of whether these markets experienced significant negative abnormal returns. Overall the results support "rational" behavior in 
the mining industry following the incidence of fraud in the Toronto gold markets particularly given the psychological impact of a recognition among regulators that there was a lack of adequate security market law enforcement. 


\section{CHAPTER VI - CONCLUSION}

Employing three separate methodologies, empirical evidence was presented on the relationship between behavioral factors and investor reactions to changing market conditions. Research questions were analyzed using the framework suggested by Kahneman \& Tversky's Prospect Theory. The issues that motivated the study included:

I. Whether or not traders behaved (as displayed by their trading activity) differently after periods of significant wealth contractions.

2. Whether evidence based on sentiment data confirmed a relationship between aggregate sentiment and changing market conditions.

3. Whether evidence of contagion in intemational markets exists and if so, could still be found after adjusting for heteroskedasticity.

Summary and Conclusions of the Research

Chapter III on trader behavior questioned how the extent of the losses an investor incurs can incite behavior changes and finds strong evidence for an important Prospect Theory assumption that investors behave differently after sizeable wealth losses. Systematic errors and biases are uncovered at two large brokerage houses. Traders here possibly because of past accomplishments believed they had the wherewithal or intuition to correctly 'time' their market purchases. Chapter IV identified regime shifts in aggregate investor sentiment and rigorously determined when and if structural change occurred in the relationship between aggregate behavioral factors like consumer/investor sentiment and stock market returns. It also lends support to Prospect Theory with the 
finding that stock market returns have a bigger impact on consumer sentiment when market returns are above average.

The literature has made use of correlation analysis to determine whether the strength of the transmission mechanism of economic disturbances is stable over time. The central idea is to determine whether the correlation cocfficient between the stock markets under investigation changes across periods of low and high volatility. Recent research builds upon structural models of simultaneous equations that consider interdependencies, and ensure these relationships are not mistaken for contagion. Using a methodology designed by Forbes and Rigobon, this study found that the transmission mechanism remains stable over time, suggesting contagion does not exist.

Chapter V reported on the lack of evidence for contagion once adjustments were made for heteroskedasticity even in different industries. A test of contagion in the returns of the industrialized countries of the $\mathrm{G} 9$ was given to determine if a crisis originating in Canada affected the trading behavior of investors in other parts of the industrialized world. The crisis considered involved an instance of fraud in the mining industry and implicated Indonesia, so that country was also checked for evidence of contagion as was the mining industry of the different regions of the world. The finding of no contagion suggests that investors reacted to this crisis rationally. The inference here is that since the condition of contagion implies trader/investor herding behavior it is deemed irrational, and "no contagion" suggests rational behavior.

The literature offers many explanations for anomalies to rational human behavior and this study attempted to provide evidence beyond anecdotal and experimental. Conflicting evidence was found in certain instances. While the predicaments of the Dow 
Jones Industrial Average were found to incite trader reactions, neither the condition of the S\&P500 nor the S\&P/TSX exhibited similar tendencies. The evidence presented on contagion supported FR's observation that the magnitude of the originating crisis as well as the methodology for its determination affected the conclusions. Some of these findings display evidence in support as well as repudiate the rational activity of homo economicus. The literature review in Chapter II details why investors continue to sell stocks after crises using a Prospect Theory framework. More recently however, situations arise where markets do not exhibit the massive sell-offs that occurred in the past beyond fundamental concerns. The evidence presented in the chapter on contagion suggests that investor education on behavioral biases has influenced investors' trading decisions. The dissemination of this type of research has encouraged investors to recognize the heuristics that can lead to poor market performance. While the limits of arbitrage has been previously provided as an explanation as to why the markets fail to eliminate bounded rationality it may not necessarily be the case in the situations discussed in this dissertation exercise.

\section{Contributions to the Literature}

The goal of this research is to deepen the understanding of the links between investor reactions and fundamental market information. This work increases our knowledge regarding investors' trading reactions to different information. This dissertation contributes to the literature in at least three main respects. First, Chapter III

\footnotetext{
${ }^{3}$ Malkiel (2003) pointed out some rational fundamental reasons even for the crash of October 1987. He showed that there were genuine reasons, such as the development of the Internet, for higher stock prices, but he argued that as a result of psychological factors, "investors are exposed to a feedback mechanism whereby higher stock prices beget even higher stock prices without diminishing investor confidence."
} 
provided direct evidence on Prospect Theory based on a proprietary data set from two different brokerage houses. Specifically, the risk seeking behavior of a trader on a given trading day was approximated using a logit regression model of the probability of absolute position changes as a function of market returns and a dummy variable tbat varies according to the level of market returns. The results of this study show that traders behave differently during periods of severe losses as measured by a loss in the market value of market portfolios. The finding that the probability that a trader changes positions is different during times when stock market losses are occurring is consistent with the hypothesis that investor risk aversion changes during wealth altering circumstances. The trader buying activity here which showed the commitment of traders to follow their intuition even in the presence of extensive selling, may have been in part determined by overconfidence.

An alternative specification of the metbodology presented in Chapter III included checking for other explanatory factors that may influence a trader's behavior. The timeperiod in the study (October 6, I987 - October 30, 1992) does not suffer from confounding effects that could be caused by shifts in the data nor above average performance during a period in time when all tbe major stock averages experienced excellent performance. Consequently since the period under consideration has not been identified in history as being part of a major bull market nor bear market, the results have the potential of being more robust.

Second, Chapter IV tested for regime shifts in the relationsbip between behavioral factors identified under Prospect Theory and market returns. Specifically, a concise threshold model was designed to check for changes in aggregate consumer sentiment in 
relation to varying market conditions in the context of the U.S and Canadian markets. The results suggest that the stock market is an important determinant of consumer sentiment and that their co-movement varies depending on the level of stock market returns. In the threshold framework, the parameters of the model change depending on whether returns take a value above or below a certain threshold value, which is determined within the model. This suggests that investors exhibit different emotions about the stock market during periods of rising versus falling markets and during periods of high and low returns volatility. The implications here are that, investors propensity to buy/sell, to the extent that it is represented by investor sentiment, changes during times when stock market returns are above average, consistent with the assumptions of Prospect Theory.

Finally by following the methodology formulated by Forbes and Rigobon (2002), the tests for contagion in Chapter $\mathrm{V}$ validate their contention of no contagion, only interdependence. Tests performed which excluded their recommended heteroskedasticity corrections provided some evidence on contagion. Additionally this study extended the tests into the mining industry as a whole. The herding characteristics shown were not extensive, suggesting investor education has partially succeeded in the avoidance of irrational tendencies.

\section{Limitations of this Study}

As is typical of much research on human behavior, the data presented in Chapter III on trader reactions left many unanswered questions. The most important limitation in that chapter is the reliance of the empirical model on the assumption that trader buy/sell 
decisions reflect investor risk preferences, an assumption which is necessary in the absence of another appropriate direct measure of risk aversion. Chapter IV acknowledges the deficiency in using an empirical model, which does not consider a simultaneous relationship between aggregate sentiment and market returns data. Since the market returns data is the threshold variable to which aggregate sentiment responds, it was not modeled as an endogenous variable. Chapter $\mathrm{V}$ found little evidence of contagion even without the heteroskedasticity adjustment. One of the reasons for the lack of evidence of contagion in this chapter may be the magnitude of the initial shock chosen for the study or the relevance of this shock to the gold markets of the rest of the world.

\section{Implications for Practitioners}

Mark Twain noted, "The past does not repeat itself, but it rhymes." This dissertation study has presented empirical research on actual trader behavior. It is evident that while investors are now more cognizant of their behavioral biases, sometimes this recognition is not enough to avoid less than perfectly rational behavior. Specifically, the results of this study suggest that practitioners should not solely rely on forecasting models that assume rational behavior. Predictions of investor behavior and their implications on markets returns may be improved if behavioral variables such as sentiment, market liquidity ${ }^{2}$ and even weather ${ }^{3}$ are considered as well.

\footnotetext{
${ }^{2}$ Baker, Malcolm, and Jeremy Stein, 2004, Market liquidity as a sentiment indicator, Journal of Financial Markets 7, 271 299 .

${ }^{3}$ Hirshleifer, D.A, Shumway, T, (2003) Good Day Sunshine: Stock Retums and the Weather, Journal of Finance, $58,1009+1032$.
} 
Implications for Future Research

This dissertation concludes by offering paths for future research. Each one of the empirical chapters relates to a large literature and has unlocked the potential for additional explanatory work. To that end, the dissertation study concludes by offering paths for future research.

Additional researcb in Chapter III may include incorporating additional behavioral factors to approximate risk aversion as well as other explanatory variables such as lagged market returns, employment data, and otber relevant macroeconomic variables. Another approach may be to extend Fama-French's three factor model by incorporating mean excess returns and using a VAR framework.

Several potential enhancements to the methodology are presented in Chapter IV. One simple improvement may be to identify additional explanatory variables that have the potential to be present when the threshold model shows a regime shift in the relationship between sentiment and returns. A more elaborate extension, which requires a more advanced econometric model, is to consider more than one threshold variable. For example, aggregate sentiment may depend not only on the level of market returns but also on the level of aggregate wealth. In this case, the model would include two threshold variables, wealth and market returns.

Chapter $\mathrm{V}$ on Contagion hypothesizes how the methodology can be used to test for contagion in various industries, not just across countries. The existence of nonlinearities in the transmission of idiosyncratic shocks has important implications for portfolio management and the measurement of the potential benefits from international portfolio diversification. In as much as turmoil conditions in one region results in a loss 
of a portfolio's value, wealth effects can be considered and their possible influence on interdependence of regional returns. Further research should assess the implications of these results for the empirical measurement of the benefits of international portfolio diversification.

The aim of this entire dissertation is to analyze the risk - reward tradeoffs while acknowledging and identifying the extraneous psychological factors that affect that evaluation. Through this process it should become possible to eliminate the psychological barriers to successful trading and investing. 


\section{BIBLIOGRAPHY}

Allais, M. (1953). "Le Compontement de l'Homme Rationnel devant le Risque, Critique des Postulats et Axiomes de l'Ecole Americaine," Econometrica, 21:503-546.

Agresti, A. 1996. An Introduction to Categorical Data Analysis. John Wiley \& Sons: New York.

Arkes, H.R. \& Blumer, C., (1985), The Psychology of Sunk Cost, Organizational Behavior and Decision Processes, 35, $124-140$.

Bae. Kee-Hong, Karolyi G.A., Stulz, R.M. (2003), A New Approach to Measuring Financial Contagion, Review of Financial Studies, 2003 16:717.763

Baig, T. and 1. Goldfain, 1998, Financial Market Contagion in the Asian Crisis, $I M F$ Working Paper WP/98/155

Baker and Wurgler, (2003), Investor sentiment and the cross-section of stock returns, NBER Working Paper 10449 November 2003

Barber and Odean, (2000), Trading is hazardous to your wealth: The common stock performance of individual investors, Journal of Finance, 55, 773-806.

Barber, B and T. Odean (2001), Boys will be boys: Gender, overconfidence, and common stock investment, Quarterly Journal of Economics 116, 261-292.

Barberis, N. and M. Huang (2001), Mental accounting, loss aversion, and individual stock returns, Journal of Finance 56, 1247-1292.

Barberis, N., A. Shleifer, and R. Vishny, (1998), A model of investor sentiment, Journal of Financial Economics 49, 307-343.

Barberis, N., M. Huang and T. Santos (2001), Prospect Theory and asset prices, Quarterly Journal of Economics 116, 1-53

Benartzi, S. and R.H. Thaler (2001), Naive diversification strategies in defined contribution savings plans, American Economic Review 91, 79-98.

Biais, B. and R. Shadur (2000), Darwinian selection does not eliminate irrational traders, European Economic Review 44, 469 490.

Bleichrodt, Han, Jose Luis Pinto, \& Peter P. Wakker (2001), Making Descriptive Use of Prospect Theory to Improve the Prescriptive Use of Expected Utility, Management Science 47, 1498-1514. 
Brown and Cliff (2004), Investor Sentiment and the Near-Term Stock Market (Journal of Empirical Finance 11 2004, 1-27)

Campbell, J. Y., A. W. Lo and A. C. MacKinlay (1997), The Econometrics of Financial Markets. Princeton, NJ: Princeton University Press.

Caporale, G.M., Cipollini, A. and Spagnolo, N. (2002), Testing for Contagion: A Conditional Correlation Analysis. D. P. no. 01-2002. London: Centre for Monetary and Financial Economics, Journal of Empirical Finance, forthcoming in 2005

Charoenrook (2003) - Does sentiment matter? Presented at FMA 2004

Chordia, T., A. Subramanyam and V.R. Anshuman, (2001), Trading activity and expected stock Returns, Joumal of Financial Economics, 59, 3-32.

Corsetti, G., Pericoli, M., Sbracia, M. (2002), Some Contagion, Some Interdependence: More Pitfalls in Tests of Financial Contagion, Joumal of International Money and Finance (forthcoming).

Corsetti, G., Pericoli, M., and Sbracia, M., (2002), Some Contagion, Some Interdependence: More Pitfalls in Tests of Financial Contagion, University of Rome III - Department of Economics, Banca d'ltalia and New York University Department of Economics.

Coval, J.D., and T. Shumway (2002), Do Behavioral Biases Affect Prices? Paper Presented at the 2001 Western Finance Association.

Coval, J.D., D. Hirshleifer and T. Shumway (2002), Can Individual Investors Beat the Market? Working Paper

Cox, D. R., and E. J. Snell. (1989), Analysis of binary data. 2 Ed. Chapman and Hall, New York, New York, USA.

Daniel, K., D. Hirshleirfer, and A. Subrahmanyam, (1998), Investor psychology and security market under- and over-reactions, Joumal of Finance, 53, 1839-1886.

Daniel, K., D. Hirshleirfer, and A. Subrahmanyam, (2001), Overconfidence, Arbitrage and equilibrium asset pricing, Joumal of Finance, 56, 921-965

De Bondt, W., and R. Thaler (1987), Further evidence on investor overteaction and stock market seasonality, Joumal of Finance 42:557-581.

DeLong, J. B., Shleifer, A., Summers, L. H. and Waldmann, R. J. (1990), Noise trader risk in financial markets. Journal of Political Economy 98(4): 703-738. 
Ding, Charoenwong and Seetoh, (2004), Prospect Theory, Analyst Forecasts, and Stock Returns, Journal of Multinational Financial Management Volume 14, December $2004,425-442$

Dungey and Zhumabekova (2001), Testing for Contagion using Correlations: Some words of Caution, Center for Pacific Basin Monetary and Economic Studies, Economic Research Dept. Federal Reserve Bank of San Francisco, Working Paper No. PB01.09

Falato, Antonio, (2003), Happiness Maintenance and Asset Prices, Working Paper, Department of Economics, Columbia University New York.

Fama, Eugene F., (1998), Market Efficiency, Long-Term Returns, and Behavioral Finance, Journal of Financial Economics, 49, 283-306.

Fama, E. \& French, K. (1992), The cross-section of expected stock returns, Journal of Finance, vol. 47, pp. 427-67.

Fama, Eugene and Kenneth French, (1993), Common risk factors in the retums of stocks and bonds, Journal of Financial Economics 33, 3-55.

Fiegenbaum, A. (1990), Prospect Theory and the Risk-Retum Association, An Empirical Examination in 85 industries, Joumal of Economic Behavior and Organizations, $14,187-203$.

Fielding, D and Stracca, L (2003), Myopic Loss Aversion, Disappointment Aversion, and the Equity Premium Puzzle, European Central Bank Working Paper Series, Working Paper No. 203.

Fishbum, P., (1988), Nonlinear Preference and Utility Theory, Baltimore, MD: The John Hopkins University Press

Forbes, K and Rigobon, R (2002), No contagion, only interdependence: measuring stock market co-movement, Journal of Finance, 2002, 57, 5, 2223-2261.

French, K.R., and J.M. Poterba, (1991), Investor diversification and international equity markets, American Economic Review, Papers and Proceedings, 222-226.

Friedman, Milton, (1953), Essays in Positive Economics, University of Chicago Press

Friedman, Milton, (1982), Capitalism and Freedom Chicago, IL: University of Chicago Press. 
Gerrard, B., (1994), Beyond Rational Expectations: A Constructive Interpretation of Keynes' Analysis of Behaviour Under Uncertainty, The Economic Journal Mar 1994(104):327-337

Gervais and Odean, (2001), Learning to be overconfident, Review of Financial Studies, $14,1-27$

Grinblatt, Mark and Matti Keloharju, (2001), What Makes Investors Trade? The Journal of Finance, April 2001, Vol. 56 No. 2, pp. 589-616.

Hansen, B and Caner, M., (2004), Instrumental Variable Estimation of a Threshold Model, Econometric Theory, (2004), 20, 813-843

Hansen, B. and B. Seo, (2002), Testing for twomregime threshold cointegration in vector error correction models, Journal of Econometrics 110, 293-318.

Hansen,B., (1996), Inference When a Nuisance Parameter is Not Identified Under the Null Hypothesis, Econometrica, 1996, Volume 64, pp 413-430.

Hansen,B.,(2000), Sample splitting and Threshold estimation, Econometrica Volume 68 , No. 3 May 2000 pp575-603

Hirshleifer, David (2001) Investor Psychology and Asset Pricing, Journal of Finance, August 2001, Vol. 56 No. 4, pp. 1533-1597.

Hon M.T.; Strauss J.; Yong S-K, (2004) Contagion in financial markets after September 11: myth or reality?, The Joumal of Financial Research Vol. 27, No. 1, pp. 95114.

Hong, H. and J. C. Stein, (1999), A unified theory of underreaction, momentum trading and overreaction in asset markets, Journal of Finance, 54, December 1999, 21432184.

Kahneman and A. Tversky, (1979), Prospect Theory: An Analysis of Decision under Risk, Econometrica (47):262-291

Karolyi, Andrew G., and René M. Stulz, (2003), Are financial assets priced globally or locally? Handbook of the Economics of Finance, George Constantindies, Miton Harris, and René M. Stulz, eds., North Holland, Volume 1B.

Keim and R. Stambaugh, (1986), Predicting Returns in the Stock and Bond Markets, Journal of Financial Economics, (17): 357-390

Khwaja, A. and Mian, (2003), Trading in Phantom Markets: An In-depth Exploration of an Emerging Stock Market, Working Paper, July 2003 
Kim, C.J, (1993), Unobserved-component time series models with Markov-switching heteroskedasticity: Changes in regime and the link between inflation rates and inflation uncertainty, Journal of Business and Economic Statistics 11 (3), 1993, $341-349$.

Kim, C.-J., (1994), Dynamic Linear Models with Markov Switching, Journal of Econometrics 60 (1994), 1-22

Kogan, L., Ross, S., Wang, J. and Westerfield, M. (2003), The Price Impact and Survival of Irrational Traders, NBER Working Paper Series, Working Paper 9434, January 2003

Kyle A.S., Xiong W. (2001), Contagion as a Wealth Effect, Journal of Finance, August 2001 , vol. 56, no. 4, pp. 1401-1440(40)

Kyle, A.S., Ou-Yang, H., and Xiong, W., (2004), Prospect Theory and Liquidation Decisions, Joumal of Economic Theory, September 15, 2004

Lakonishok, J., A. Shleifer, and R. W. Vishny (1994). Contrarian Investment, Extrapolation and Risk, The Journal of Finance, 49(5): 1541-1578.

Lakonishok, J and Smidt, S., (1988), Are seasonal anomalies real? A ninety-year perspective Review of Financial Studies, vol. 1, no. 4, pp. 403-425(23)

Lee, S. and K. Kim, (1993), Does the October 1987 crash strengthen the co-movements among national stock markets? Review of Financial Economics 3, 89-102.

Levy and H. Markowitz, (1979), Approximating Expected Utility by a Function of Mean and Variance, The American Economic Review, (69): 308-317

Ljungqvist, A. and W.J. Wilhelm, (2005), Does Prospect Theory Explain IPO Market Behavior? Journal of Finance, Forthcoming August 2005.

Ljungqvist, A., V. Nanda, and R. Singh, (2001), Hot markets, investor sentiment, and IPO pricing , Journal of Business, forthcoming. Glucksman Runner-Up Award for Best Working Paper in Finance, 2001/2, Stern School of Business, NYU.

Locke, Peter and Steven Mann, (1999), Do professional traders Exhibit Loss Realization Aversion? Texas Christian University, Working Paper

Loughran and Ritter, (2000), Uniformly least powerful tests of market efficiency, Journal of Financial Economics, 55, 361-389

Maddala, G.S., (1992), Introduction to Econometrics, Macmillan Publishing Company, second edition 
Malkiel, Burton G., (2003), The Efficient Market Hypothesis and Its Critics, Journal of Economic Perspectives, Vol 17, No. 1: $59-82$

Marsh and Merton, (1986), Dividend Variability and Variance Bound Tests for the Rationality of Stock Prices, American Economic Review, June 1986:483-497

McCullagh, P. and J.A. Nelder. (1989), Generalized Linear Models. Chapman and Hall: London

Miller, E, (1977), Risk, Uncertainty and Divergence of Opinion Journal of Finance, Volume 32, 1ssue 4, 1151-1168

Mullainathan, S \& Richard Thaler, (2000), Behavioral Economics, MIT Department of Economics Working Paper No. 00-27

Newman, D.P, (1980), Prospect Theory: Implications for Information Evaluation, Accounting Organizations and Society, (5): 217-230

Nofsinger, J.R., and R. W. Sias, (1999), Herding and Feedback Trading by Institutional and Individual Investors, Joumal of Finance 54, no. 6: 2263-2295.

Odean, Terrance, (1998), Are Investors Reluctant to Realize their Losses, Journal of Finance $53,1775-1798$.

Odean, Terrance, (1998), Do Investors Trade Too Much? American Economic Review1989, 1279-1298

Otoo, Maria, (1999), Consumer sentiment and the stock market, Nov 1999-60, Finance and Economics Discussion Series from the Board of Governors of the Federal Reserve System

Plous, Scott, (1993), The Psychology of Judgment and Decision Making, (Philadelphia: Temple University Press, [hardcover]

Pratt, J., (1964), Risk Aversion in the Small and in Large. Econometrica., 32: 122-136.

Goldfeld, S.M. and Quandt, R.E. (1976), Studies in Nonlinear Estimation, Cambridge, MA: Ballinger Publishing Company

Rigobon, R., (2003), Identification through Heteroskedasticity, The Review of Economics and Statistics, 1 November 2003, vol. 85, no. 4, pp. 777-792(16)

Rubinstein, Mark (2001), Rational Markets: Yes or No? The Affirmative Case, Financial Analysts Joumal, May/June, 15-29 
Rudd, A. T., (1979), The Revised Dow Jones Industrial Average: New Wine In Old Bottles? Financial Analysts Journal, November-December, 57-63.

Savage, L. J. (1954), "The Sure-Thing Principle." In Leonard J. Savage, The Foundations of Statistics. New York: John Wiley, pp. 21-26.

Shefrin, Hersh, (2005), A Behavioral Approach to Asset Pricing, Academic Press (Elsevier) Advanced Finance Series

Shefrin, Hersh and Meir Statman. (1985), The Disposition to Sell Winners Too Early and Ride Losers too Long. Journal of Finance. 40, pp. 777-792.

Shefrin and Statman, (1994), Behavioral capital asset pricing theory, Journal of Financial and Quantitative Analysis, 29, 323-349.

Shefrin, Hersch and Meir Statman, (2000), Behavioral Portfolio Theory, Journal of Financial and Quantitative Analysis, June 2000, Vol. 35 No. 2, pp. 127-152.

Shleifer, A. and Vishny, R. W., (1997), The limits of arbitrage, Joumal of Finance 52: $35-55$

Shiller, Robert, (2000), Irrational Exuberance, Princeton University Press

Simon, Herbert. (1955), A Behavioral Model of Rational Choice. Quarterly Joumal of Economics.pp. 99-118.

Sinha, Tapen, (1994), Prospect Theory and the Risk Return Association: Another Look, Joumal of Economic Behavior and Organization, 1994, v24 (2), 225-231

Slovic, Paul, (2000), The Perception of Risk, London; Sterling, VA: Earthscan Publications

Soane, Emma, (2001), Knowing the Risks: Theory and Practice in Financial Market Trading, Human Relations, Vol 54, Issue 7

Subramanyam, K. (1996), The pricing of discretionary accruals, Journal of Accounting and Economics, 1996, 22, 249-281.

Thaler, Richard, (1985), Mental accounting and consumer choice, Marketing Science 4, 199-214.

Thaler, R., Tversky, Kahneman \& Schwartz, (1997), The Effect of Myopia and Loss Aversion on Risk Taking: An Experiment Test, The Quarterly Journal of Economics, May 1997: 647 - 661 
Toda, Hiro Y and Peter C. B. Phillips, (1993) Vector Autoregressions and Causality, Econometrica Volume: 61, 1ssue: 6

Toda, Hiro. Y and Taku Yamamoto (1995), Statistical inference in vector autoregressions with possibly integrated processes, Journal of Econometrics Volume 66, Issues 12, pp 225-250

Tong, H. (1983), Threshold Models in Non-linear Time Series Analysis : Lecture Notes in Statistics 21. Berlin: Springer-Verlag.

Tong, H., (1990), Non-Linear Time Series: A Dynamical System Approach. New York: Oxford University Press.

Tversky and D. Kahneman, (1992), Advances in Prospect Theory: Cumulative Representation of Uncertainty, Journal of Risk and Uncertainty 1992(5): 292-323

Varian, H., (1985), Divergence of opinion in complete markets: A note, Journal of Finance, 1985, 40,

Vriend, Nicolaas J., (1996), Rational Behavior and Economic Theory, Journal of Economic Behavior and Organization, 1996, v29 (2, Mar), 263-285

Willman, Paul, Mark Fenton, O'Creevy, Nigel Nicholson, Emma Soane, (2001), Traders, Managers and Loss Aversion in Investment Banking, Journal of Accounting, Organization and Society (January 2001).

Xie, Yu, and Charles F. Manski, (1989), The Logit Model and Response-Based Samples, Sociological Methods and Research 17(3):283-302. 


\section{APPENDICES}

\section{Appendix I}

Theory of Asymmetric Information, the Precursor to Behavioral Finance Markets with Asymmetric Information

Many markets are characterized by asymmetric information: actors on one side of the market have much better information than those on the other. Borrowers know more than lenders about their repayment prospects, managers and boards know more than shareholders about the firm's profitability, and prospective clients know more than insurance companies about their accident risk. During the 1970s, this year's Laureates laid the foundation for a general theory of markets with asymmetric information. Applications have been abundant, ranging from traditional agricultural markets to modern financial markets. The Laureates' contributions form the core of modem information economics.

George Akerlof demonstrated how a market where sellers have more information than buyers about product quality can contract into an adverse selection of low-quality products. He also pointed out that informational problems are commonplace and important. Akerlof's pioneering contribution thus showed how asymmetric information of borrowers and lenders may explain skyrocketing borrowing rates on local Third World markets; but it also dealt with the difficulties for the elderly to find individual medical insurance and with labor market discrimination of minorities.

Michael Spence identified an important form of adjustment by individual market participants, where the better informed take costly actions in an attempt to improve on their market outcome by credibly transmitting information to the poorly informed. Spence showed when such signaling will actually work. While his own research emphasized education as a productivity signal in job markets, subsequent research has suggested many other applications, e.g., how firms may use dividends to signal their profitability to agents in the stock market.

Joseph Stiglitz clarified the opposite type of market adjustment, where poorly informed agents extract information from the better informed, such as the screening performed by insurance companies dividing customers into risk classes by offering a menu of contracts where higher deductibles can be exchanged for significantly lower premiums. In a number of contributions about different markets, Stiglitz has shown that asymmetric information can provide the key to understanding many observed market phenomena, including unemployment and credit rationing.

Source: Press Release - The 2001 Sveriges Riksbank (Bank of Sweden) Prize in Economic Sciences in Memory of Alfred Nobel, 10 October 2001 
Appendix II

Subset of the Excel Data File (Collected at First Boston, originally in Lotus)

\begin{tabular}{|c|c|c|c|c|}
\hline \multicolumn{2}{|c|}{ FIRST BOSTON } & \multirow{2}{*}{$\begin{array}{l}\text { SECURITY } \\
\text { SYMBOL }\end{array}$} & \multirow{2}{*}{$\begin{array}{l}\text { OPENING } \\
\text { POSITION }\end{array}$} & \multirow{2}{*}{$\begin{array}{l}\text { CLOSING } \\
\text { POSITION }\end{array}$} \\
\hline DATE & SECURITY NAME & & & \\
\hline \multirow[t]{2}{*}{$6 \cdot 0 \mathrm{ct}-87$} & Hudson's Bay Co. & $\mathrm{HBC}$ & 50850 & 95360 \\
\hline & Molson Inc. Cl A & MOL.A & 2000 & 28000 \\
\hline \multirow[t]{3}{*}{ 7-OCt-87 } & Bank of Nova Scotia & BNS & 16000 & 25000 \\
\hline & American Barrick & $A B X$ & 25000 & 60000 \\
\hline & Hudson's Bay Co. & $\mathrm{HBC}$ & 95360 & 95360 \\
\hline $8-0 \mathrm{ct}-87$ & Teck Cominco Lto. & TEK.B & 25000 & 75000 \\
\hline \multirow[t]{3}{*}{$9-0$ ct- 87} & American Barrick & $A B X$ & 60000 & 70000 \\
\hline & Weston Ltd. George & WN & 15000 & 125000 \\
\hline & Teck Cominco Ltd. & TEK.B & 75000 & 98000 \\
\hline $13-0 \mathrm{ct}-87$ & Weston Ltd. George & WN & 125000 & 75000 \\
\hline \multirow[t]{2}{*}{$14-0 \mathrm{ct}-87$} & Imperial Ois & INO & 5000 & 25000 \\
\hline & CAE Inc. & CAE & 9800 & 50000 \\
\hline \multirow[t]{2}{*}{$15-$ Oct -87} & Weston Ltd. George & WN & 75000 & 75000 \\
\hline & Cott Corp. & $\mathrm{BCB}$ & 6000 & 50000 \\
\hline \multirow[t]{2}{*}{$16-0 \mathrm{ct}-87$} & TransCanada Corp & TAP & 22000 & 100300 \\
\hline & CAE Inc. & CAE & 0 & 50000 \\
\hline $19-0 \mathrm{ct}-87$ & Cara Operations & CAO.A & 17000 & 30000 \\
\hline $20-0 \mathrm{ct}-87$ & Rothman's inc. & $\mathrm{ROC}$ & 4000 & 28000 \\
\hline \multirow[t]{2}{*}{$21-0 \mathrm{ct}-87$} & Imperial OI & MO & 3000 & 70500 \\
\hline & Maple Leat Foods Inc. & MFI & 5000 & 75000 \\
\hline \multirow[t]{2}{*}{$22-0 \mathrm{ct}-87$} & $\mathrm{BCE}$ lnc. & $\mathrm{BCE}$ & 12000 & 75000 \\
\hline & Bank of Nova Scotia & BNS & 12400 & 100000 \\
\hline $23-$ Oct -87 & Leon's Furniture & LNF & 8700 & 95000 \\
\hline \multirow[t]{2}{*}{$26-0 \mathrm{ct}-87$} & Bank of Nova Scotia & BNS & 100000 & 90000 \\
\hline & Leon's Furniture & LNF & 95000 & 85000 \\
\hline $27-0 \mathrm{ct}-87$ & Cara Operations & CAO.A & 3000 & 100000 \\
\hline \multirow[t]{2}{*}{$28-0 \mathrm{ct}-87$} & Molson Inc. Cl A & MOL.A & 28000 & 200000 \\
\hline & Weston Ltd. George & WN & 100000 & 50000 \\
\hline $29-0 \mathrm{ct}-87$ & CAE Inc. & CAE & 11200 & 125000 \\
\hline \multirow[t]{2}{*}{$30-0 c t-87$} & $\mathrm{CCl}$ Industries & $\mathrm{CCO} . \mathrm{B}$ & 115000 & 100000 \\
\hline & Molson inc. CI A & MOL.A & 200000 & 100000 \\
\hline 2-Nov-87 & Rothman's Inc. & ROC & 12500 & 55000 \\
\hline 3-Nov-87 & American Barrick & $A B X$ & 60000 & 60000 \\
\hline 4-Nov-87 & Imperial Oi\} & IMO & 3000 & 80000 \\
\hline 5-Nov-87 & TransCanada Corp & TAP & 5400 & 70000 \\
\hline \multirow[t]{2}{*}{$6-$ Nov-87 } & Shoppers Drug Mart & SC & 25000 & 75000 \\
\hline & Brascan Corp., ClA & BNN.A & 12000 & 85000 \\
\hline \multirow{2}{*}{$9-\mathrm{Nov}-87$} & American Barrick & $A B X$ & 40000 & 100000 \\
\hline & Imperial Oi & IMO & 25000 & 75000 \\
\hline 10-Nov-87 & BCE inc. & BCE & 15000 & 50000 \\
\hline \multirow[t]{2}{*}{$11-$ Nov-87 } & Bank of Nova Scotia & BNS & 26000 & 125000 \\
\hline & Brascan Corp., $\mathrm{ClA}$ & BNN.A & 12000 & 90000 \\
\hline
\end{tabular}


Subset of the Excel Data File (Collected at Merrill Lynch, originally in Lotus)

PARTIAL LIST OF MONTHLY TRADING POSITIONS OF OVER $10 \%$ OF TOTAL EOUITY PORTFOLIO (AS AT CLOSE)

MERRILL LYNCH

DATE

$$
\text { Abitibi-Consolidated }
$$

7-Oct-87 Systemhouse

Canadian Pacific Railway

8-Oct-87 Hudson's Bay Co.

9-Oct-87 Weston Lid. George

Teck Cominco Ltd.

American Barrick

13-Oct-87 Molson inc. Cl A

14-Oct-87 Weston Ltd. George

15-Oct-87 Bank of Nova Scotia Imperial $\mathrm{Oil}$

16-Oct-87 BCE Inc.

CAE Inc.

19-0ct-87 Cara Operations

20-Oct-87 Leon's Furniture

21-Oct-87 Bank of Nova Scotia

Abitibi-Consolidated

22-Oct-87 Systemhouse

Canadian Pacific Railway

23-Oct-87 Hudson's Bay Co.

26-Oct-87 TransAlta Corp.

CAE inc.

27-Oct-87 Cara Operations

28-Oct-87 Rothman's Inc. Imperial Oil

29-Oct-87 BCE Inc.

30-Oct-87 Cott Corp.

Leon's Furniture

2-Nov-87 Systemhouse

3-Nov-87 TransAlta Corp.

4-Nov-87 Bank of Montreal

5-Nov-87 CAE inc.

6-Nov-87 CCL industries

Canadian Imperial Bank

9-Nov-87 Leon's Furniture

Molson inc. Cl A

10-Nov-87 BCE Inc.

11-Nov-87 Bank of Nova Scotia

\begin{tabular}{|c|c|c|}
\hline $\begin{array}{l}\text { SECURITY } \\
\text { SYMBOL }\end{array}$ & $\begin{array}{l}\text { OPENING } \\
\text { POSITION }\end{array}$ & $\begin{array}{l}\text { CLOSING } \\
\text { POSITION }\end{array}$ \\
\hline MOL.A & 15000 & 100000 \\
\hline A & 60000 & 220000 \\
\hline$S H C$ & 15000 & 89000 \\
\hline CNR & 17000 & 95000 \\
\hline$H B C$ & 25000 & 112000 \\
\hline WN & 10000 & 55000 \\
\hline TEK.B & 30000 & 112000 \\
\hline$A B X$ & 18000 & 100000 \\
\hline MOL.A & 22000 & 122000 \\
\hline WN & 25000 & 55000 \\
\hline BNS & 20000 & 100000 \\
\hline $1 \mathrm{MO}$ & 15000 & 90000 \\
\hline $\mathrm{BCE}$ & 2500 & 75000 \\
\hline CAE & 25000 & 125000 \\
\hline CAO.A & 2000 & 142000 \\
\hline LNF & 10000 & 110000 \\
\hline BNS & 25000 & 150000 \\
\hline A & 30000 & 100000 \\
\hline SHC & 12000 & 50000 \\
\hline CNR & 5000 & 125000 \\
\hline$H B C$ & 30000 & 120000 \\
\hline TA & 4000 & 120000 \\
\hline CAE & 15000 & 135000 \\
\hline CAOA & 25000 & 125000 \\
\hline $\mathrm{ROC}$ & 3000 & 103000 \\
\hline $1 \mathrm{MO}$ & 15000 & 150000 \\
\hline $\mathrm{BCE}$ & 2000 & 75000 \\
\hline $\mathrm{BCB}$ & 25000 & 125000 \\
\hline LNF & 5000 & 105000 \\
\hline SHC & 20000 & 100000 \\
\hline TA & 10000 & 150000 \\
\hline BMO & 40000 & 200000 \\
\hline CAE & 40000 & 150000 \\
\hline CCO.B & 50000 & 200000 \\
\hline $\mathrm{CM}$ & 20000 & 120000 \\
\hline LNF & 25000 & 150000 \\
\hline MOLA & 10000 & 75000 \\
\hline$B C E$ & 25000 & 125000 \\
\hline BNS & 5000 & 200000 \\
\hline
\end{tabular}


Appendix III

Summary Statistics for US Data Monthly From January 1979 - December 2004

Percentage Change

in Consumer Sentiment

\begin{tabular}{lr}
\hline \multicolumn{2}{c}{ Columnl } \\
\hline & \\
Mean & 0.045976 \\
Standard Error & 0.259692 \\
Median & -0.21622 \\
Mode & $\$ \mathrm{~N} / \mathrm{A}$ \\
Standard & \\
Deviation & 4.667237 \\
Sample Variance & 21.7831 \\
Kurtosis & 2.632954 \\
Skewness & 0.018386 \\
Range & 39.29651 \\
Minimum & -17.3236 \\
Maximum & 21.97286 \\
Sum & 14.85024 \\
Cotint & 323 \\
\hline
\end{tabular}

Percentage Change

In DJIA

\begin{tabular}{lc}
\hline \multicolumn{2}{c}{ Columnl } \\
\hline & \\
Mean & 0.817172 \\
Standard Error & 0.249083 \\
Median & 0.943706 \\
Mode & $\#$ N/A \\
Standard & \\
Deviation & 4.476578 \\
Sample Variance & 20.03975 \\
Kurtosis & 4.450213 \\
Skewness & -0.97144 \\
Range & 39.36309 \\
Minimum & -26.4195 \\
Maximum & 12.94355 \\
Sum & 263.9466 \\
Count & 323 \\
\hline
\end{tabular}

Summary Statistics for Monthly Canadian Data from September 2001 to December 2004

Percentage Change

In Consumer Sentiment

Columnl

$\begin{array}{lc}\text { Mean } & 0.212929 \\ \text { Standard Error } & 0.400251 \\ \text { Median } & 0.712859 \\ \text { Mode } & \text { N/A }\end{array}$

Standard Deviation 2.743984

Sample Variance 7.529449

Kurtosis

0.191835

Skewness

$-0.13735$

Range

12.71972

Minimum

$-5.61178$

Maximum

7.107947

Sum

10.00765

Count
Percentage Change

In TSX

\begin{tabular}{lc}
\hline \multicolumn{2}{c}{ Columnl } \\
\hline & \\
Mean & -0.01723 \\
Standard Error & 0.621023 \\
Median & 0.686376 \\
Mode & \#N/A \\
Standard Deviation 4.257522 \\
Sample Variance & 18.12649 \\
Kurtosis & 1.56144 \\
Skewness & 1.10642 \\
Range & 21.86222 \\
Minimum & -14.3136 \\
Maximum & 7.548669 \\
Sum & -0.80997 \\
Count & 47
\end{tabular}




\section{VITA}

\section{DEANNE BUTCHEY}

\section{EDUCATION}

2005

Doctoral Candidate in Business Administration (Finance)

Florida International University

Miami, Florida

1985

Master of Business Administration (Finance)

York University

Toronto, Canada

1983

Bachelor of Arts (Honors Econometrics)

York University

Toronto, Canada

1981

Bachelor of Arts (General)

University of Western Ontario

London, Canada

\section{AWARDS}

2001

Excellence in Teaching Award

Florida International University

1985

Member of Dean's Honors Roll

York University

1983

Member of Dean's Honors Roll

York University

1979

Class Valedictorian

Naparima Girls' High School

PUBLICATIONS AND PRESENTATIONS

Butchey, D., (1999) Arbitrage Pricing Theory - Seminal Paper

Butchey, D., (2000) Direct Foreign Investment - Seminal Paper 
Butchey, D., Dandapani, K., (2000) International Hurricane Center - Disaster Mitigation and Insurance on Residential and Mobile Homes - Research Grant Provided by the Florida Department of Community Affairs

Butchey, D., Dandapani, K., (2000) International Hurricane Center - Disaster Mitigation and Insurance on Residential and Mobile Homes Paper Presented at ISINI Miami, FL

Butchey, D., Parhizgari, A.M., (2001) Irrationality in the Stock Market - Prospect Theory, Presented at ISINI Miami, Florida

Butchey, D., (2005) Globalization of Tertiary Education, Presented at Financial Education \& the Association Academy of Business Education, Orlando 2005

Butchey, D., (2005) Globalization of Tertiary Business Education, Journal of the Academy of Business Education, Volume 6, pp 21-25

Butchey, D., Parhizgari, A.M., (2005) Was There Financial Contagion in the Mining Industry in the Aftermath of Bre- $X$ ? To be presented at the 2005 Annual Meeting of the Association for Global Business Miami, Florida

Butchey, D., Parhizgari, A.M., (2005) Was There Financial Contagion in the Mining Industry in the Aftermath of Bre-X? Forthcoming in the Journal of Current Research in Global Business - JCRGB (ISSN 1050-6292) 